\title{
Andréia Carradori
}

\section{Estudo comparativo do efeito da retenção a barra no ciclo mastigatório de pacientes usuários de overdentures}

Dissertação apresentada à Faculdade de Odontologia da Universidade de São Paulo, para obter o título de Mestre, pelo Programa de Pós-Graduação em Odontologia.

Área de Concentração: Prótese Dentária

Orientadora: Profa. Dra. Regina Tamaki

\section{São Paulo}




\section{FOLHA DE APROVAÇÃO}

Carradori A. Estudo comparativo do efeito da retenção a barra no ciclo mastigatório de pacientes usuários de overdenture [Tese de mestrado]. São Paulo: Faculdade de Odontologia da USP; 2005.

São Paulo, / / 2005

\section{Banca Examinadora}

1)Prof(a).Dr(a).

Titulação:

Julgamento:

Assinatura:

2) $\operatorname{Prof}(a) \cdot \operatorname{Dr}(a)$.

Titulação:

Julgamento :

Assinatura:

3) $\operatorname{Prof}(a) \cdot \operatorname{Dr}(a)$.

Titulação:

Julgamento:

Assinatura: 


\section{DEDICATÓRIA}

Dedico este trabalho:

À minha a minha mãe, Merle, que em todos os momentos está ao meu lado, me dando forças e fazendo com que eu entenda o sentido de todos os acontecimentos da minha vida. Amo-te mais do que tudo.

Ao meu pai, Laércio, que sempre me deu todos os subsídios necessários para que eu pudesse me dedicar aos estudos, dando o exemplo de perseverança na vida.

À minha irmã, Adriana, que me orienta, através de sua experiência pessoal, para que eu possa transpor todos as minhas dificuldades com maior facilidade.

À minha avó e ao meu avô (in memorian) que me criaram com todo o amor e toda a ternura.

À Profa. Dra. Regina, que com sua maneira singular de conduzir seus alunos, fez deste curso de mestrado uma experiência enriquecedora que só me deixará boas lembranças. Com muita inteligência e carinho soube como ninguém me conduzir neste momento da minha vida. Agradeço a Deus por ter colocado você em meu caminho. 


\section{AGRADECIMENTOS}

À Deus, por sempre colocar pessoas boas em meu caminho.

À Faculdade de Odontologia da Universidade de São Paulo, dirigida pelo Prof. Dr. Ney Soares de Araújo, pela qualidade de ensino que me ofereceu na graduação e na pós-graduação.

Ao Prof. Dr. João Humberto Antoniazzi, coordenador do programa de pósgraduação em Odontologia da USP.

Ao Departamento de Prótese Dentária, dirigido pelo Prof. Dr. Carlos Gil. Em especial à Disciplina de Prótese Total pela chance de ingressar neste curso de pósgraduação de valor incalculável.

À Profa. Dra. Maria Cecília Miluzzi Yamada, coordenadora do programa de pós-graduação na área de Prótese Dentária da FOUSP, por sempre ter me recebido com disposição quando solicitada por mim.

À Profa. Dra. Regina Tamaki que me formou neste momento tão importante da minha vida profissional. Obrigada pelo carinho, paciência e conhecimento adquirido.

Ao Prof. Dr. Atlas Nakamae pela oportunidade deste curso de mestrado e pela confiança que em mim depositou como aluna. Serei sempre grata.

Aos Profs. Drs. Vyto Kiausinis e Roberto Nobuaki Yamada, pelos quais tenho um carinho especial, que me deram a oportunidade de um aprendizado continuado que solidificou meu ainda modesto conhecimento.

Ao Prof. Dr. Antônio Sérgio Guimarães por oferecer a oportunidade deste experimento. 
Aos amigos do curso de mestrado: Viviane, Vanessa, Tarcisio, Tatiana, Flávio, Max, Marina e Murilo. Em especial ao Max, por ter dividido comigo quase que integralmente os momentos deste curso. À Marina pela amizade sincera e momentos de descontração que nos dava forças para continuar. Ao Murilo, pelo exemplo como pessoa e profissional, além da dedicação e perseverança nos estudos.

Aos funcionários da biblioteca em especial ao Renato, Amarildo e Glauce por entenderem as dificuldades do momento pelo qual estava passando e me ajudarem no que estava ao seu alcance.

Às secretárias do Departamento de Prótese Dentária, em especial à Sandra e à Regina pela disponibilidade.

Aos técnicos do Departamento, em especial ao Luis, que em todas as vezes que precisei, parou suas atividades para sentar e me auxiliar no que fosse necessário.

Aos amigos do Sesc Pinheiros, que além de me fazerem crescer profissionalmente, me proporcionam o prazer de trabalhar junto a eles.

Ao Jun por disponibilizar parte de seu tempo no auxílio ao meu trabalho.

Aos amigos que cultivo por longos anos e que me provam a cada dia que posso contar com eles sempre que necessário. Aline, Camila, Dennys, Duddu, Kim, Luciane, Juliana, Marcela, Marcinho, Renata, Ronald, Tatiana: direta ou indiretamente todos vocês me ajudaram a completar esta missão.

Um agradecimento especial ao Binho que deixa de resolver seus problemas no trabalho para dar atenção aos meus. Mesmo que eu sempre te auxilie quando for solicitada, jamais conseguirei retribuir toda a sua ajuda. 
Carradori A. Estudo comparativo do efeito da retenção a barra no ciclo mastigatório de pacientes usuários de overdenture [Tese de Mestrado]. São Paulo: Faculdade de Odontologia da USP; 2005.

\section{RESUMO}

A reabilitação dos pacientes edentados totais tem sido um desafio para os profissionais da área, que têm a responsabilidade de restabelecer a função e a estética alteradas com a perda progressiva dos dentes. Com o surgimento das reabilitações protéticas com implantes, o prognóstico dessas reabilitações melhorou e a satisfação dos pacientes aumentou.

O presente trabalho teve como objetivo analisar as alterações que poderiam ou não estar presentes no ciclo mastigatório de pacientes portadores de prótese total convencional superior e overdentures mandibulares, com e sem a retenção da barra, simulando nesta última condição, uma prótese apenas mucoso-suportada. Foram selecionados 9 pacientes com idade entre 35 e 58 anos, sem histórico ou sintomatologia de disfunção da articulação têmporo-mandibular e que foram reabilitados na Clínica da Fundação para o Desenvolvimento Científico e Tecnológico da Odontologia (FUNDECTO). Os registros foram obtidos através do aparelho Arcus Digma (Kavo Dental $\mathrm{GmbH} \&$ Co. KG. Alemanha) que permite a análise dos movimentos mandibulares nas suas três dimensões. No intuito de simular uma mastigação normal onde o alimento exigisse um esforço contínuo do paciente mesmo após a degradação inicial do mesmo, optou-se por pedaços de cenoura crua padronizados em $1 \mathrm{~cm}^{3}$. O paciente não foi induzido quanto ao lado de mastigação e esse registro foi feito em dois momentos: primeiro com a manutenção da barra e segundo com a remoção da mesma. Escolheurse o plano frontal para a avaliação dos resultados. Os ciclos mastigatórios foram avaliados quanto a sua forma, largura máxima, comprimento máximo e área total, e os registros com e sem a barra foram comparados. Quanto à forma, encontrourse uma variação interindividual grande, porém, uma similaridade marcante quando se analisaram os dois registros de um mesmo paciente, o que evidenciou a existência de um padrão de caráter individual. Nos registros com a barra, pôde-se notar, de modo geral, que os ciclos foram mais regulares, lisos e com melhor direcionamento que nos registros sem a barra, sugerindo uma mastigação mais efetiva. Em relação à largura, 4 
pacientes apresentaram aumento dos valores quando dos registros com a barra. Para a altura, 5 pacientes com a barra apresentaram aumento desta variável. Quanto à área total dos ciclos, 7 pacientes apresentaram aumento da área total com a barra, o que sugere que nessa condição, no geral, os ciclos foram mais largos. A análise estatística com a aplicação do teste não paramétrico de Wilcoxon adotando o nível de significância de $5 \%$, para p menor ou igual a 0,05 , não encontrou diferenças significantes para os registros com e sem a barra. Os resultados demonstraram que existe um padrão individual do ciclo mastigatório para cada paciente e uma grande variação interindividual do mesmo. Existem pequenas, porém, importantes diferenças na conformação geral do ciclo quando se compararam os registros com e sem barra.

Palavras-chave: Overdenture - Ciclo mastigatório - Prótese total - Padrão mastigatório 
Carradori A. Comparative study of the bar retention effect in the masticatory cycle in overdenture wearers [Tese de Mestrado]. São Paulo: Faculdade de Odontologia da USP; 2005.

\section{ABSTRACT}

Rehabilitating edentulous patients has been a challenge for the professionals that have the responsibility of restoring the function and esthetics altered by the looseness of the teeth.

The aim of the present research was to evaluate the changes that could exist in the masticatory cycle of an upper conventional complete denture and mandibular overdentures wearers, with and without the bar fixation, simulating in this last condition, a conventional denture. Nine patients aged from 35 to 58 years old without signs or symptoms of join disfunction were selected, and rehabilitated in the Fundação para o Desenvolvimento Científico e Tecnológico da Odontologia (FUNDECTO). The recordings were obtained from Arcus Digma (Kavo Dental GmbH \& Co. KG) that is capable to register the mandibular movements in three dimensions. In order to simulate a normal mastication, when the food would ask the patient a continuous effort even after the first strokes, the carrot measuring $1 \mathrm{~cm}^{3}$ was used. The patient was not induced to a preferred side of mastication and the recording was made in two times: first with the maintenance of the bar and second with its removal. The frontal plane was chosen to evaluate the results. The form, area, width and length of the masticatory cycles were evaluated and the results with and without the bar fixation were compared. Concerning the form of the cycle, a large inter-individual variation was found. However, a similar pattern was presented when analyzing the two recordings of a single patient, what means that an individual pattern exists for each person. The cycles with the bar were, generally, more regular, smooth, and with a better direction when compared with the recordings without the bar, suggesting a more effective mastication. Regarding the width, four patients presented higher values for the recordings with the bar fixation. Five patients had their recording changed to higher values with the bar fixation when analyzing the length of the cycles. Seven patients presented an enlargement of the total area of the masticatory cycles when the recordings were made with de bar fixation, what suggests that, with the bar, the cycles were generally larger. Test of differences between the two 
registrations were made by means of the Wilcoxon test, which did not find significant differences between the results with and without the bar fixation. The results demonstrated an individual pattern of the masticatory cycle for each patient and a large interindividual variation.

Having considered all aspects, when comparing the results with and without the bar fixation, there are few but important differences in the general pattern of the masticatory cycle.

Keywords: Overdenture - Masticatory cycle - Complete denture - Masticatory pattern 


\section{LISTA DE ILUSTRAÇÕES}

Figura 4.1 - Monitor do aparelho Arcus Digma .75

Figura 4.2 - Vista frontal do aparelho conectado ao paciente .76

Figura 4.3 - Garfo fixado à prótese inferior com resina acrílica .77

Figura 5.1 - Registros com barra e sem barra dos ciclos mastigatórios do paciente 7. .80

Figura 5.2 - Registros com barra e sem barra do ciclo mastigatório da paciente 4 .80 


\section{LISTA DE GRÁFICOS}

Gráfico 5.1-Representação de valores em $\mathrm{mm}$ da largura máxima dos ciclos mastigatórios com e sem a barra de retenção ...............................82

Gráfico 5.2-Representação de valores em $\mathrm{mm}$ do comprimento máximo dos ciclos mastigatórios com e sem a barra de retenção

Gráfico 5.3-Representação de valores em $\mathrm{mm}^{2}$ da área dos ciclos mastigatórios com e sem a barra de retenção... 85

Gráfico 5.4-Diagrama Box-plot para a largura com e sem barra..... 87

Gráfico 5.5-Diagrama Box-plot para o comprimento com e sem a barra. .88

Gráfico 5.6-Diagrama Box-plot para a área com e sem a barra. .90 


\section{LISTA DE TABELAS}

Tabela 5.1 - Valores em mm da largura dos ciclos mastigatórios com a barra e sem a barra de retenção.

Tabela 5.2 - Valores em mm do comprimento dos ciclos mastigatórios com a barra e sem a barra de retenção.

Tabela 5.3 -Valores em $\mathrm{mm}^{2}$ da área total dos ciclos mastigatórios com a barra e sem a barra de retenção.

Tabela 5.4- Representação dos dados descritivos da largura dos ciclos mastigatórios com e sem barra .86

Tabela 5.5-Representação dos dados descritivos do comprimento dos ciclos mastigatórios com e sem barra. .88

Tabela 5.6- Representação dos dados descritivos da área dos ciclos mastigatórios com e sem barra.

Tabela 5.7- Representação dos valores de $p$ no teste não paramétrico de Wilcoxon. 


\section{LISTA DE ABREVIATURAS E SIGLAS}

FUNDECTO Fundação de Desenvolvimento Científico e Tecnológico de Odontologia

$\mathrm{mm}$

milímetro

$\mathrm{mm}^{2}$

milímetro quadrado

$\mathrm{cm}^{3}$

centímetro cúbico 


\section{SUMÁRIO}

p.

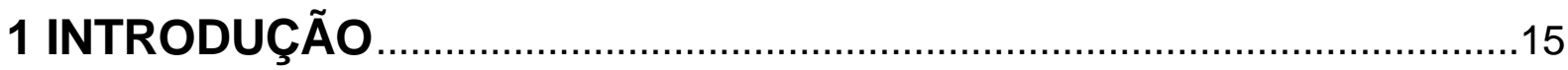

2 REVISÃO DA LITERATURA ...........................................................17

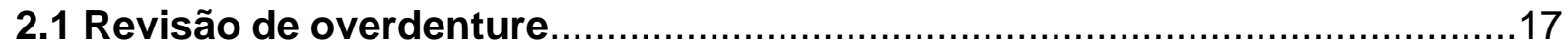

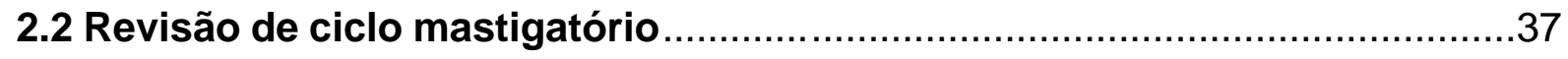

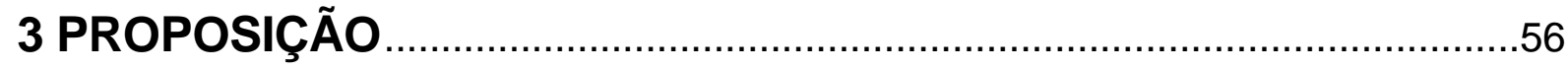

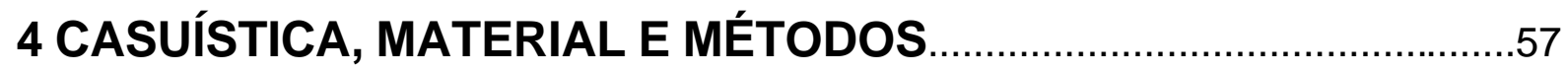

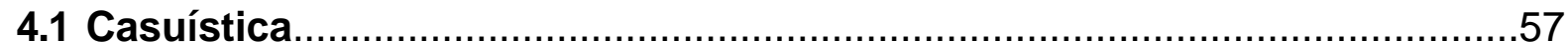

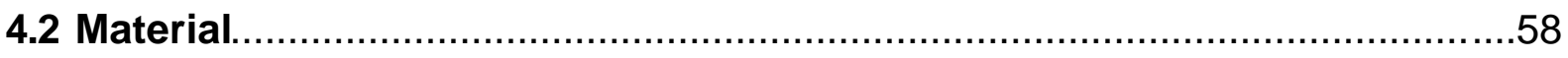

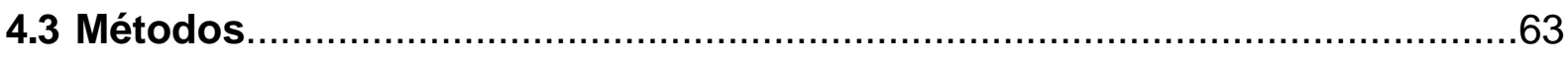

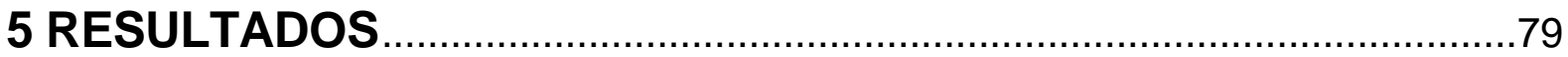

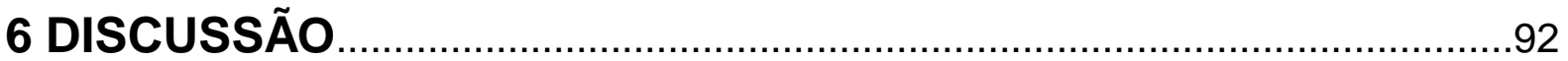

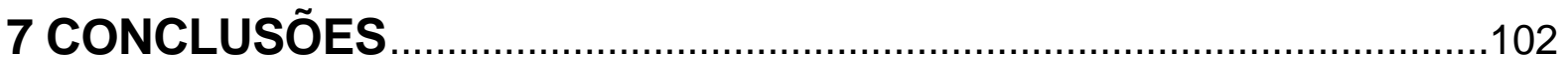

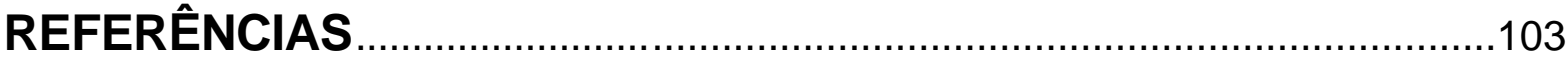

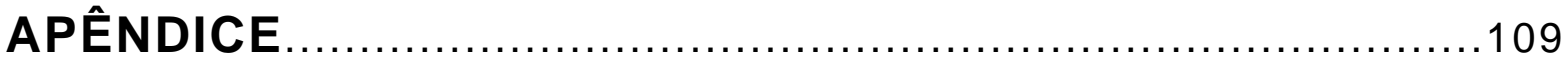

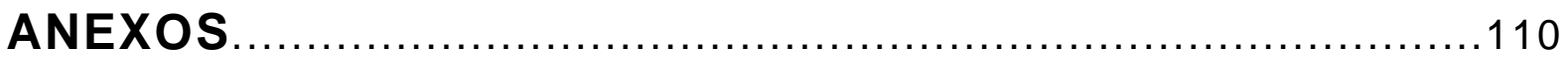




\section{INTRODUÇÃO}

Com a perda progressiva dos elementos dentários, o paciente é levado à condição que chamamos de edentado total, quando muitas transformações são observadas no seu sistema estomatognático como: perda de função, de dimensão vertical, prejuízo da estética e fonética. Para suprir suas necessidades funcionais, os pacientes edentados totais ficaram dependentes de uma reabilitação com prótese total convencional bimaxilar desde os primeiros registros do uso da prótese total.

É sabido que a reabilitação oral por uma prótese total convencional, mesmo quando bem executada, pode não resolver completamente todos os problemas funcionais e psicológicos dos pacientes edêntulos. Ao lado da redução quantitativa da eficiência da mastigação, os pacientes reabilitados por uma prótese convencional também sofrem uma alteração qualitativa da função mastigatória (PERA et al., 1998).

Além disso, existem muitos casos, onde a confecção de uma prótese total mandibular se torna difícil devido à escassa espessura e altura do rebordo alveolar bem como a falta de controle neuromuscular do paciente. Essa condição propicia à prótese, suporte inadequado com pequena retenção e estabilidade durante as funções do aparelho mastigatório (ATT; STAPPARD, 2003).

A partir da década de 80, o paciente edentado total ganhou mais subsídios na área de prótese dentária com as inovações das reabilitações com implantes, possibilitando que uma prótese total convencional fosse então, retida por implantes osseointegrados aumentando a fixação da base da prótese ao rebordo. Isso é o que chamamos de overdenture: uma prótese implanto-retida e mucoso-suportada. Como 
a prótese total mandibular é a mais comumente apontada pela falta de retenção e estabilidade, sendo motivo de insatisfação para o paciente, esta é atualmente, substituída com maior freqüência pela overdenture nos casos bem indicados (GEERTMAN et al., 1996).

A literatura tem sugerido que a presença de implantes pode melhorar a função oral dos pacientes edentados, em especial os com rebordo inferior bem reabsorvido, restaurando, possivelmente, a função oral desses pacientes. Um alto grau de sucesso vem sendo documentado em estudos com próteses suportadas por implantes, pois os pacientes reportam menos reclamações, se sentem mais satisfeitos e alcançam maior habilidade e eficiência da mastigação (AWAD et al., 2003; BENZING et al., 1994; BOERRIGTER et al., 1995b; GEERTMAN et al., 1996, 1999; FONTJIN-TEKAMP et al., 2000; JEMT; LINQUIST; HEDEGARD, 1985; LI et al., 2002; PERA et al., 1998).

Essa foi uma razão para acreditar que um tratamento com suporte de implantes realmente influencia os movimentos mastigatórios e bordejantes da mandíbula, assim como o ciclo mastigatório (BENZING et al., 1994; JEMT; LINQUIST; HEDEGARD, 1985).

Com o avanço do uso da implantodontia na confecção de próteses totais, fica clara a importância de se realizar estudos comparativos com o objetivo de se destacar as overdentures como uma possibilidade de tratamento para pacientes edêndulos.

O intuito deste trabalho é o de destacar as características morfológicas dos ciclos mastigatórios de pacientes com e sem a fixação da barra em suas overdentures. 


\section{REVISÃO DA LITERATURA}

A revisão da literatura foi dividida em dois assuntos: overdenture e ciclo mastigatório. Essa divisão teve como objetivo facilitar a leitura e a compreensão do texto. Em overdenture o enfoque foi em relação à sua indicação, utilização para pacientes desdentados totais, vantagens, desvantagens, meios de retenção, eficiência mastigatória e satisfação do paciente. Em ciclo mastigatório, a revisão permite analisar a função do aparelho mastigatório de pacientes com esse tipo de reabilitação.

\subsection{Revisão de overdenture}

A confecção de próteses totais convencionais na reabilitação de pacientes edentados totais vem sendo usada como tratamento de primeira escolha por muitas décadas. Porém, com o advento da implantodontia na década de 80 , a colocação de implantes com a possibilidade de melhorar a retenção da prótese total ganhou corpo e vem sendo largamente usada e estudada pelos profissionais da área.

A princípio, o tratamento dos pacientes com a colocação de implantes pode parecer um desafio, porém, os trabalhos encontrados na literatura mostram que é um tratamento adequado para as necessidades dos pacientes quando comparado à prótese total convencional. 
Comprovando o sucesso do tratamento com implantes Cune, Putter e Hoogstraten (1994a) avaliaram clinicamente o tratamento com overdentures com 2 ou 4 implantes esplintados com uma barra em um total de 429 pacientes. Encontraram uma alta taxa de sucesso, especialmente para os implantes colocados na mandíbula; os implantes da maxila no geral se apresentaram menos promissores. Os problemas relacionados a esses se tratavam predominantemente de inflamação do tecido peri-implantar devido à pobre higiene oral da maioria dos pacientes. As overdentures foram avaliadas quanto à retenção, oclusão e delimitação da área basal. Dentro destes quesitos, a qualidade das overdentures foi ótima, acreditandose que esse ratamento é efetivo e pode ser realizado com segurança apesar da manutenção que a prótese requer.

Cune, Putter e Hoogstraten (1994b) em um segundo estudo objetivaram determinar os efeitos do tratamento com overdentures com sistema barra-clip nas reclamações dos pacientes a respeito de suas próteses totais. Foram 4 grupos de pacientes: um com pré-tratamento (questionário antes e depois da reabilitação), dois com pós-tratamento (avaliação após a reabilitação) e um grupo controle de pacientes com próteses totais convencionais que preencheram um questionário sobre insatisfações com as próteses. O questionário consistiu de tópicos englobando a função, estética, retenção e aceitação das próteses. As diferenças entre os grupos foram analisadas. Pequenas alterações foram vistas na satisfação do paciente com relação à prótese maxilar, apesar de muitos quererem aumento da retenção e estabilidade da prótese maxilar após o tratamento com implantes na mandíbula. 16\% dos pacientes que não tiveram acesso ao tratamento com implantes apresentaram reclamações das próteses mandibulares que foram mais severas que as 
apresentadas pelos pacientes com overdenture mandibular, sendo fortes candidatos à colocação de implantes. Os resultados mostraram que o tratamento com overdenture é muito efetivo na maioria das reclamações com as próteses convencionais, pois os problemas com função estética e conforto foram reduzidos.

Burns et al. (1995) encontraram em sua pesquisa resultados que indicaram a overdenture como um tratamento que oferece os melhores resultados para pacientes edentados totais, pois além, de diminuir a reabsorção óssea, também, possui boa estabilidade e retenção. Pacientes com próteses totais muito antigas que se apresentam, portanto, mal adaptadas e com a oclusão desbalanceada pelo desgaste dos dentes, apresentam maior taxa de reabsorção óssea, pois as cargas mastigatórias incidem sobre o rebordo de maneira deletéria. Esse mecanismo por sua vez proporciona uma reabsorção óssea mais veloz. Os autores avaliaram em 17 pacientes com próteses totais convencionais pré-existentes, a retenção e estabilidade das próteses após a colocação de dois implantes mandibulares e transformação da prótese total convencional em uma overdenture. O estudo indicou uma clara superioridade da overdenture quando comparada às próteses totais convencionais originais na estabilidade e retenção das próteses e na diminuição da reabsorção alveolar.

Um grande problema enfrentado por pacientes edentados totais que leva a uma condição oral desfavorável é a contínua reabsorção óssea da maxila e da mandíbula. Existem casos nos quais uma prótese total convencional pode já ter sido útil e satisfatória na reabilitação protética, porém, com o avanço dos anos, a contínua reabsorção alveolar conduziu a um quadro clínico desfavorável para uma 
retenção e estabilidade adequadas da prótese mandibular. A excessiva reabsorção óssea pode comprometer a terapia com próteses totais convencionais, e a reabilitação com implantes tem solucionado muitos problemas através da retenção e estabilidade, aumentado a funcionalidade da prótese afirmam (a) Att e Stappert (2003) que descreveram uma reabilitação com quatro implantes com barras em ambos os arcos dentários. Em retornos de 2, 7 e 30 dias após o tratamento encontraram um restabelecimento da estética, fonética e função mastigatória no paciente tratado e uma melhora significante na qualidade de vida se notou. Concluíram que em comparação com os pacientes que usam prótese total convencional, a overdenture oferece melhor função oral e conforto.

A overdenture tem muitas vantagens sobre as próteses totais convencionais, pois é sabido que os implantes conservam o osso periimplantar segundo McCord e Blum (2003). Esses mesmos autores, interessados em prevenir a reabsorção óssea que a extração dos dentes pode causar, apresentam em uma revisão da literatura, o sucesso na preservação de osso em overdentures. Para os autores existe uma clara relação entre a perda dos dentes e a reabsorção contínua do processo alveolar, perda de dimensão vertical, alterando a fisionomia do paciente e causando um falso prognatismo mandibular. As próteses híbridas são uma boa solução para a manutenção do osso marginal entre as raízes, porém deve ser levada em consideração a possibilidade de surgimento de lesões cariosas, doença periodontal e falta de manutenção por parte do paciente. As próteses retidas por implante são aceitas como meio de preservação do osso peri-implantar. A mesma proporção de manutenção do osso alveolar foi encontrada tanto para overdentures quanto para próteses fixas retidas por implantes, o que confirma o potencial de prevenção de 
osso periimplantar. No caso de próteses convencionais as forças oclusais criam uma pressão negativa na crista do rebordo remodelando o osso adjacente e no caso de implantes essa pressão é positiva.

Para os pacientes que requerem maior retenção, estabilidade, função e estética nas suas próteses totais, a overdenture é uma alternativa satisfatória para as próteses convencionais. Com o desenvolvimento de materiais cada vez mais biocompatíves, eliminando a possibilidade de falha na osseointegração e de técnicas cirúrgicas que se mostram cada vez menos traumáticas a colocação de implantes vem sendo feita com baixos riscos de insucesso como constataram Doundoulakis et al. (2003) em uma revisão de literatura. Os autores analisaram os benefícios e os riscos do tratamento. Na opinião dos mesmos, as desvantagens das próteses convencionais são: a limitação da retenção e estabilidade, contínua reabsorção óssea, função mastigatória diminuída e perda de estética com o uso. Já as overdentures têm vantagens como: requerer pequeno número de implantes, boa estabilidade e retenção do aparelho através dos encaixes e diminuição da reabsorção óssea. Alerta que o tratamento com implantes deve ser cauteloso em pacientes fumantes, diabéticos e com quantidade e qualidade óssea pobres. Em se tratando de casos com boa indicação, concluíram que a alta taxa de sucesso na colocação de implantes na região anterior aos forames $(95 \%)$ indica resultados previsíveis na superioridade da overdenture quanto à retenção, estabilidade, função e satisfação do paciente em comparação a uma prótese total convencional.

Para Klemetti et al. (2003), um dos maiores objetivos da implantodontia é melhorar a retenção das próteses totais que são com freqüência associadas com 
insatisfação em pacientes com rebordo reabsorvido. Em seu trabalho, os autores afirmaram que a taxa de sucesso na colocação de implantes na região anterior da mandíbula é muito alta. Por esse fator e pelo baixo custo é comum tratar pacientes edêntulos com a colocação de dois implantes e uma barra para retenção da prótese ao invés de quatro implantes e uma barra. Foram reabilitados 30 pacientes com overdenture mandibular e prótese total superior convencional e 30 pacientes com prótese total convencional bimaxilar. A estabilidade das overdentures foi excelente e a dimensão da região lingual da prótese foi estendida apenas até a linha milohióidea proporcionando maior conforto à língua. As visitas de controle posterior à instalação foram em menor número para as overdentures que para as próteses convencionais no primeiro ano de uso.

Sadowsky e Caputo (2004) avaliaram a influência do número de implantes e cantilever na distribuição de stresse no osso adjacente por método fotoelástico. Os modelos receberam dois ou três implantes conectados entre si por barra que se ligavam à prótese através de clip ou SwissLoc. Forças verticais foram aplicadas na região de primeiro molar e primeiro pré-molar. Todas as peças apresentaram uma baixa transferência de carga para os implantes co-laterais e contra-laterais, porém, a overdenture que demonstrou menor transferência de carga para os implantes e maior retenção foi a confeccionada com dois implantes e SwissLoc, seguida da confeccionada com dois implantes e barra/clip. Esse sistema pode ser usado como alternativa de tratamento em pacientes que necessitam de retenção nas próteses mandibulares e que têm limitação cirúrgica e/ou econômica. 
Timmerman et al. (2004) interessados em determinar o melhor encaixe e número de implantes para as overdentures através de um período de oito anos, estudaram por questionário três grupos de pacientes com rebordo inferior bem reabsorvido insatisfeitos com a função de suas próteses totais convencionais originais. Os grupos num total de 103 pacientes diferiram quanto ao encaixe e número de implantes das overdentures: 2 implantes e encaixe tipo bola; 2 implantes e barra simples e 4 implantes e barra tripla. Quanto à fonética, estética e função a satisfação do paciente ao longo dos anos é alta e não dependente do tipo de tratamento. Inicialmente, quase a totalidade dos pacientes relatou, satisfação com as próteses, porém ao longo dos anos a satisfação quanto à retenção e estabilidade diminuiu mais com os casos de dois implantes e encaixe tipo bola que para os pacientes com barra. Mostraram que ter mais que dois implantes para reter a prótese não leva a uma satisfação e função aumentadas. O sucesso na retenção das overdentures não é diretamente proporcional ao número de implantes, ou seja, nem sempre quanto maior o número de implante maior a retenção oferecida para a prótese. Isso sugere que a retenção e estabilidade que uma overdenture mandibular oferece, guiam mais a satisfação do paciente, que o nível de retenção que os implantes ofereceriam por si só. Ainda afirmaram que a satisfação do paciente é um dos maiores objetivos no tratamento de edentados, porém a satisfação é um fenômeno muito complexo influenciado por um número muito grande de variáveis e não estritamente relacionado ao sistema estomatognático. O estudo sugere que uma overdenture retida por dois implantes com uma barra simples vem a ser o melhor tratamento para pacientes edentados com rebordo reabsorvido. 
Visser et al. (2005) avaliaram o sucesso e a satisfação do tratamento com overdentures mandibulares retidas por dois ou três implantes e sistema barra/clip em 60 pacientes com altura de rebordo entre $12 \mathrm{~mm}$ e $18 \mathrm{~mm}$. Os grupos se equipararam quanto à colocação dos implantes e confecção das próteses. Os pacientes foram reavaliados anualmente por cinco anos. Nenhum dos pacientes se queixou de desconforto nos lábios e bochecha e nenhuma diferença quanto à satisfação ou quanto à reabsorção óssea foi observada entre os dois grupos. Essa satisfação quanto à função e estética aumentou após a reabilitação com a overdenture e se tornou estável ao longo dos anos. O grupo com dois implantes teve maior manutenção protética e o grupo com quatro implantes apresentou mais problemas com tecido mole.

Para Kenney e Richards (1998) quando dois implantes são usados para retenção de uma prótese total removível uma ótima distribuição de forças para os implantes é necessária. Os autores estudaram através de análise fotoelástica o stresse gerado ao redor dos implantes com dois tipos de encaixes: O-ring e barra/clip. Forças laterais e oblíquas de 10 a 200lb foram aplicadas unilateralmente nos primeiros molares. Com a avaliação da resultante na distribuição do stresse verificourse que com forças verticais, o O-ring transferiu mínimo stress aos implantes enquanto que para o sistema barra/clip a geração de stresse nos implantes foi de maior magnitude. A força posterior oblíqua resultou em stress similar para ambos os sistemas com um discreto aumento pra barra/clip e nenhum encaixe transferiu stress para a região contralateral. 
Quando da confecção de uma overdenture é importante lembrar que por definição uma overdenture é suportada parcialmente pelo tecido, portanto uma força de compressão desse encaixe só pode acontecer em conjunto com o tecido adjacente, caso contrário, as forças geradas podem ser destrutivas para o implante, conexão, tecido e prótese, segundo Winkler et al. (2002). Os autores descreveram em seu trabalho, com overdenture inferior e outro com prótese parcial removível superior, a funcionalidade do encaixe O-ring para próteses sobre implantes. Afirmaram que o encaixe tem um grande número de vantagens como facilidade de uso e manutenção, boa retenção, baixo custo e possibilidade de eliminação de uma estrutura como a barra. Porém, com o uso, esses encaixes perdem retenção gradualmente e precisam ser trocados periodicamente. Além do mais, esse tipo de conexão exige paralelismo entre si para evitar fratura na região do pescoço.

Botega et al. (2004) avaliaram a retenção e a resistência à fadiga de dois sistemas de encaixe muito usados em overdenture: o sistema barra-clip e O-ring. Como o uso diário da prótese, na inserção e remoção, bem como o ambiente oral podem resultar em perda da função do componente, os corpos de prova foram imersos em saliva artificial e submetidos à fadiga pela inserção e remoção de 55000 vezes e a força de retenção foi avaliada três vezes. Observaram que a deformação constante e permanente dos componentes plásticos da conexão pela inserção e remoção da prótese causando aspereza ou endurecendo, pode aumentar a retenção. A retenção do encaixe tipo bola se tornou estável com um discreto aumento devido talvez à estabilidade e resistência à dureza do seu material de confecção (borracha-silicone). O sistema barra clip obteve resultados mais satisfatórios, já que tem uma área de contato satisfatória o que faz com que a 
retenção fosse maior; já que quanto maior a área de contato, maior a fricção e maior a retenção dos componentes. Esse teste simulou um uso de 5 anos das próteses sem que os valores de retenção diminuíssem ou houvesse fratura dos componentes em uma determinada trajetória, sem relevar forças oblíquas na mastigação.

Para Kwok-Hung et al. (2004), em pacientes com idade avançada, os encaixes devem permitir uma fácil colocação e remoção da prótese e aqueles de fácil higienização devem ser escolhidos. Ultimamente os encaixes mais apropriados para overdentures deveriam permitir uma função atraumática ou de boa distribuição de stresse para as estruturas biológicas e mecânicas de suporte daquela prótese. Devido à simples configuração geométrica e superfície plana, os magnetos mostraram a menor retenção e força para deslocamento. Esses encaixes devem ser usados em pacientes com pobre destreza manual, que podem ter dificuldade em colocar e retirar a prótese. Portanto, em situações especiais, mesclar a capacidade retentiva de um encaixe com a condição física do paciente pode ser uma consideração clínica importante para o sucesso do tratamento. Os autores analisaram através da aplicação de forças de tensão a retenção de encaixes em modelos in vitro que receberam dois implantes na região de caninos e overdenture. Os encaixes foram: sistema barra-clip; Locator LR, encaixe tipo bola, magnetos e sistema ERA. O sistema ERA gray obteve a maior retenção. A menor retenção foi obtida com os magnetos seguidos do Locator LR pink. Com retenção média estão de forma crescente: Locator LR White, o encaixe tipo bola, o sistema barra-clip e o ERA white. 
Para Svetilize e Bodereau (2004) a correta escolha de um encaixe para implante e retenção para overdentures implica no grau de retenção que se deseja alcançar e na proteção dos tecidos subjacentes que ele poderá fornecer. Os autores estudaram através de testes de tensão a retenção em modelos iguais in vitro em overdentures retidas por dois ou quatro implantes de diferentes encaixes: magnetos; bola; barra pré fabricada (tipo Dolder) e pós fabricada, Ceka Revax e Zaag. Para o grupo dos magnetos não houve resultado significante. Já, uma diferença significante na retenção foi obtida com o sistema tipo bola, Ceka Revax, Zaag e barras préfabricadas; enquanto uma forte mudança foi observada com as barras pósfabricadas. Os resultados indicaram que as barras pós-fabricadas são encaixes apropriados para dar retenção à overdenture e superar seu deslocamento ânteroposterior.

Lindiquist e Carlsson (1982) trataram 25 pacientes com problemas na adaptação de suas próteses totais convencionais com próteses novas e depois com overdentures mandibulares. A função mastigatória foi avaliada por três métodos: por questionário, capacidade de trituração de amêndoas e força de mordida. Nenhuma melhora significante foi observada após a instalação das próteses novas, porém, após a colocação dos implantes, houve aumento da habilidade mastigatória, eficiência mastigatória e força de mordida. Oito dos dez alimentos apontados no questionário eram retratados como difíceis ou impossíveis de serem mastigados antes da reabilitação, porém, nenhum após a colocação da overdenture. O tempo de mastigação caiu de 49s para 43s com a nova prótese e para 20s com a overdenture. A força de mordida aumentou em $15 \%$ com as próteses novas e em $85 \%$ com a colocação dos implantes. 
Haraldson et al. (1988) avaliaram 9 pacientes edentados totais, antes e até 1 ano após a reabilitação com overdentures mandibulares, quanto à força de mastigação e eficiência mastigatória. Esses pacientes relatavam problemas funcionais com suas próteses antigas. Foram usadas amêndoas no teste. A maioria dos pacientes apresentou uma melhora subjetiva (através de questionários) e todos uma melhora clínica de força e eficiência mastigatória; o tempo do ciclo mastigatório não foi alterado. Concluíram que a overdenture proporciona ganhos mastigatórios na função oral quando comparada com a situação anterior.

Geertman et al. (1994) avaliaram em um teste de mastigação com alimento artificial, 84 pacientes reabilitados com prótese total convencional ou overdenture com duas ou uma barra, ocluindo com uma prótese total convencional superior. As avaliações foram feitas após a instalação das próteses. Pacientes com próteses convencionais precisaram de 1,5 a 3,6 mordidas a mais que os com implantes, para atingir o mesmo tamanho da partícula. Sugeriram que o aumento da estabilidade e retenção da prótese mandibular, mais que o grau de suporte dos implantes ou mucosa alveolar, determinam a habilidade dos pacientes na mastigação. A reabilitação com overdenture em pacientes com condições que comprometem o uso de próteses convencionais com sucesso, restabelece a habilidade mastigatória.

Boerrigter et al. (1995), compararam três tipos de próteses mandibulares quanto à satisfação e habilidade de mastigação: overdentures, próteses convencionais com e sem cirurgia pré-protética. Foram 38 homens e 52 mulheres com altura média do rebordo anterior de $21 \mathrm{~mm}$. Após 1 ano de avaliação com 86 
pacientes, 5 dos 7 pontos do questionário, voltados para o que se queria avaliar como função da prótese inferior, mostraram significante melhora para os dois grupos que fizeram cirurgia. O mesmo foi encontrado para o grau de satisfação. Todos ficaram satisfeitos com a estética. Para os autores, primeiro as próteses suportadas por implantes e depois as feitas após vestíbuloplastia e aprofundamento do assoalho promovem uma maior satisfação no geral que as próteses convencionais.

O objetivo do estudo de Boerrigter et al. (1995) foi, através da avaliação subjetiva (questionário) do paciente perante sua satisfação ao tratamento, estabelecer um plano de tratamento com prótese retidas ou não por implantes para pacientes edentados totais. Participaram do estudo 148 pacientes com média de $13 \mathrm{~mm}$ de altura óssea e insatisfação com as próteses mandibulares. Uma parte desses pacientes foi reabilitada com próteses totais bimaxilares novas, e a outra parte do grupo com prótese total superior e overdenture inferior. Através de questionários com 6 questões a respeito de satisfação, após 1 ano da instalação, 3 dos pontos obtiveram melhores marcas para o grupo de implantes, bem como para satisfação geral: fala, conforto e função; empatando em estética com o outro grupo. Acreditam que para pacientes com severa reabsorção mandibular, a overdenture promove uma solução mais satisfatória para esses problemas relacionados às prótese convencionais.

Geertman et al. (1996), em seu estudo, objetivaram estudar os efeitos do tratamento de overdentures e próteses totais convencionais em rebordos alveolares bem reabsorvidos em 151 pacientes, dos quais 91 pacientes receberam uma overdenture e 60 uma prótese total convencional bimaxilar. Idade, sexo, período de 
edentulismo, número de próteses anteriores, tempo de uso da prótese atual e altura do rebordo foram critérios usados a título de comparação dos grupos estudados. Os resultados da pesquisa foram avaliados antes da reabilitação e 1 ano após o tratamento. Antes do tratamento os grupos de pacientes estavam insatisfeitos com suas próteses mandibulares pela dificuldade de mastigar alimentos duros. Após 1 ano de instalação o grupo de overdentures estava satisfeito com o resultado; porém, o outro grupo tinha apenas um terço de satisfação. Quanto à habilidade de mastigação o grupo de overdentures obteve um resultado bem melhor que o grupo de próteses convencionais.

Para avaliar os benefícios de uma overdenture em relação a próteses totais convencionais Garret et al. (1998) conduziram um estudo clínico comparando a efetividade na função mastigatória de overdentures e próteses totais convencionais inferiores em pacientes com diabetes mellitus. Oitenta e nove pacientes completaram o tratamento, sendo que 37 foram reabilitados com prótese convencional e 52 com overdentures retidas a barra e dois implantes. Testes mastigatórios foram aplicados antes do tratamento, e depois de 6 e 24 meses do fim do tratamento. Os dois grupos foram comparáveis em termos de idade, qualidade das próteses originais, tecido de suporte e próteses anteriores. Nenhuma diferença foi encontrada para pacientes tratados com ou sem insulina. Neste trabalho os autores encontraram melhora na mastigação de pacientes reabilitados tanto com overdenture quanto com prótese convencional em relação aos pobres índices iniciais. Os testes com as próteses originais foram mais positivos para o grupo de próteses totais convencionais que para o das overdentures. Porém, os testes posteriores à reabilitação foram similares pelos benefícios que o grupo das 
overdentures obtiveram. Por fim, pacientes que tiveram baixos índices nos testes iniciais tiveram boas melhoras depois do tratamento tanto com a prótese convencional quanto com a overdenture.

Outro trabalho que segue essa mesma linha de pesquisa avaliando os mesmos 89 pacientes diabéticos com diferentes níveis de satisfação foi o de Kapur et al. (1999). Foi usado um questionário para avaliar as próteses antigas, e as atuais após 6 e 24 meses após a reabilitação. Os resultados mostraram melhora em ambos os grupos, com maior vantagem para o grupo de overdentures, que se destacou sobre as próteses originais na habilidade mastigatória até os 6 meses; conforto na mastigação e segurança. Mas, diferenças estatisticamente significantes foram representadas por habilidade mastigatória e menor dificuldade em mastigar alimentos duros. Depois, ao fim dos 24 meses essas diferenças não tiveram significância. Concluíram que as overdentures oferecem maiores vantagens para a função mastigatória que as próteses convencionais em pacientes insatisfeitos ou com problemas crônicos de adaptação a próteses convencionais.

Para Schmitt e Zarb (1998) sua pesquisa suporta a noção de que próteses retidas por implantes podem oferecer a estabilidade necessária para resolver os problemas dos pacientes usuários de próteses totais convencionais insatisfatórias. Os autores reuniram 96 pacientes insatisfeitos com suas próteses totais convencionais que buscaram tratamento onde próteses fixas ou overdentures foram indicadas. Nas consultas de retorno (até 15 anos depois) as próteses foram avaliadas quanto à retenção, suporte, estabilidade, oclusão, avaliação subjetiva de eficiência mastigatória, conforto e estética. Tirando os implantes com insucesso, dos 45 pacientes com próteses fixas, 38 estavam usando as próteses com sucesso; dos 
pacientes com overdentures, todos continuaram usando a prótese com sucesso. Após o período inicial de ajuste, as overdentures exigiram menos tempo para resolução dos problemas, e se mostraram úteis na reabilitação de pacientes com falta de adaptação às próteses convencionais.

Geertamn et al. (1999) estudaram clinicamente e através de questionário a relação de um teste artificial de comida e a eficiência mastigatória. O exame constou da comparação entre dois tipos de overdentures retidas a barra e próteses totais convencionais mandibulares num total de 84 pacientes (64 mulheres e 20 homens) com média de 57 anos. A eficiência mastigatória foi substancialmente melhor para as próteses retidas por implantes comparada ao grupo com próteses totais convencionais. Não se observou variação entre os dois grupos de overdentures, quanto ao número de implantes e barras. Ambos os grupos com implantes tiveram maiores problemas quanto à mobilidade da prótese superior que o grupo com próteses totais convencionais, porém o autor acredita que esses e outros problemas são superados pela melhora da função com essas próteses.

Em um grupo com 61 pacientes reabilitados com overdenture e $60 \mathrm{com}$ próteses totais convencionais Meijer et al. (1999) avaliaram habilidade mastigatória e satisfação no primeiro ano de uso das próteses. Após esse período, $23 \%$ dos pacientes do segundo grupo, insatisfeitos com o resultado do tratamento, puderam ser reabilitados com uma overdenture. No geral, os pacientes com próteses retidas por implante estavam mais satisfeitos que os com prótese convencional após 1 e 5 anos; apesar de que em 5 anos a satisfação foi um pouco menor que em 1 ano, talvez pelo fato dos pacientes se habituarem com uma situação melhor. 
Raghoebar et al. (2000) avaliaram a satisfação e a habilidade da mastigação através de questionário em pacientes edentados tratados com overdentures, próteses totais convencionais ou essas com aumento da área basal. Noventa pacientes com altura média de $20,7 \mathrm{~mm}$ de rebordo inferior foram avaliados antes do tratamento, e depois de 1 e 5 anos da instalação. A satisfação aumentou para todos os grupos até 1 ano. Após 1 ano do tratamento, os dois grupos cirúrgicos se equivaleram nos melhores resultados, mas após 5 anos o grupo de overdentures teve maior satisfação por parte dos pacientes, sem diferenças entre os dois outros grupos. Concluíram que tanto a curto quanto a longo prazo, o resultado das overdentures é mais satisfatório, sendo assim, um tratamento apropriado para reabilitação do arco inferior mesmo em pacientes que não têm severa reabsorção óssea.

Raghoebar et al. (2005) avaliaram este mesmo grupo de pacientes após 10 anos. Todos esses pacientes apresentavam problemas com suas próteses antigas e foram então avaliados com questionário em relação à satisfação e habilidade mastigatória de diferentes alimentos. A avaliação foi feita antes do tratamento, e após 1, 5 e 10 anos da reabilitação. Ao fim, 75 pacientes conseguiram ser avaliados pelos 10 anos. No primeiro ano de tratamento a avaliação foi mais positiva para os dois grupos cirúrgicos e após 5 anos a avaliação caiu para o grupo com aumento da área basal, porém o grupo de overdentures continuou se destacando em relação aos outros. Após 10 anos de tratamento a satisfação aumentou para o grupo com implantes e pacientes que estavam insatisfeitos com o tratamento inicial puderam optar pela reabilitação com overdenture. As reclamações com a prótese superior não 
demonstraram diferenças entre os três grupos. Os resultados revelaram que as overdentures são um tratamento favorável para pacientes com insatisfação na prótese total convencional inferior.

Melas, Marcenes e Wright (2001) investigaram em 43 pacientes reabilitados com overdenture se essa condição oral proporcionaria mais satisfação e menos dificuldade em mastigar alimentos de diferentes consistências que em 40 pacientes com prótese total convencional. Os grupos foram equivalentes quanto ao sexo, idade das próteses e duração do edentulismo e avaliados através de questionário. Pacientes com overdentures eram mais satisfeitos com o conforto da prótese, tinham convívio social maior, a fonética era mais clara e mastigavam os alimentos com menos dificuldade. Com os resultados, acreditam que o tratamento com overdenture deva ser considerado em pacientes edentados.

Para avaliar o efeito da overdenture na mastigação, Bakke, Holm e Gotfredsen (2002) usaram 12 pacientes que tinham problemas na retenção de suas próteses totais inferiores. Num primeiro momento, todos receberam novas próteses e após três meses de adaptação, dois implantes foram colocados na região anterior. Os pacientes foram avaliados com questionário, testes de mastigação, força de mordida e eletromiografia com a prótese convencional nova após 3 meses; e 1 e 5 anos após a colocação dos implantes. Após a reabilitação, todos os pacientes foram capazes de mastigar alimentos mais duros, a máxima força de mordida e a atividade mastigatória aumentaram e a duração do ciclo diminuiu. Tiveram aumento de função e redução de dor na mastigação. Entretanto, sete pacientes não completamente satisfeitos com a função da overdenture, apresentaram menor atividade muscular, 
mesmo após a colocação dos implantes quando comparado com as pessoas totalmente satisfeitas. Concluíram que as overdentures possibilitam melhor atividade mastigatória que as próteses convencionais.

Awad et al. (2003) quiseram comparar a eficiência de overdentures mandibulares retidas por dois implantes e uma barra e próteses totais convencionais em pacientes de 35-65 anos. Quarenta e oito pacientes receberam próteses convencionais e 54 overdentures. Foram avaliados por questionário quanto ao conforto, habilidade de mastigação, de higiene, de fala e estabilidade antes da reabilitação e 2 meses após a instalação. Foi encontrada uma satisfação significantemente maior no grupo das overdentures que no das próteses convencionais para os quais a facilidade de mastigar alimentos não alterou significantemente. Idade e sexo não foram associados com o grau de satisfação. Além disso, o grupo das overdentures obteve maiores marcas em relação ao conforto, estabilidade e facilidade em mastigar; porém, não diferiram quanto à estética, habilidade de fala ou de limpeza da prótese. Concluíram que uma overdenture mandibular retida por dois implantes com uma prótese total convencional maxilar é um tratamento mais satisfatório que apenas próteses totais convencionais bimaxilares.

Um trabalho que define bem a questão da relação entre a altura do rebordo e o grau de eficiência mastigatória é o de Kimoto e Garret (2003). Os autores avaliaram 63 pacientes com suas próteses antigas e 6 meses depois da nova reabilitação. Os pacientes foram divididos em três grupos quanto à altura do rebordo: baixo - rebordo com altura menor que $21 \mathrm{~mm}$; moderado - entre $21 \mathrm{~mm}$ e $28 \mathrm{~mm}$; alto 
- maior que 28mm. Teste de eficiência mastigatória com o lado de preferência foi feito mastigando amendoim e cenoura. Entre os três grupos com diferentes alturas de rebordo, os autores encontraram melhora no tempo e qualidade da mastigação nos pacientes reabilitados com overdenture que possuíam rebordo reabsorvido. Pouca melhora foi sentida nos paciente com rebordo médio. Afirmam que a terapia com implante é escolhida para aumentar a retenção e estabilidade das próteses porque se acredita que a habilidade mastigatória está relacionada à fixação da base da prótese. Entretanto, nesse estudo, nenhuma diferença foi observada em paciente com rebordo alto, apesar da forte retenção do implante. A avaliação mostrou que a retenção e estabilidade da base são limitantes na influência sobre a mastigação. Apesar do aumento da retenção dos implantes em todos os rebordos, isso não se relaciona diretamente coma habilidade mastigatória.

Fontijin-Tekamp et al. (2000) mediram força de mordida e eficiência mastigatória com métodos iguais para pacientes com overdentures, prótese total convencional (estes, com rebordo alto) e dentados. Encontraram que a força de mordida encontrada nos pacientes com overdentures está entre a encontrada nos pacientes com prótese total e os pacientes usados como controle. A eficiência da mastigação das overdentures foi menor com relação aos dois grupos. Para todos os grupos uma significante correlação foi encontrada entre a força de mordida e a eficiência da mastigação. Concluíram que o uso de implantes não é a solução para todos os problemas em pacientes edentados e que pode não restabelecer a função oral para o nível esperado. 
Allen, McMillan e Walshaw (2001) em seu estudo avaliaram o nível de saúde e satisfação de pacientes usuários de prótese total convencional após a reabilitação com overdenture ou com prótese total convencional nova. Um grupo pediu e recebeu a colocação de implantes; outro grupo pediu implantes, mas recebeu próteses totais convencionais e o último grupo pediu e recebeu novas próteses totais convencionais. Antes do tratamento, a satisfação com as próteses era baixa para os três grupos. Após o tratamento, os três grupos tiveram melhoras na satisfação, especialmente aqueles que foram reabilitados com a opção de tratamento que desejavam e que lhes era melhor indicada independente da colocação de implantes.

\subsection{Revisão de ciclo mastigatório}

Em um grupo de 35 pacientes mastigando cenouras ou goma, Ahlgren (1966) foi capaz de classificar os ciclos mastigatórios em sete grupos diferentes. Os movimentos foram registrados com a mastigação de cenoura, para simular uma mastigação natural, por 10 s em cada lado. Os pacientes com oclusão normal apresentaram ciclos com padrão mais simples e regular; a forma era semicircular com pequena variação individual. Pacientes com maloclusões demonstraram ciclos chamados pelo autor de chopping, reversed, contralateral e irregular. Formas irregulares com grande variação individual. Pacientes com mordida cruzada demonstraram particularmente padrões mastigatórios irregulares. Para o autor, ainda não foi estabelecida uma relação direta entre o tipo de oclusão dos dentes e o padrão mastigatório apresentado. 
Tipo I: abertura próxima à linha média e leve fechamento ipsilateral.

Tipo II: abertura no lado contralateral, leve movimento rumo a ipsilateral e fechamento.

Tipo III: abertura com um movimento direto para ipsilateral e fechamento lateral ao movimento de abertura.

Tipo IV: abertura para ipsilateral, alteração de direção no meio da abertura, porém, permanecendo neste lado. Fechamento em direção à linha mediana: chopping. Tipo V: abertura no ipsilateral e fechamento medial à abertura: reversed.

Tipo VI: abertura contralateral em quase toda a extensão e fechamento medial à abertura: contralateral.

Tipo VII: abertura e fechamento sem padrão ou ritmo consistentes. Freqüentes transposições entre abertura e fechamento: irregular.

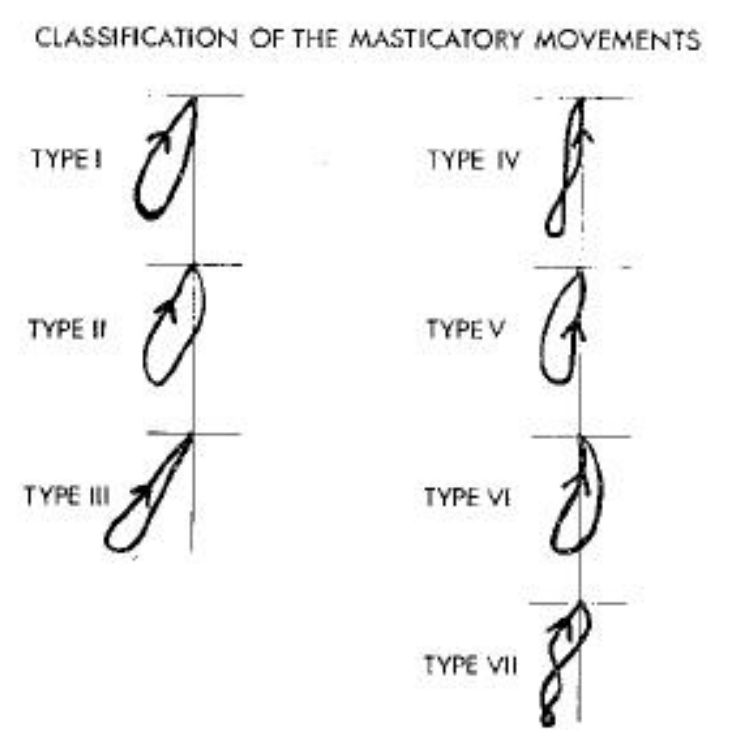

Figura 2.1- Classificação dos ciclos mastigatórios (Ahlgren, 1996) 
Camani (1952) descreveu o movimento mastigatório no plano frontal da seguinte forma: a boca se abre (depois de um pequeno e eventual deslocamento do arco inferior contra o superior, com direcionamento lateral) até um terço da sua posição caudal máxima. Então a mandíbula se move obliquamente, cranial e lateralmente, habitualmente para o lado que tem melhores condições de articulação, até uma posição lateral máxima. A mandíbula alcança a posição oclusal depois de um eventual deslizamento do arco inferior contra o superior.

Bradley (1986) afirmou que o movimento mais importante da mastigação consiste na separação e aposição rítmicas dos maxilares. Existem também pequenos movimentos para frente, para trás e laterais que ocorrem antes, durante e depois do contato dentário. O movimento não é similar ao de uma dobradiça, não existindo um eixo de rotação fixo da mandíbula. Os movimentos normais envolvem um movimento de dobradiça simultâneo com um deslizamento dos côndilos e como as articulações têmporo-mandibulares de ambos os lados estão conectadas entre si pela mandíbula, a ação de uma delas será influenciada pela outra.

Existe considerável variabilidade no padrão e duração do ciclo mastigatório entre diferentes indivíduos e para o mesmo indivíduo, dependendo do tipo de alimento e grau de redução do mesmo, quando se analisa o movimento em plano frontal. Ainda que a forma geral do ciclo em cada um dos indivíduos seja similar, existem diferenças significativas. Essa variação entre distintos indivíduos poderia estar relacionada com a disposição anatômica do aparelho mastigatório. A retroalimentação sensorial, via sistema nervoso central, modifica cada ciclo mastigatório em resposta ao grau de redução do alimento. A mordida inicial, quando o alimento é colocado na boca requer forças distintas das que precisa a mordida 
final, quando o alimento é reduzido. Alimentos pegajosos e duros devem aumentar a duração do ciclo mastigatório. Durante o ciclo a mandíbula se move a uma velocidade constante alcançando a velocidade máxima no começo dos movimentos de abertura e de fechamento.

Os movimentos da mandíbula durante a mastigação não representam os movimentos limites que ela pode realizar (movimentos bordejantes). Se, deliberadamente, se coloca a mandíbula na posição mais retrusiva, mais protrusiva ou mais lateral durante seu abaixamento e elevação, é possível traçar uma borda ao redor dos movimentos usuais.

Gibbs et al. (1971) objetivaram estudar os movimentos mandibulares e a relação maxilomandibular durante a mastigação para conseguir suprir as especificações dos articuladores e transportar uma condição que ocorre na boca. Também, estudaram a maneira e a intensidade que as diferenças de oclusão causavam nos movimentos mandibulares durante a mastigação. Doze pacientes participaram do estudo. Quatro com oclusão normal: todos os dentes presentes, bom alinhamento dental, intercuspidação Classe I de Angle e periodonto sadio; quatro com reabilitações satisfatórias e quatro com maloclusões evidentes. Mostrou que a mandíbula inicia a abertura em uma posição anterior e inferior com os dois côndilos se movendo ao mesmo tempo; no fechamento o movimento do côndilo de trabalho é retruído e superior até a oclusão. Portanto o ciclo é dividido entre a posição mais vertical da mandíbula e a intercuspidação. Como existe uma fase de oclusão no ciclo, ela quase sempre (97\%) termina lateralmente do lado oposto de mastigação. No plano vertical com os planos separados, observou-se que pacientes com oclusão normal têm boa reprodutibilidade dos ciclos e o fechamento retorna à mesma 
posição de abertura. Os incisivos mostram uma fase de platô, referente a uma parada de 0,2 s na fase de oclusão do ciclo; exceto nos primeiros ciclos onde o alimento se encontra muito grande e a oclusão não é alcançada fazendo com que o movimento de mastigação não pare. Para pacientes com maloclusão, a reprodução do ponto onde o ciclo se inicia e termina é pobre. Sua forma é mais irregular e a forma ondulada dos ciclos vista no plano vertical indica que o movimento é contínuo sem toque dos dentes antagonistas. Todos os pacientes apresentaram uma redução da abertura dos ciclos assim que o alimento foi sendo degradado.

Mongini, Tempia-Valenta e Benvegnu (1986) desenvolveram um sistema computadorizado que analisa os movimentos mandibulares, para estudar em indivíduos Classe I normofuncionais, a função mastigatória dentro de condições de saúde. Seis homens e 6 mulheres classe I sem história nem sinais de disfunção articular participaram do estudo, mastigando um pedaço de pão por 15 segundos por três vezes. Foram avaliados com eletromiografia e com sirognatógrafo (indutor de campo magnético) para os movimentos mandibulares. Apesar das variações inter e intra-individuais, encontraram algumas semelhanças. No início da mastigação para a maioria dos indivíduos, os ciclos foram bem estendidos (maior que 20mm) no sentido vertical, e depois diminuíram suavemente; a pausa entre o fechamento e a abertura aumentou gradualmente com a degradação do alimento; apesar das variações individuais, os ciclos tiveram movimentos rítmicos com distribuição balanceada e simétrica dos movimentos alternando com os dois lados; a velocidade foi maior em abertura, tendendo a diminuir com o fim do ciclo, devido ao contato do alimento com os dentes. Observou-se alguns padrões de ciclo: ciclo com movimentos côncavos em abertura e fechamento; ciclo com abertura com leve curvatura e fechamento côncavo; ciclo alternando os dois lados de mastigação; ciclo 
com movimento vertical até a metade do movimento e leve forma em gota ao fim. Como esperado para a eletromiografia, os valores para masseter e temporal em abertura foram baixos, e aumentaram gradualmente com o fechamento da mandíbula.

Jemt e Olsson (1986) analisando o ciclo mastigatório de 15 dentados totais através de computador (LED), em duas tomadas (com dois registros cada) com 4 semanas de diferença, viram como vantagens, a possibilidade de reprodução fiel dos registros de um determinado movimento, diminuindo os erros do método e aumentando a chance de observar diferenças entre os registros repetidos. Os pacientes apresentaram uma estabilidade no padrão dos ciclos mastigatórios, que mostrou alta reprodutibilidade. O padrão de forma, tempo e amplitude mostra características individuais que são únicas para um dado indivíduo e faz com que esse padrão seja distinguível entre os outros pacientes. Apenas pequenas alterações são observadas: na segunda tomada no mesmo dia, foi encontrado um aumento da velocidade mandibular em abertura e diminuição da duração do ciclo; essas mudanças sutis mostraram a adaptação ao teste, já que a situação oral do paciente não se alterou.

Karlsson e Carlsson (1990) avaliaram em dois registros de mastigação até a deglutição de pão torrado, o padrão dos movimentos mandibulares de 14 dentados idosos, com média de 80 anos e 30 dentados jovens com média de 26 anos com LED (light-emiting-diode). Não encontraram diferenças entre a duração das tomadas e na componente lateral em abertura entre os dois grupos, mas a velocidade mandibular foi menor para o grupo de idosos. Apesar das grandes variações 
interindividuais, o grupo de idosos apresentou menores variações dos deslocamentos verticais. A idade foi associada com a redução de deslocamento vertical e da velocidade.

A performance mastigatória é uma expressão da capacidade funcional das articulações e dentes. Eu seu trabalho Wilding e Lewin (1994) estudaram a possibilidade da performance mastigatória estar relacionada com certos padrões do movimento mandibular em pacientes dentados sem disfunção articular. Neste caso, os valores que mais contribuiriam para a melhor performance deveriam ser os mais ideais para o sistema mastigatório. Foram analisadas 8 variáveis do movimento mandibular durante a mastigação. A mastigação foi feita com amêndoas e o teste do ciclo com goma registrado com Sirognatógrafo. Algumas características do ciclo mastigatório se mostraram indicativas de uma mastigação eficiente. Uma delas foi: ciclos mastigatórios bilaterais, largos, com padrão de fechamento predominantemente lateral. Outro exemplo foram os ciclos com movimento liso e contínuo com mínima alteração de velocidade. A inclusão de áreas de contato oclusal no modelo não aumentou sua previsível capacidade. Concluíram que certas características dos ciclos mastigatórios são significantes determinantes da performance mastigatória, e, portanto, podem contribuir para desenvolver um protocolo básico para uma função mastigatória normal.

Yamashita, Hatch e Rugh (1999) em uma revisão da literatura sobre a relação entre um padrão ideal do ciclo mastigatório para a melhor eficiência mastigatória, concluíram que no momento não há um padrão de ciclo que possa ser usado em pesquisas para indicar a saúde do aparelho mastigatório ou a eficiência mastigatória 
do paciente. Segundo a revisão está claro que a complexidade da dinâmica da mastigação está sob controle do sistema nervoso central, mas, também é influenciada pela morfologia articular e dental. A parte mais importante do ciclo é durante a fase de oclusão, onde os contatos deslizantes ocorrem devido à posição intercuspídica. A maior capacidade mastigatória provavelmente ocorrerá quando o padrão do ciclo seguir a anatomia dental de cada indivíduo. O ciclo mastigatório parece aumentar a componente lateral do movimento quando um aumento da eficiência mastigatório é requerido, em alimentos duros, por exemplo. Isso inclui aumento da dureza do bolo alimentar, posição do bolo e resultados das sucessivas mordidas. O padrão do ciclo mastigatório para cada indivíduo é influenciado por inúmeros fatores, então não é surpreendente que um ideal não tenha sido atingido até agora.

Acreditando que o ciclo mastigatório é um processo complexo que depende de vários fatores Filipic e Keros (2002) investigaram a influência de alimentos de diferentes consistências nos movimentos da mandíbula no ciclo mastigatório. Dezenove pacientes dentados mastigaram três tipos de alimento: banana, pão e cenoura e seus movimentos mandibulares foram registrados. Foi observado que com o aumento da consistência dos alimentos, aumentou também a extensão dos movimentos laterais, inferiores e de protrusão durante a mastigação. Para os autores, apesar de haver variação entre os pacientes, o ciclo mastigatório é dependente da consistência do alimento em questão, pois com o aumento da consistência dos alimentos, em todos os pacientes foi observado aumento da extensão do movimento mandibular. 
Anderson et al. (2002) quiseram estudar os efeitos da dureza dos alimentos na forma, duração e velocidade do ciclo mastigatório em 26 pacientes com oclusão classe I de Angle. A duração do ciclo não foi alterada com a dureza da goma, mas a velocidade e a extensão em todas as direções dos movimentos excursivos aumentaram (exceto durante a fase de oclusão). A forma do ciclo foi similar, mas o tamanho geral aumentou com a goma mais dura. Os resultados sugeriram que o esforço muscular maior na mastigação de alimento duro produz uma maior aceleração da mandíbula em todas as fases, exceto na de oclusão, onde a mandíbula é mais lenta.

Jemt (1981) registrou com LED o padrão mastigatório de 10 indivíduos dentados e 10 edentados totais, usuários de próteses totais convencionais. Os grupos foram comparados quanto ao ritmo mastigatório, deslocamento e velocidade mandibulares. Os pacientes dentados apresentaram menor número de mordidas até a deglutição; maior ritmo e velocidade mandibulares e maiores ciclos mastigatórios.

Chong-Shan, Guan e Tian-Wen (1991) usaram um sistema computadorizado que coleta simultaneamente os movimentos mandibulares e a atividade mioelétrica em 15 pacientes dentados totais e 11 edentados totais durante a mastigação de goma em ambos os lados. Os pacientes tiveram em suas próteses totais, a relação maxilo-mandibular restabelecida e boa retenção. Avaliaram o deslocamento e a velocidade mandibulares, o ciclo mastigatório e a atividade muscular. Não houve diferenças significantes entre os lados de mastigação, o que indica um padrão mastigatório respeitado para ambos os lados. A velocidade mandibular, duração do ciclo, da fase de abertura e fechamento foram similares para pacientes dentados ou 
edentados. Então, pacientes que tiveram em suas próteses totais, a relação maxilomandibular restabelecida e boa retenção, obtiveram o restabelecimento da mastigação e a saúde do sistema estomatognático.

Em abertura ou fechamento a atividade dos músculos responsáveis por cada etapa foi maior para os pacientes dentados. Os ciclos começaram e retornaram na máxima intercuspidação. Nos pacientes dentados os desvios desse ponto foram de $0,1 \mathrm{~mm} \circ$ que indica que a boa oclusão confina esses desvios, já, nos pacientes com próteses, desvios são mais presentes, afetando a retenção da prótese.

Postic, Krstic e Teodosijevic (1992) analisaram o ciclo mastigatório em mastigação habitual e em mastigação unilateral em 35 pacientes portadores de prótese total com rebordo alveolar satisfatório e em 35 pacientes dentados que serviram de grupo controle. A avaliação do comprimento, largura, ângulos e forma do ciclo na mastigação habitual encontrados para os pacientes edentados foram similares aos pacientes dentados. Porém, quando esses registros foram analisados em ciclos separados no início da mastigação unilateral, significantes diferenças na performance do movimento foram encontradas. O ciclo do paciente com prótese total se mostrou mais largo, muitas vezes caracterizando um ciclo circular, que ocupa os dois lados da mastigação. O autor acredita que na necessidade do paciente estabilizar a prótese total no rebordo e dificuldade de centralizar o bolo alimentar, um esforço adicional muscular projeta a mandíbula para ciclos mais largos. A análise da área onde alguns contatos dentais ocorreram, definiu as diferenças na conformação dos movimentos de contato durante a mastigação. 
Ow, Carlsson e Karlsson (1998) avaliaram um método para determinar as associações entre performance mastigatória e movimentos mandibulares na mastigação. Dez dentados adultos e três pacientes com prótese total bimaxilar participaram do estudo e estes preencheram um questionário sobre a eficiência mastigatória que foi positivo para os dois grupos. A performance mastigatória foi determinada com uma seqüência de 10 segundos de mastigação e outra seqüência que terminava com a deglutição e os movimentos mandibulares por um aparelho específico. A mastigação foi feita com amêndoas e uma peneira com orifícios de 0,65mm foi usada para a medição das partículas mastigadas. Os resultados dos registros foram bem diferentes para os pacientes dentados e os com prótese btal. Os pacientes dentados tiveram uma reprodutibilidade dos resultados em todos os testes aplicados, com diferenças não significantes. A duração total do ciclo, bem como, da fase de abertura e fechamento foram menores para os dentados que para os usuários de prótese; já, a velocidade e a amplitude mandibulares foram maiores; o que foi associado com uma performance mastigatória aprimorada. A magnitude dos movimentos laterais foi similar para os dois grupos. Observoutse uma redução extrema da performance mastigatória para os pacientes com prótese total após 10 segundos de mastigação. A performance mastigatória mostra uma forte correlação com os parâmetros da velocidade mandibular. O estudo confirma que a performance mastigatória é relativamente estável e claramente associada com parâmetros dos movimentos mandibulares específicos.

Jemt e Karlsson (1980) registraram com LEDs os movimentos mandibulares em 6 pacientes edentados totais antes e depois da reabilitação com próteses totais convencionais novas. Foi estudada a duração total do ciclo, bem como a duração da 
abertura, do fechamento e oclusão com a mastigação de pão duro e macio. 0 movimento vertical máximo da mandíbula e a direção do movimento lateral também foram avaliados. Não houve diferença significante no número de ciclos e duração total do ciclo antes ou após a reabilitação. O movimento vertical e a duração de cada ciclo não diminuíram durante toda a mastigação. A fase de fechamento teve a mais longa duração das três fases (0.36s) e representou $45 \%$ da duração de todo o ciclo mastigatório. Apenas pequenas diferenças no padrão mastigatório foram encontradas com diferentes consistências de alimentos e após a reabilitação. Cada indivíduo apresentou seu próprio padrão mastigatório, mesmo quando mastigou alimentos moles ou duros; ou com a prótese nova ou antiga. Talvez os alimentos desse estudo - pão mole e duro - tenham sido muito similares para causar alguma variação no número e padrão mastigatório.

Jemt, Lindquist e Hedegard (1985), analisaram possíveis mudanças que poderiam ocorrer no ciclo mastigatório entre 16 pacientes edentados com próteses totais convencionais novas e após a reabilitação com overdentures. Os registros foram feitos em três oportunidades: no primeiro exame, 2 meses após a instalação das próteses totais convencionais e 2 meses após a colocação dos implantes; mas, apenas os dois últimos foram usados para análise. Uma clara estabilidade foi encontrada para o padrão geral do ciclo entre os dois testes. Após a reabilitação com implantes, a área do ciclo mastigatório aumentou e se aproximou ao padrão dos pacientes dentados; mesmo esses pacientes tendo próteses superiores convencionais. Conclui dessa forma, que a reabilitação inferior com overdentures resulta em uma melhora funcional para o paciente. 
Jemt (1986) conduziu experimentos para avaliar alterações nos movimentos mandibulares na mastigação entre 15 dentados e 16 pacientes com prótese total reabilitados com overdentures mandibulares. O grupo de dentados fez experimentos com maçã e pão e o grupo com implantes fez o teste com pão. O dispositivo usado para análise do ciclo gravou e analisou cada ciclo com relação ao seu ritmo, velocidade e deslocamento mandibulares. Esses parâmetros foram analisados no caso de variações intra e interindividuais tanto em ciclos isolados quanto em toda a seqüência. Os resultados indicaram que diferentes pacientes apresentam diferentes padrões de mastigação quando trituram o mesmo tipo de alimento. Tamanho e consistência de alimento afetam o ciclo mastigatório, pois quando do teste da maça, os pacientes apresentaram menor deslocamento mandibular devido ao tamanho maior da partícula. Concluíram que o trabalho suporta o conceito de uma característica individual da performance mastigatória e que alterações sistemáticas dentro da seqüência mastigatória parece serem mais relacionadas com o indivíduo e com o tipo de alimento que com o estado oral do paciente.

Para Jemt e Stalblad (1986) o padrão dos movimentos mandibulares parece ser afetado pela função oral diminuída, principalmente por uma diminuição da velocidade e dos deslocamentos mandibulares. Entretanto, pode ser levantada a questão dessas alterações serem afetadas pelo aumento da estabilidade e retenção ou por outros aspectos da nova prótese instalada. O objetivo do estudo foi analisar o padrão dos movimentos mandibulares em pacientes com próteses totais, antes e depois, de suas próteses serem convertidas para overdentures, apenas alterando sua retenção e estabilidade pelo reembasamento das bases, sem alteração da dimensão vertical. Os 23 pacientes estavam insatisfeitos com as próteses originais e 
sua retenção e estabilidade estavam comprometidas. Nove pacientes receberam a colocação de implantes e encaixes para retenção da prótese e 14 pacientes tiveram suas prótese reembasadas. Todos receberam oclusão e dimensão vertical balanceadas. No grupo das próteses reembasadas, a maioria dos pacientes mostrou em geral um padrão consistente do ciclo mastigatório, com mínimas alterações de tamanho e forma. O número de mordidas até a deglutição variou bastante, e a duração do ciclo e abertura, fechamento e fase de oclusão diminuíram. O deslocamento mandibular em abertura e fechamento teve uma significativa redução. Essa tendência de redução de deslocamento mandibular atingiu níveis significantes devido aos deslocamentos laterais máximos. No grupo dos pacientes com overdenture o padrão mastigatório se aproximou mais dos pacientes dentados que o grupo de próteses reembasadas. O número de mordidas também teve uma variação individual grande, porém diminuiu significantemente após a reabilitação. A duração do ciclo diminuiu e, portanto em abertura, fechamento e fase de oclusão. A velocidade mandibular aumentou e o deslocamento teve variações para valores maiores ou menores após a reabilitação.

Através de medidas eletrognatográficas Setz et al. (1989), compararam os movimentos bordejantes e o ciclo mastigatório em 18 pacientes portadores de overdentures com e sem a colocação da barra. A colocação e a remoção da barra foi a única diferença entre os dois registros. Encontrou ciclos mais largos e com movimentos mais estáveis com as overdentures; movimentos irregulares foram reduzidos; a área do ciclo mastigatório sem fixação de implantes foi $56 \%$ da área com suporte de implantes. Todos os pacientes com barra apresentaram aumento da área do ciclo, e da amplitude em vertical. A média de amplitude vertical para os 
registros sem barra foi de $12 \mathrm{mmm}$ e de $17 \mathrm{~mm}$ para os registros com barra. Uma clara melhora no direcionamento dos movimentos foi encontrada em 7 pacientes. Apenas 3 pacientes não mostraram alterações na forma dos seu movimentos bordejantes no plano frontal. A média de duração da abertura foi maior com o a próteses suportada por implantes. Observou através de medidas de força que os implantes recebiam stress durante o ciclo e até durante a fixação da barra e deglutição.

Benzing et al. (1994), compararam os movimentos bordejantes no plano sagital e frontal e o ciclo mastigatório em 15 pacientes. Os primeiros registros foram feitos com as próteses totais antigas e após a reabilitação mandibular com próteses retidas por implantes, os movimentos foram novamente registrados. Os resultados demonstraram uma melhora no direcionamento e regularidade dos movimentos mandibulares com margens mais largas, pela estabilização da base da overdenture; movimentos torcidos e desvios foram reduzidos. O comprimento da abertura e fechamento, a largura, bem como a área do ciclo no plano frontal aumentaram com a barra; porém não significantemente. No plano frontal apenas um aumento de 10,75mm2 na área foi medido após a colocação da overdenture, pois movimentos laterais foram freqüentes sem a barra. $O$ autor concluiu que essa reabilitação leva a formas mais harmônicas nos movimentos do ciclo mastigatório e, portanto, maior eficiência da mastigação.

Numa análise a longo prazo da eficiência mastigatória, ciclo mastigatório e grau de satisfação, Pera et al. (1998), analisaram antes e 12 meses após a reabilitação com overdentures inferiores, 12 pacientes com média de 66 anos e 
rebordo extremamente reabsorvido. A avaliação foi feita com a confecção de uma prótese total convencional inferior e posterior colocação de dois implantes. Encontraram que a eficiência mastigatória aumentou significantemente e os ciclos mastigatórios tiveram sua amplitude aumentada (em altura, largura e área) após o suporte da prótese por implantes. A altura aumentou em média 45\%; a largura $92 \%$ e a área $171 \%$. Nos registros com a prótese convencional os ciclos eram mais irregulares. A componente do ciclo mastigatório que mais influenciou o aumento da área funcional foi a lateral. Foi encontrada uma correlação entre o aumento da componente lateral e o aumento da eficiência da mastigação alcançada com as overdentures. O aumento do grau de satisfação dos pacientes não foi relacionado com o aumento da eficiência da mastigação nem com o da função oral e sim com aspectos subjetivos.

Karkazis (2002) investigou a influência da consistência dos alimentos no resultado da eletromiografia do masseter em 6 pacientes com overdentures mandibulares. Os alimentos duros e macios foram representados por cenoura e maçã, respectivamente. Encontraram que para alimentos mais duros, um número maior de mastigação em $10 \mathrm{~s}$, de atividade eletromiográfica, e número de contrações, acompanhado por menores durações dos ciclos, foram encontrados. Concluiu também que a reabilitação com overdentures pode resultar em ciclos mastigatórios mais regulares com mais alta atividade elétrica do masseter, aprimorando o conforto e a função mastigatória.

Um autor que comparou a eficiência da mastigação de overdentures, próteses híbridas e próteses totais convencionais foi Li et al. (2002). Os grupos em número de 
14 cada foram avaliados quanto à eficiência da mastigação com amêndoa e os resultados avaliados com traçados mandibulares do ciclo e eletromiografia dos músculos masseter e temporal. Concluíram que os pacientes com overdentures obtiveram os melhores graus de eficiência da mastigação, logo acompanhados pelos pacientes com próteses híbridas e por fim os com próteses convencionais. Essa seqüência se repetiu com relação aos traçados do ciclo mastigatório. O controle dos ciclos mastigatórios (regularidade dos mesmos) e a centralização do fim de cada ciclo foram mais precisos para pacientes com implantes que para pacientes com prótese total convencional. Isso pode indicar que a overdenture pode ajudar a melhorar os movimentos do ciclo mastigatório dos pacientes, aproximando-os do padrão normal. Proprioceptores no periósteo e a excelente retenção e estabilidade podem contribuir para esses achados. Acredita que a eficiência mastigatória está mais relacionada com e excursão mandibular do que com a atividade mioelétrica.

Para os autores o tipo de encaixe usado na overdenture poderia influenciar a retenção e estabilidade da prótese, influenciando também na função mastigatória. Para estudar tal hipótese Van Kampen et al. (2004) analisaram 18 pacientes com dois implantes mandibulares e três encaixes diferentes: magneto, bola e barra/clip. $O$ teste com alimento consistiu na mastigação de alimento artificial (como cubos de Optosi (®) por 15 e 30 mordidas. As avaliações forma feitas com a prótese antiga, com a nova sem encaixe e com a nova com encaixe. Encontraram que a eficiência mastigatória e o padrão mastigatório melhoraram após a colocação dos implantes e a confecção da overdenture para todos os tipos de encaixe, especialmente para pacientes com pobre mastigação inicial. Apenas uma pequena diferença na performance mastigatória em benefício do sistema barra-clip e bola forma 
observados. O número de ciclos mastigatórios até a deglutição diminuiu após o tratamento com overdenture. Acreditam que uma melhor performance mastigatória combinada com um menor número de ciclos, resultam em partículas de alimento menores para serem deglutidas.

Muitos pacientes são relativamente satisfeitos com suas próteses totais apesar das mesmas estarem extremamente pobres, enquanto outros pacientes relatam insatisfação com próteses feitas com rigor técnico. No geral, $25 \%$ dos pacientes são insatisfeitos com suas prótese totais. Lechner e Roessler (2001) fizeram um levantamento em seu artigo dos aspectos envolvidos no sucesso da prótese total que não são alcançados através dos recursos técnicos. As estratégias são baseadas nos princípios de boa comunicação e bom relacionamento para motivação do paciente. Isso inclui um auxílio no desenvolvimento do controle neuromuscular e no treinamento da mastigação. Os autores enfatizaram a importância da participação do paciente na confecção da prótese e da necessidade de pacientes precisam se fazerem conscientes da sua responsabilidade em alcançar um resultado satisfatório no complexo paciente/prótese.

A contínua perda dos dentes e o gradual envelhecimento da população fazem uma combinação que produz um aumento na necessidade do tratamento com próteses totais. Para se alcançar um tratamento de sucesso, é importante considerar um grande número de variáveis durante o processo de confecção da prótese, afirmou Roessler (2003). O autor acredita que antes mesmo do início do tratamento, a motivação do paciente pelo tratamento o emocional do paciente pela prótese devem ser avaliados. Dessa forma, os pacientes ganhariam reais expectativas do que poderiam e do que não poderiam alcançar, e o dentista entenderia o que 
realmente o paciente quer. Além do mais, o dentista precisa trabalhar junto ao paciente para alcançar sucesso em situações difíceis, como o controle neuromuscular que controla a manipulação da prótese; a mastigação e a fala. Aprendendo em como transformar as reclamações do pacientes em pontos positivos, os dentistas educariam seus pacientes a resolver seus próprios problemas sozinhos. Por fim, os pacientes precisam aprender que o contínuo sucesso depende de manutenção e controle regulares. 


\section{PROPOSIÇÃO}

Considerando-se a possibilidade de alteração do ciclo mastigatório entre os registros obtidos com a utilização da prótese total inferior com e sem fixação à barra, o presente trabalho propôs os seguintes objetivos:

Objetivo geral:

Verificar a influência da fixação à barra, de próteses totais mucoso-suportadas e implanto-retidas, no ciclo mastigatório.

Objetivos específicos:

Destacar através de experimentos "in vivo", as alterações quanto à forma, largura máxima, comprimento máximo e área total dos ciclos mastigatórios em pacientes portadores de overdentures, comparando-se dois momentos: com a ativação da barra e sem a ativação da mesma. 


\section{CASUÍSTICA, MATERIAL E MÉTODOS}

\subsection{Casuística}

Nesta pesquisa participaram 9 pacientes edentados totais portadores de prótese total convencional superior e prótese total inferior retida por 2 implantes unidos por uma barra, com bom estado geral de saúde e sem histórico de sintomatologia de desordens têmporo-mandibulares (dor miofascial, limitação de abertura e movimentos)

Dos pacientes, 5 eram do sexo masculino e 4 do sexo feminino. Todos os pacientes foram atendidos e reabilitados na Clínica da Fundação para o Desenvolvimento Científico e Tecnológico de Odontologia - FUNDECTO. Não houve escolha preferencial de sexo e a idade variou entre 35 e 58 anos de idade.

Através da realização de exames clínicos e da utilização de radiografia panorâmica, foi analisada a viabilidade para instalação de 2 implantes maciços rosqueados ITI, 4,8mm de diâmetro (Instituto Straumann-Waldenburg, Suíça) com tratamento de superfície por jato de areia, larga e ataque ácido SLA (Sand-Blasted, Large-Grit, Acid-etched), Sistema SynOcta, na região compreendida entre os forames mentonianos, para cada paciente. Para conectar os dois implantes foi usada uma barra Dolder perfil oval, regular de altura de 3,0mm e clip de titânio para barra Dolder regular de altura de 4,5mm (Instituto StraumannWaldenburg, Suíça). 
Com a aprovação do Comitê de Ética (Anexo A), o experimento foi iniciado após o período necessário para a adaptação dos pacientes às bases das próteses totais e o ajuste oclusal, para que nenhum fator relacionado ao conforto e à função pudesse influenciar e alterar os resultados da pesquisa. Foi aplicado um questionário (Anexo B) para constatar a ausência de desordens têmporomandibulares.

É importante ressaltar que o presente trabalho não utilizou modelos in vitro, pois esses não corresponderiam exatamente à realidade humana, pois o sistema da mastigação é envolvido por músculos e impulsos neuronais que interagem de acordo com os estímulos locais.

Os pacientes que participaram da pesquisa após consulta e por vontade própria assinaram um termo de consentimento (Apêndice A), cujos esclarecimentos foram prestados pela própria mestranda, autorizando o uso dos resultados dos registros obtidos para a realização desta pesquisa. Os pacientes estavam cientes de que poderiam se recusar a participar do estudo, sem nenhuma conseqüência, e que sua privacidade seria garantida.

\subsection{Material}

O material, instrumentos e aparelhos utilizados na confecção das próteses totais bimaxilares deste trabalho são aqueles empregados, na Disciplina de Prótese Total da FOUSP, segundo a técnica de Tamaki (1983). 
4.2.1 materiais e instrumentais para a confecção das próteses totais

- Godiva de alta temperatura de fusão Godibar® (Lysanda, São Paulo -SP, Brasil)

- Godiva de baixa temperatura de fusão Kerr® (Kerr, Los Angeles-CA, USA)

- Plastificador de godiva (Equipos Oodntológicos Mari-Jôs, São Paulo-SP, Brasil)

- Compressas de gaze

- Lamparina a álcool

- Lâmpada de Hanau

- Álcool etílico 95\%

- Isqueiro

- Gesso comum tipo II (Pasom, São Paulo, SP, Brasil)

- Gesso pedra Herodent $®$ (Vigodent, Rio de Janeiro, RJ, Brasil)

- Gesso especial tipo IV Durone® (Dentsply, Petrópolis-RJ, Brasil)

- Vibrador para gesso

- Isolante para resina acrílica Cellac ${ }^{\circledR}$ (SSWhite, Rio de Janeiro- RJ, Brasil)

- Pote para resina acrílica com tampa

- Pote Dappen

- Resina acrílica ativada quimicamente, incolor Jet® (monômero e polímero) (Clássico, São Paulo-SP, Brasil)

- Tiras de lixa

- Bloco de espatulação

- Pasta zincoenólica Lysanda ${ }^{\circledR}$ (Lysanda, São Paulo - SP, Brasil) 
- Cera de baixa temperatura de fusão "Excelsior"

- Cera rosa 7 Wilson® ( Polidental, Cotia - SP, Brasil)

- Cera azul Kota® (Kota, São Paulo, SP, Brasil)

- Pincel n. ${ }^{0} 12$

- Pincel n. ${ }^{\circ} 8$

- Vaselina

- Placa de vidro

- Régua milimetrada

- Abrasivo constituído de $80 \%$ (volume) de gesso comum e $20 \%$ (volume) de pó de carburundum granulação de . $^{\circ} 60$ (segundo Tamaki, 1983)

- Articulador semi-ajuntável Bio-art® com arco facial (Bio-art, São Paulo-SP, Brasil)

- Pua inscritora e plataforma de registro extra-oral Polinox Dental® (Polinox Dental, São Paulo-SP, Brasil)

- Grampos para fixação dos planos de orientação

- Dentes artificiais 1/28 Trubyte Biotone® (Dentsplay, Petrópolis-RJ, Brasil)

- 2 muflas $n .^{\circ} 6$

- Prensa para bancada ( Jon, São Paulo-SP, Brasil)

- Cone de feltro ( Jon, São Paulo-SP, Brasil)

- Escova com cerdas pretas e brancas (OGP, São Paulo-SP, Brasil)

- Pedra pomes (dióxido de silício) (Wilson, São Paulo-SP, Brasil)

- Branco-de Espanha (Carbonato de Cálcio)

- Torno de bancada

- Recortador de gesso 
- Papel carbono Detecto® (Dentsply, Petrópolis-RJ, Brasil) de aproximadamente 0.03 milímetros.

- Papel carbono Accu Film $\| ®$ (Parkell, Farmingdale-NY, USA) de aproximadamente 0,008 milímetros

- Moldeiras de estoque para desdentados completos TT® (Jon, São Paulo-SP, Brasil)

- Espátulas n. ${ }^{\circ} 7$, n. $^{\circ} 31$

- Espelho clínico

- Pinça clínica

- Espátula Le Cron

- Gral de borracha

- Espátula para gesso

- Espátula n. ${ }^{\circ} 36$

- Faca para gesso

- Compasso de Willis

- Abridor de canaleta

- Lápis cópia

- $\quad$ Motor de baixa rotação com peça de mão (Dabi-atlante, São Paulo-SP, Brasil)

- Pedras montadas para peça de mão, para acabamento de resina

- Mandril para peça de mão, para tira de lixa

- Chave de fenda

- Tesoura para gesso

- Martelo

- Estilete

- Canivete 
- Broca esférica de fissura

4.2.2 materiais utilizados para confecção específica da overdenture:

- Implantes ITI SLA (Sand-Blasted, Large-Grit, Acid-etched (Superfície tratada por jato de areia, larga e ataque ácido de $4,8 \mathrm{~mm}$ de diâmetro Sistema Synocta (Instituto Straumann - Waldenburg, Suíça)

- Tampas de cicatrização para os implantes (Instituto Straumann - Waldenburg, Suíça)

- Barra de plástico calcinável Dolder perfil oval standard, regular de altura de 3,0mm (Instituto Straumann - Waldenburg, Suíça)

- Clip de titânio para barra Dolder regular de altura de 4,5mm (Sistem ITI Instituto Straumann - Waldenburg, Suíça)

- UCLA de plástico calcinável (Instituto Straumann - Waldenburg, Suíça)

- Parafuso oclusal SCS comprimento 4,4mm de titânio (Instituto Straumann Waldenburg, Suíça)

- Chave de parafuso SCS (Instituto Straumann - Waldenburg, Suíça)

- Catraca e dispositivo de controle de torque (Instituto Straumann Waldenburg, Suíça)

4.2.3 materiais e instrumentais utilizados para obtenção do ciclo mastigatório 
- Arcus Digma® (Kavo Dental GmbH \& Co. KG, Alemanha)

- Filme PVC para isolamento das superfícies

- Resina acrílica ativada quimicamente, incolor Jet (monômero e polímero) (Clássico, São Paulo-SP, Brasil)

- Pincel n. ${ }^{\circ} 8$

- Pote Dappen

- Motor de baixa rotação com peça de mão (Dabi-atlante, São Paulo-SP, Brasil)

- Pedras montadas para peça de mão, para acabamento de resina

- Mandril para peça de mão, para tira de lixa

- Tira de lixa

- Cenoura cortada com $1 \mathrm{~cm}^{3}$

\subsection{Métodos}

4.3.1 métodos para confecção das próteses totais

As próteses foram realizadas com metodologia de confecção da prótese total preconizada por Tamaki (1983) a qual será descrita a seguir. 


\subsubsection{1 moldagem anatômica}

Inicialmente, foi selecionada a moldeira para edentado total que melhor se adaptou ao rebordo do paciente. Com a moldeira selecionada, a godiva de alta temperatura de fusão foi plastificada e foi realizado o ato da moldagem. Dessa forma obteve-se o molde anatômico do rebordo e a partir dele o modelo anatômico em gesso comum.

\subsubsection{2 confecção das moldeiras individuais}

A área basal foi delimitada nos modelos anatômicos e os mesmos foram isolados devidamente com isolante para resina Cellac. Em um pote para resina com tampa foi misturado o polímero com o monômero com a proporção recomendada pelo fabricante até obter homogeneidade na resina. Essa resina foi colocada no modelo e acomodada com uma espátula até formar uma camada homogênea de $2 \mathrm{~mm}$, e com uma pequena porção de resina foi confeccionado um cabo colocado na parte anterior da moldeira. Após a polimerização total da resina, as moldeiras foram destacadas dos modelos e se procedeu ao acabamento. 


\subsubsection{3 moldagem funcional}

Após o ajuste das moldeiras, se procedeu à moldagem funcional utilizando-se o material e a técnica de acordo com a indicação de cada caso. Foi utilizada a cera de baixa fusão para moldar devidamente o selado posterior. Com os moldes prontos, foi vazado o gesso especial e obtidos os modelos funcionais.

\subsubsection{4 confecção das bases-de-prova}

Inicialmente, foram aliviadas as egiões retentivas dos modelos funcionais com cera rosa fundida e uma espátula $n .^{\circ} 31$. No pote próprio para resina, foi aglutinada a resina quimicamente ativada na proporção recomendada pelo fabricante, que logo após, foi dispensada nos modelos funcionais previamente isolados com isolante para resina, de modo a obter uma camada de espessura homogênea de $1 \mathrm{~mm}$. Uma vez polimerizada a resina, foi destacada a base de prova do modelo para proceder ao acabamento com pedras montadas e tiras de lixa.

\subsubsection{5 confecção dos planos de cera}

Após plastificar uma lâmina e meia de cera $n .^{\circ} 7$ na chama da lamparina, foram feitas dobras em forma de sanfona de uma extremidade a outra. $O$ rolete foi 
dobrado ao meio e adaptado na base-de-prova. Sobre uma placa de vidro foi criada uma curva de compensação arbitrária. O acabamento foi dado com uma espátula aquecida. Depois de acabado, o plano de cera foi levado à boca do paciente para avaliação da sua altura, limite vestibular e inclinação da curva de compensação. Com o compasso de Willis, foi obtida a dimensão vertical de oclusão (DVO) do paciente. Para isto, foi utilizada a técnica de Lytle modificada por Tamaki.

O rolete de cera para a base de prova inferior foi confeccionado da mesma maneira já descrita para o superior. Após o rolete de cera ser adaptado à base de prova, todo o conjunto foi levado à boca do paciente e pediu-se para o mesmo ocluir até atingir a dimensão vertical de oclusão (DVO), a qual foi determinada com o compasso de Willis. Foram retirados os planos superior e inferior unidos para dar acabamento da forma já descrita. Os planos foram separados e levados novamente à boca do paciente para avaliação da DVO e do espaço funcional de pronúncia, o qual deve medir aproximadamente $3 \mathrm{~mm}$.

Com instrumento próprio, foi aberta uma canaleta na porção central da face oclusal de cada plano que foi preenchida com a mistura abrasiva de quatro partes de gesso comum e uma de pó de carburundum, de modo que esse ultrapasse a altura do plano em 2 mm. Aguardou-se a presa do gesso.

4.3.1.6 obtenção da curva de compensação, confecção dos planos de orientação e montagem dos modelos no articulador

Os planos com o abrasivo foram levados à boca do paciente e pediu-se para que ele realizasse movimentos de protrusão e lateralidade a fim de desgastar a 
superfície oclusal do plano. Essa manobra é conhecida como desgaste de Paterson. O desgaste foi feito até que o paciente retornasse a DVO préestabelecida, a qual é verificada com o compasso de Willis. Terminado o desgaste, foram marcadas as linhas de referência (linha alta do sorriso, linha dos caninos e linha média) com a espátula Le Cron, que depois, foram reforçadas com cera azul fundida, uma vez fora da boca.

O passo seguinte foi a montagem do modelo superior no articulador. O plano superior foi fixado no garfo com lâmina de cera $\mathrm{n}^{\circ}$ 7. $\mathrm{O}$ conjunto foi levado à boca do paciente e posteriormente posicionado o arco facial. A posição do modelo superior em relação à base do crânio foi transferida para o articulador. O modelo funcional superior foi então fixado à base de prova e preso ao articulador com gesso comum.

Depois de retirar o plano de orientação superior do modelo já montado no articulador, foi fixada nele, com cera rosa fundida, a pua, e no plano inferior, a plataforma, de modo que estivesse esteja em continuidade com a superfície oclusal do plano inferior e perpendicular à pua. Uma camada de cera azul fundida foi colocada sobre a plataforma e os planos de cera foram recolocados na boca do paciente. O paciente foi instruído para realizar movimentos de protrusão e lateralidade partindo da relação central $(\mathrm{RC})$, a fim de registrar a trajetória desses movimentos na plataforma. Terminado esse procedimento, o paciente realizou movimentos de abertura e fechamento com pequena amplitude para determinar a posição de oclusão. Nessa posição, o plano superior foi fixado ao plano inferior com grampos metálicos aquecidos e todo o conjunto foi retirado da boca.

Este conjunto foi posicionado sobre o modelo superior já montado. Colocout se o modelo funcional inferior sobre a base inferior prendendo-o ao articulador com gesso comum. Após a presa do gesso, foram retirados os grampos e calibrou-se o 
articulador, baseando-se na curva de compensação e nos dados registrados na plataforma.

\subsubsection{7 duplicação dos planos de orientação}

Sobre os modelos montados no articulador novas bases de prova foram confeccionadas.

Com o plano de orientação inferior posicionado sobre o modelo e já vaselinado na superfície oclusal, foi confeccionado um rolete de cera $n .^{0} 7$, que foi adaptado à nova base de prova superior já posicionado sobre o modelo. $\mathrm{O}$ articulador foi fechado de modo que o pino incisal tocasse a mesa incisal. O conjunto foi removido e recebeu o acabamento necessário. Os planos foram separados e procedeu-se à duplicação do inferior, tendo como referência o plano superior já duplicado.

4.3.1.8 seleção e montagem dos dentes artificiais

A forma, cor e tamanho dos dentes foram determinados pelo formato do rosto, cor da pele, idade e sexo, e pelas linhas de referência, respectivamente para cada paciente.

Após essa seleção, os dentes foram montados nos planos de cera duplicados, fixando-os com cera rosa fundida. 


\subsubsection{9 enceramento e escultura das próteses}

Com uma espátula $n .^{\circ} 31$, foram colocadas várias camadas de cera fundida do colo dos dentes ao sulco vestibular, a fim de se obter uma espessura suficiente para a confecção da escultura.

A escultura, tanto da prótese superior como da inferior, iniciou-se pelo recorte dos colos gengivais com a espátula Le Cron seguindo com a confecção do sulco mesiodistal. A partir dele, com a espátula $\mathrm{n} .{ }^{0} 7$, foram esculpidas as bossas radiculares e os sulcos verticais. O acabamento foi dado com a lâmpada Hanau.

4.3.1.10 prova da prótese

As próteses foram levadas à boca do paciente e a estética, posição de oclusão, DVO, espaço funcional de pronúncia foram avaliados. A opinião do paciente é importante, portanto foi considerada. 


\subsubsection{1 métodos para confecção da overdenture inferior}

A confecção da overdenture inferior seguiu os mesmos passos da prótese total convencional superior, exceto no que diz respeito à colocação dos implantes e das estruturas que são fixadas sobre ele.

Para cada paciente, foi realizada a cirurgia de colocação de dois implantes observando-se todos os procedimentos cirúrgicos recomendados pelo fabricante (Instituto Straumann, Waldenburg, Suíça).

Os objetivos da reabilitação protética com retenção à barra são: estabilização e ferulização dos implantes; fixação da prótese de forma a evitar as forças de levantamento; distribuição das forças de deslizamentos e compensação da resiliência por graus de liberdade.

No que diz respeito ao encaixe, o sistema classicamente descrito consiste de duas partes: uma barra com secção ovóide, fundida e parafusada nos implantes osseointegrados. Esta forma permite o movimento da prótese com três graus de liberdade (movimentos de translação e rotação) que reduz o torque sobre os implantes. O outro componente apresenta-se como uma luva metálica (clip metálico) com projeções laterais, que possui retenções as quais permitem que esse seja fixado nas bases da prótese. $\mathrm{O}$ uso de clip único permite que os graus de liberdade da prótese sejam mantidos. As barras plásticas não podem ser curvadas, para não afetar a retenção do clip que se encaixa sobre a mesma. A barra deve ser colocada horizontalmente, mesmo existindo diferença de nível, pois uma disposição inclinada impede o funcionamento correto da articulação da barra e cria componentes de força horizontais não desejados. A barra é colocada perto dos tecidos gengivais para 
ajudar a evitar torque quando forem aplicadas forças sobre a prótese, portanto, é necessário haver um espaço de $2 \mathrm{~mm}$ entre este componente e a gengiva para a manutenção da higiene. A barra é uma conexão direta entre os implantes e é perpendicular à bissetriz das duas cristas maxilares. Nesta condição, a prótese pode girar ligeiramente sobre seu eixo, para compensar, mudanças na resiliência tecidual. Se a barra sofrer curvatura ao longo do arco, pode transformar o conjunto em prótese total suportada somente por dois implantes; por razões mecânicas isso não é aconselhável.

Desta forma, uma vez os implantes colocados e osseointegrados, foi confeccionado um modelo em gesso com análogos e componentes protéticos posicionados para receber a barra. A barra de plástico é cortada para se encaixar no espaço entre os implantes. Ela foi fixada aos UCLAs calcináveis com duralay e cera, e o conjunto foi fundido em níquel-cromo. Após a fundição, o conjunto foi provado na boca do paciente, radiografado e parafusado na boca em posição sobre os implantes quando da instalação das próteses. O clip de metal foi processado pelo laboratório na base da prótese inferior.

\subsubsection{2 inclusão na mufla das próteses totais}

Com os dentes montados e a escultura pronta, as próteses testadas pelo paciente foram novamente fixadas nos modelos, com cera rosa. Verificoutse a adaptação do modelo à mufla deixando $5 \mathrm{~mm}$ de folga até a parede vertical e 
horizontal. A mufla foi untada com vaselina e o modelo hidratado foi posicionado na base da mufla preenchida com gesso comum deixando a superfície lisa e expulsiva para oclusal. Após a presa total do gesso, foi untada com vaselina toda a superfície de gesso. Antes de incluir a futura prótese no gesso, construiu-se uma muralha de gesso pedra em torno de todos os dentes, procurando dessa forma evitar a alteração da posição dos dentes. A contramufla foi assentada na base e preenchida com gesso comum. O conjunto foi mantido sob pressão da prensa da bancada até a cristalização total do gesso, para a posterior acrilização no laboratório.

\subsubsection{3 prensagem da resina acrílica das próteses totais}

Uma vez o gesso cristalizado, a mufla foi mergulhada na água em ebulição a 150 graus por 5 minutos. Decorrido este tempo, ela foi aberta com auxílio de uma faca para gesso, e a base de prova removida com auxílio da espátula ํㅜ 31. A cera amolecida foi totalmente eliminada com jato de água fervente. Para aumentar a retenção da resina acrílica da base da prótese, foram eitas retenção com broca esférica em todos os dentes.

Antes da condensação da resina acrílica, o gesso da mufla e contramufla foi isolado com vaselina, tomando o cuidado para que 0 isolante não atingisse os dentes. A resina foi preparada em um pote para resina com $25 \mathrm{~mm} 3$ de polímero e com monômero suficiente para saturá-lo. Após misturar os dois componentes, o pote foi fechado para que a reação química seja alcançada até a fase plástica. 
A resina foi separada em três partes: duas em forma de bastão para serem adaptadas com os dedos sobre o arco superior e inferior e outra parte para ser adaptada sobre o palato. Distribuída convenientemente, juntourse a mufla e a contramufla e o conjunto é levado á prensa. Pressionourse o êmbolo lentamente, interrompendo a prensagem para que a resina em excesso possa escoar. Repetiut se a operação até que as partes de metal da mufla e da contramufla se encostassem. O conjunto foi levado ao aparelho de polimerização.

\subsubsection{4 acabamento e polimento das próteses totais}

A desinclusão das próteses já acrilizadas foi feita com a ajuda de uma chave de fenda para abrir a mufla e de um martelo para remoção do gesso. O acabamento correspondeu à remoção das rebarbas, imperfeições e aspereza com a pedra de carburundum e ao alisamento com tira de lixa. Para a obtenção do brilho da prótese total o polimento foi dado na seguinte ordem: polimento com cone de feltro e pedra pomes, polimento com escova preta e pedra pomes e polimento final com escova branca e "branco-de-espanha" $\left(\mathrm{CaCO}_{3}\right)$. 


\subsubsection{5 instalação das próteses totais}

As próteses totais superior e inferior foram instaladas e a oclusão, estética e fonética foram novamente avaliadas. Os pacientes retornaram para controle posterior em quatro consultas semanais até a total adaptação das bases aos rebordos.

\subsection{2 métodos para obtenção do ciclo mastigatório}

Para a execução do experimento, os pacientes foram atendidos na Clínica do Instituto da Cabeça da Universidade Federal de São Paulo, onde foi usado o aparelho Arcus Digma (Kavo Dental GmbH \& Co. KG, Alemanha). Este aparelho é um gnatógrafo digital que funciona baseado em um localizador 3D- ultrassônico, operando em uma freqüência de $40 \mathrm{KHz}$ e uma taxa de leitura de 50 vezes, resultando em um registro de 12 segmentos do movimento de abertura máxima.

O aparelho é capaz de registrar em três dimensões o comportamento dinâmico dos movimentos mandibulares do paciente nos planos frontal, sagital e horizontal; bem como o comportamento do ciclo mastigatório, oferecendo informações importantes com relação aos movimentos da articulação têmporomandibular.

O Arcus Digma conta com um software que deve ser gravado para que os registros efetuados por este aparelho possam ser transmitidos e lidos por um 
computador. A troca de dados é alcançada com o uso de um chipcard. Todos os movimentos são gravados neste chipcard pela unidade do Arcus Digma, e por meio de um leitor conectado ao computador, onde os dados podem ser lidos.

O software do Arcus Digma é usado para armazenar os registros obtidos. Como já mencionado, o aparelho registra os movimentos mandibulares do paciente tridimensionalmente. Com o auxílio do software esses dados podem ser armazenados e depois revistos em outro momento. Os registros gerados servem para programar o articulador da Kavo, o Protar, com o intuito de confeccionar uma prótese o mais funcional possível. Além disso, alterações funcionais específicas na seqüência dos movimentos podem ser examinadas com detalhe.

O corpo do aparelho consiste de um monitor onde todas as funções são apresentadas e registradas.

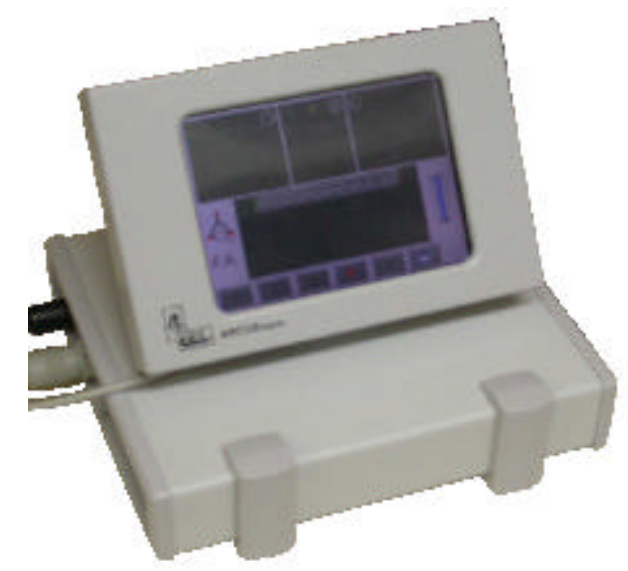

Figura 4.1- Monitor do aparelho Arcus Digma

Com o paciente sentado na cadeira odontológica na posição ereta, foi colocado no mesmo, o arco facial fixado na parte posterior da cabeça, na altura das orelhas, e no ponto násio como mostra a figura 4.2. A parte anterior do arco facial 
possui uma peça imantada onde é ligado o receptor para o arco superior. O receptor para o arco inferior é fixado através de imantação na plataforma de fixação do arco inferior.

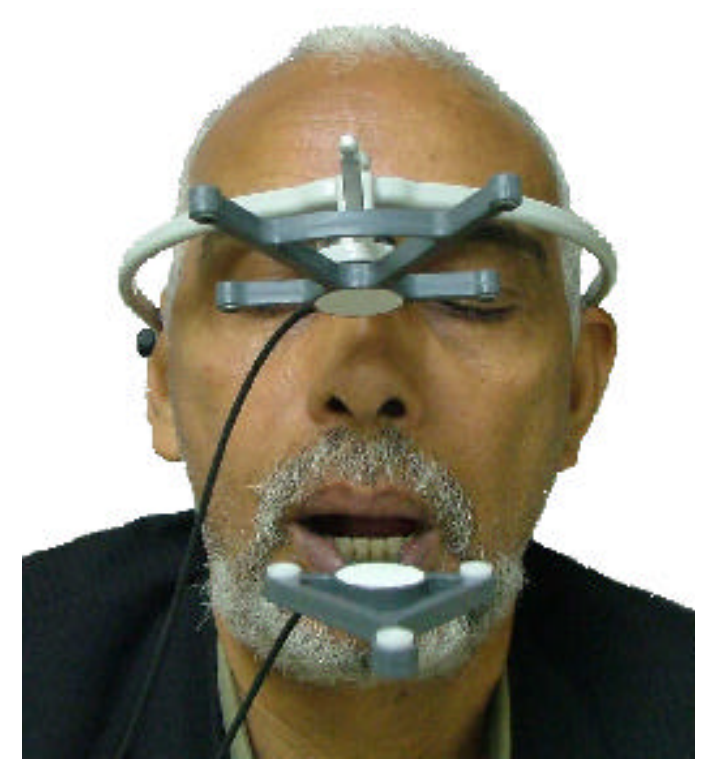

Figura 4.2 - Vista frontal do aparelho conectado ao paciente

Esta plataforma foi fixada na região vestibular da prótese total inferior através de três pontos com resina acrílica: um na parte anterior e dois na parte posterior de cada lado. Foi tomada a precaução para que o material acrescentado não interferisse na oclusão das próteses. Como o peso de receptor inferior é pequeno, este não interferiu na estabilidade das próteses, nem tão pouco, nos registros tomados. 


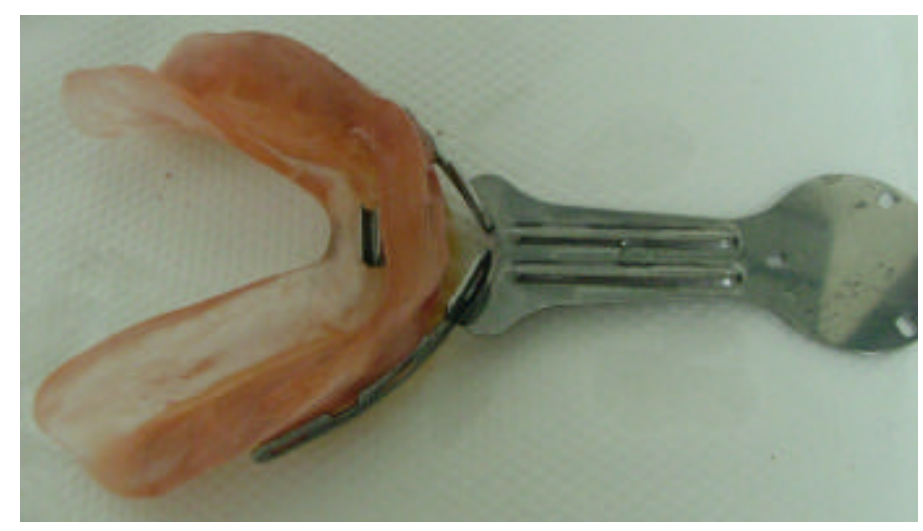

Figura 4.3 - Garfo fixado à prótese inferior com resina acrílica

Para individualizar o aparelho para um dado paciente, o Arcus Digma passou pelo que se chama de calibragem que consiste em registrar três vezes a protrusão, a lateralidade esquerda e a lateralidade direita e a abertura máxima. Depois do aparelho calibrado, passourse para os registros dos movimentos de interesse do estudo. No caso, foi registrada a seqüência do ciclo mastigatório para todos os pacientes.

Para o registro do ciclo mastigatório o paciente foi solicitado a mastigar um pedaço de œnoura crua padronizado em $1 \mathrm{~cm}^{3}$, considerado um alimento de dura consistência. Não houve indução de tempo ou do lado de mastigação de preferência. Para padronizar a tomada dos registros, todas as medições foram feitas sob as mesmas condições: local, tempo e pedaços de cenoura crua de $1 \mathrm{~cm}^{3}$.

Os registros foram analisados no programa Autocad® (Autocad 2004, Autodesk. Inc., San Rafael, USA). As figuras dos ciclos mastigatórios foram vetorizadas e o programa forneceu as medidas da largura máxima, comprimento máximo a área total do conjunto de ciclos mastigatórios de cada paciente. 
Após a avaliação da forma e do cálculo da largura máxima, comprimento máximo e área total dos ciclos mastigatórios, os registros de cada paciente foram comparados, tanto com a manutenção da barra, quanto com a remoção desta, servindo este então de controle.

4.3.3 métodos para análise estatística

Foi usada a análise descritiva para o cálculo da média, mediana, desvio padrão, coeficiente de variância e o diagrama Box-plot dos registros com e sem a barra.

Para o cálculo de inferência estatística foi usado o teste não paramétrico de Wilcoxon, adotando o nível de significância de 5\%. 


\section{RESULTADOS}

Para cada um dos nove pacientes foram obtidos dois registros, sendo um referente à mastigação com a overdenture retida pela barra e outro referente à mastigação sem a barra, este último, simulando uma prótese total convencional bimaxilar mucoso-suportada.

Com isso, pôde-se analisar para cada registro dos ciclos mastigatórios, a conformação geral dos mesmos, a largura máxima, o comprimento máximo e a área total para cada paciente, analisando as variações intra-individuais. Cada item será descrito separadamente como se segue:

\subsection{Análise da conformação geral dos ciclos mastigatórios}

Os registros dos ciclos mastigatórios d'os pacientes 4 e 7 ilustram as características que aparecem com maior freqüência nos nove pacientes estudados. 

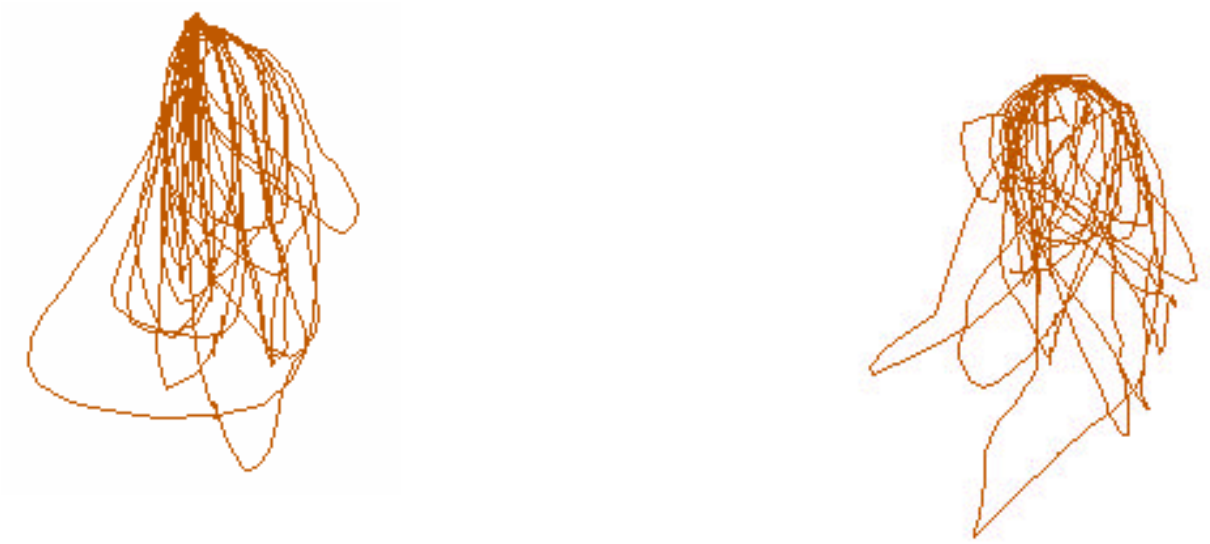

Figura 5.1 - Registros com barra (esquerda) e sem barra (direita) dos ciclos mastigatórios do paciente 7

$\mathrm{Na}$ mastigação sem barra a paciente apresentou ciclos sem sincronia, com formas irregulares e larguras variáveis. No registro com barra, o paciente conseguiu coordenar os ciclos e eles se mostraram com forma e amplitude similares. A forma em gota, muito apontada em alguns trabalhos como a ideal, foi a predominante.
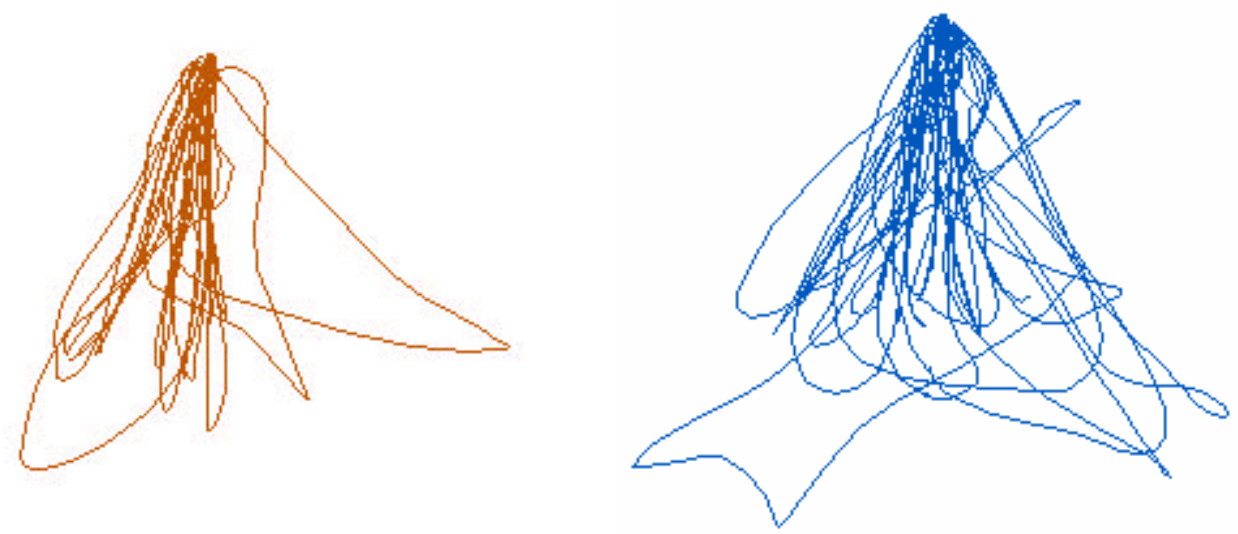

Figura 5.2 - Registros com barra (esquerda) e sem barra (direita) dos ciclos mastigatórios da paciente 4 
No registro sem barra notourse um número grande de ciclos descoordenados, que não seguem um padrão quanto à forma e têm direcionamentos diversos. No registro com barra esse tipo de ciclo aparece em menor número e ciclos elípticos aparecem com maior freqüência.

5.2 Análise da largura máxima (amplitude horizontal máxima) dos ciclos mastigatórios

Tabela 5.1 - Valores em mm da largura dos ciclos mastigatórios dos registros com a barra e sem barra de retenção.

\begin{tabular}{lcc}
\hline & \multicolumn{2}{c}{ LARGURA $(\mathbf{m m})$} \\
\hline PACIENTE & COM BARRA & SEM BARRA \\
\hline 1 & 11,38 & 9,06 \\
2 & 3,55 & 5,93 \\
3 & 6,91 & 3,92 \\
4 & 20,13 & 23,43 \\
5 & 7.20 & 9,68 \\
6 & 12,20 & 12,46 \\
7 & 13,02 & 13,24 \\
8 & 6,48 & 6,29 \\
9 & 9,17 & 7,99 \\
\hline
\end{tabular}




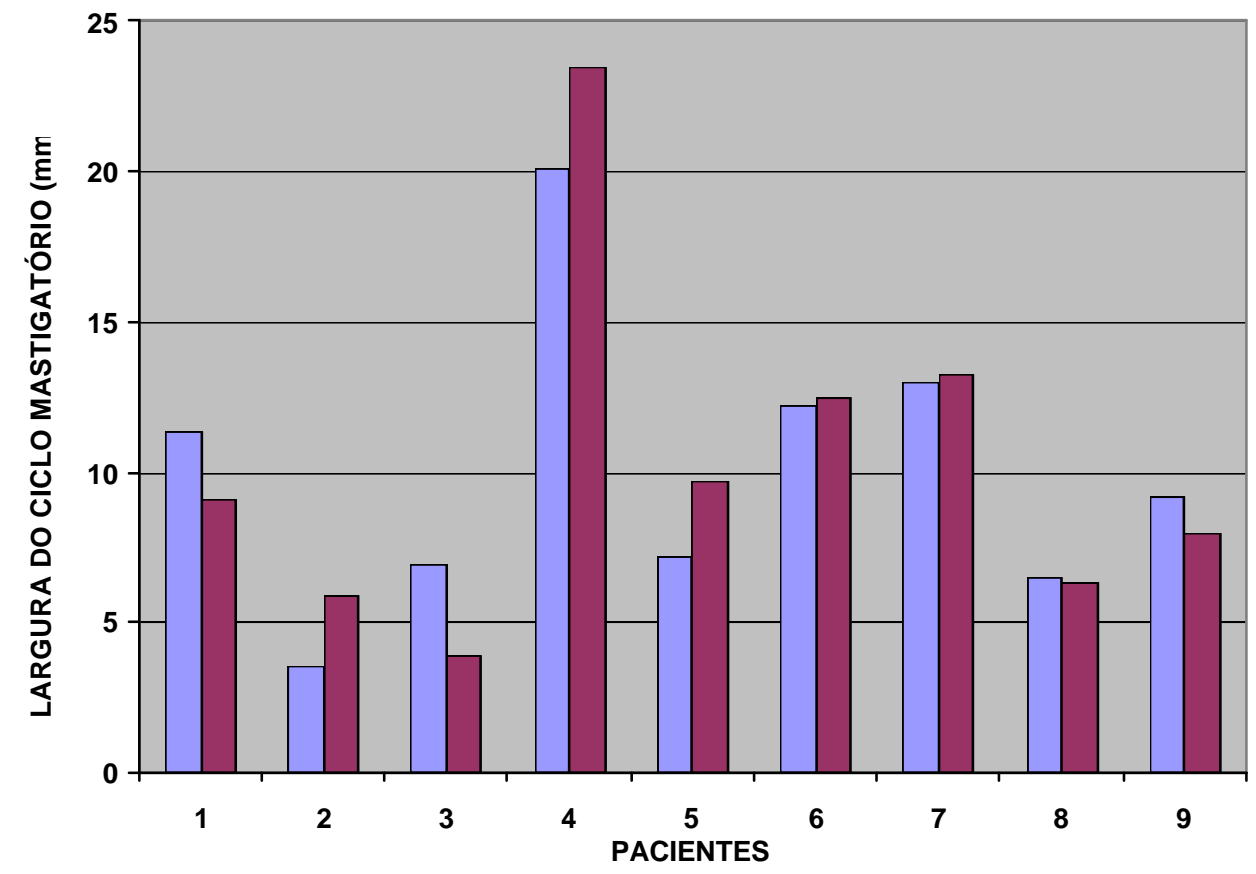

口 COM BARRA $\square$ SEM BARRA

Gráfico 5.1 - Representação dos valores em mm da largura máxima dos ciclos mastigatórios dos registros com a barra e sem a barra de retenção

No caso da largura máxima dos ciclos mastigatórios, 5 pacientes apresentaram valores superiores quando os registros foram efetuados sem a barra em relação aos registros com a barra . A média do valor para os pacientes quando os registros foram efetuados com a barra foi de $10,0 \mathrm{~mm}$ e para os valores obtidos sem a barra foi de 10,2mm. 


\subsection{Análise do comprimento máximo (amplitude vertical máxima) dos ciclos}

\section{mastigatórios}

Tabela 5.2 - Valores em mm do comprimento máximo dos ciclos mastigatórios dos registros com a barra e sem a barra de retenção

\begin{tabular}{lcc}
\hline & \multicolumn{2}{c}{ COMPRIMENTO(mm) } \\
\hline PACIENTE & COM BARRA & SEM BARRA \\
\hline 1 & 16,56 & 11,10 \\
2 & 14,97 & 18,29 \\
3 & 17,60 & 10,90 \\
4 & 17,14 & 20,26 \\
5 & 25,55 & 18,85 \\
6 & 14,51 & 14,51 \\
7 & 18,29 & 18,38 \\
8 & 11,99 & 10,91 \\
9 & 15,16 & 11,96 \\
\hline
\end{tabular}

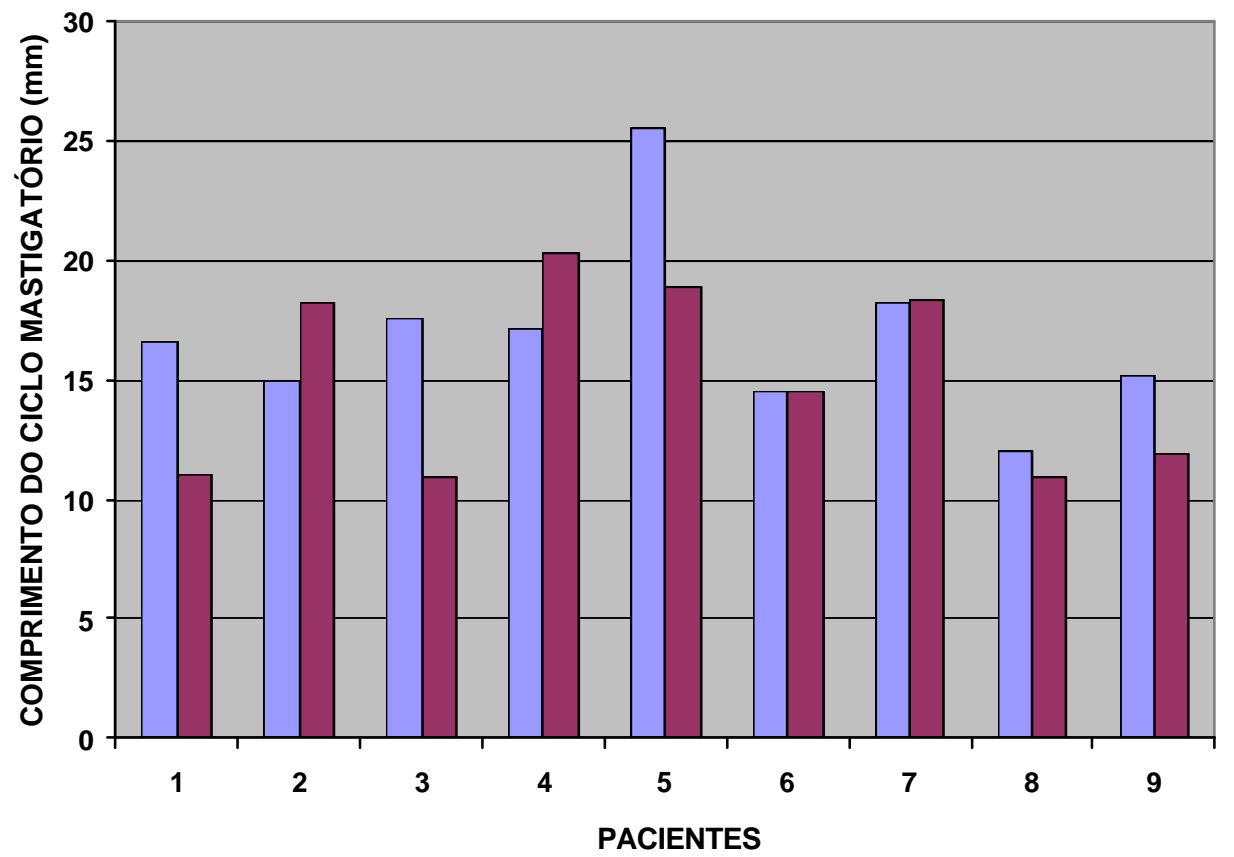

口 COM BARRA $\square$ SEM BARRA

Gráfico 5.2 - Representação dos valores em mm do comprimento máximo dos ciclos mastigatórios dos registros com a barra e sem a barra de retenção 
Para o comprimento máximo dos ciclos mastigatórios, 4 pacientes sem a barra apresentaram valores maiores que os mesmos pacientes com a barra. A média para os registros com a barra foi de $16,8 \mathrm{~mm}$ e sem a barra foi de $15,0 \mathrm{~mm}$.

\subsection{Análise da área total dos ciclos mastigatórios}

Tabela 5.3- Valores em $\mathrm{mm}^{2}$ da área total dos ciclos mastigatórios dos registros com a barra e sem a barra de retenção

\begin{tabular}{lcc}
\hline & \multicolumn{2}{c}{ ÁREA $(\mathbf{m m} 2)$} \\
\hline PACIENTE & COM BARRA & SEM BARRA \\
\hline 1 & 105,20 & 36,39 \\
2 & 35,02 & 56,99 \\
3 & 64,29 & 17,60 \\
4 & 130,67 & 180,81 \\
5 & 102,51 & 90,93 \\
6 & 82,40 & 75,13 \\
7 & 128,22 & 114,35 \\
8 & 44,02 & 33,65 \\
9 & 56,66 & 28,87 \\
\hline
\end{tabular}




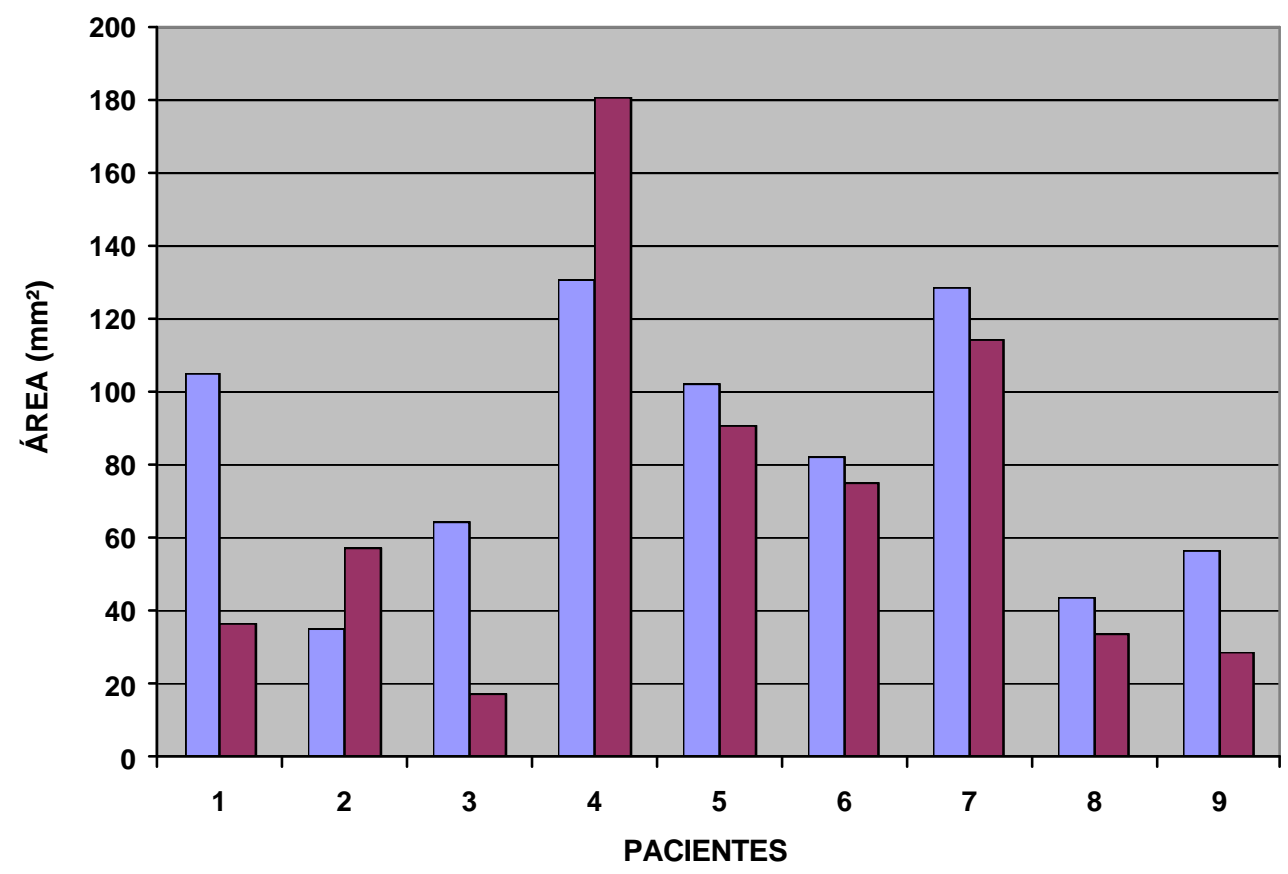

口 COM BARRA $\square$ SEM BARRA

Gráfico 5.3 - Representação dos valores em $\mathrm{mm}^{2}$ da área total dos ciclos mastigatórios dos registros com a barra e sem a barra de retenção

Como se pode avaliar pela tabela e pelo gráfico, dos 9 pacientes participantes da pesquisa, 7 apresentaram valores mais altos da área total dos ciclos mastigatórios quando os registros forma feitos com a barra. A média da área total em $\mathrm{mm}^{2}$ para os registros com a barra foi de $83,2 \mathrm{~mm}^{2}$; e para os registros sem a barra foi de $70,5 \mathrm{~mm}^{2}$. Isso indica que a maioria dos pacientes, quando da fixação prótese à barra, apresentou no geral ciclos maiores que propiciaram um aumento da área total. 


\subsection{Análise estatística}

A análise estatística consistiu da análise descritiva com determinação das medidas resumo tais como: média, mediana, desvio padrão, mínimo, máximo e coeficiente de variação. Para uma melhor visualização da distribuição dos dados obtidos para a largura máxima, comprimento máximo e área total dos ciclos mastigatórios, foram construídos diagramas Box-plot. No Box-plot, os dados são representados por meio de um retângulo que é formado pelo $1^{\circ}$ e $3^{\circ}$ quartis e a linha que o divide representa a mediana ( $50 \%$ dos dados). A linha horizontal mais inferior representa o valor mínimo e a superior o valor máximo aceitável baseado na distância inter-quartil (amplitude do retângulo). Os valores tidos fora deste limite são considerados como discrepantes. Quanto maior o retângulo maior a dispersão dos dados.

$\mathrm{Na}$ inferência estatística, o teste não paramétrico de Wilcoxon avaliou a significância das diferenças dos valores registrados.

5.5.1 análise descritiva da largura

Tabela 5.4 - Representação dos dados descritivos da largura do ciclo mastigatório com e sem barra

\begin{tabular}{lcc}
\hline & LARGURA COM BARRA & LARGURA SEM BARRA \\
\hline $\mathrm{N}$ & 9 & 9 \\
Média & 10,00 & 10,22 \\
Mediana & 9,17 & 9,06 \\
D.P. & 4,88 & 5,80 \\
Mínima & 3,55 & 3,92 \\
Máxima & 20,13 & 23,43 \\
C.V. & $49 \%$ & $57 \%$ \\
\hline
\end{tabular}


O coeficiente de variação é alto indicando que os valores dos nove pacientes são diferentes entre si. O coeficiente para o registro sem barra é maior em relação ao registro com barra, indicando maior variabilidade entre os valores.

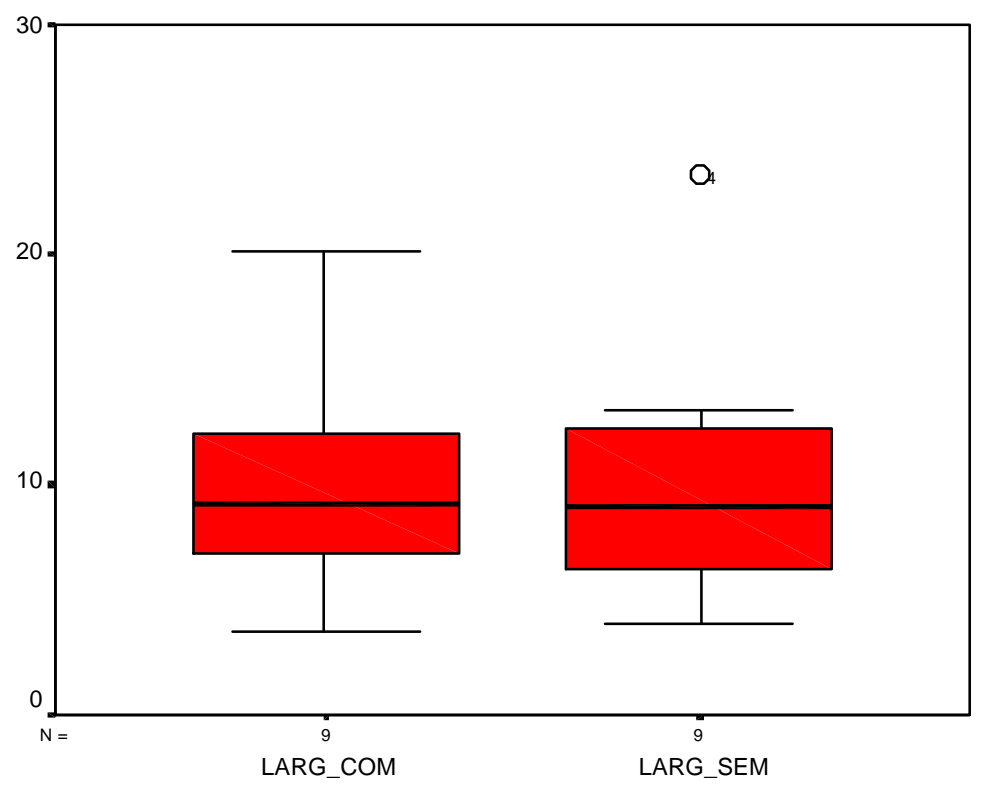

Gráfico 5.4 - Box -plot para a largura com e sem barra

Neste diagrama pode-se observar que a distribuição dos valores da largura para os registros com barra e sem barra é similar. Os valores mínimos e a mediana são próximos e os valores máximos têm um distanciamento maior, inclusive com um valor discrepante (outlier) para o registro sem barra. Como tem-se um conjunto pequeno de dados, essa diferença pode não ser significativa. 
5.5.2 análise descritiva do comprimento

Tabela 5.5- Representação dos dados descritivos do comprimento do ciclo mastigatório com e sem barra

\begin{tabular}{lcc}
\hline & COMPRIMENTO COM BARRA & COMPRIMENTO SEM BARRA \\
\hline $\mathrm{N}$ & 9 & 9 \\
Média & 16,86 & 15,02 \\
Mediana & 16,56 & 14,51 \\
D.P. & 3,77 & 3,92 \\
Mínima & 11,99 & 10,90 \\
Máxima & 25,55 & 20,26 \\
C.V. & $22 \%$ & $26 \%$ \\
\hline
\end{tabular}

O coeficiente de variação para o comprimento foi menor que o da largura o que indica menor variabilidade entre os dados, especialmente para o registro com barra que teve um valor menor para o coeficiente comparado com o registro sem barra.

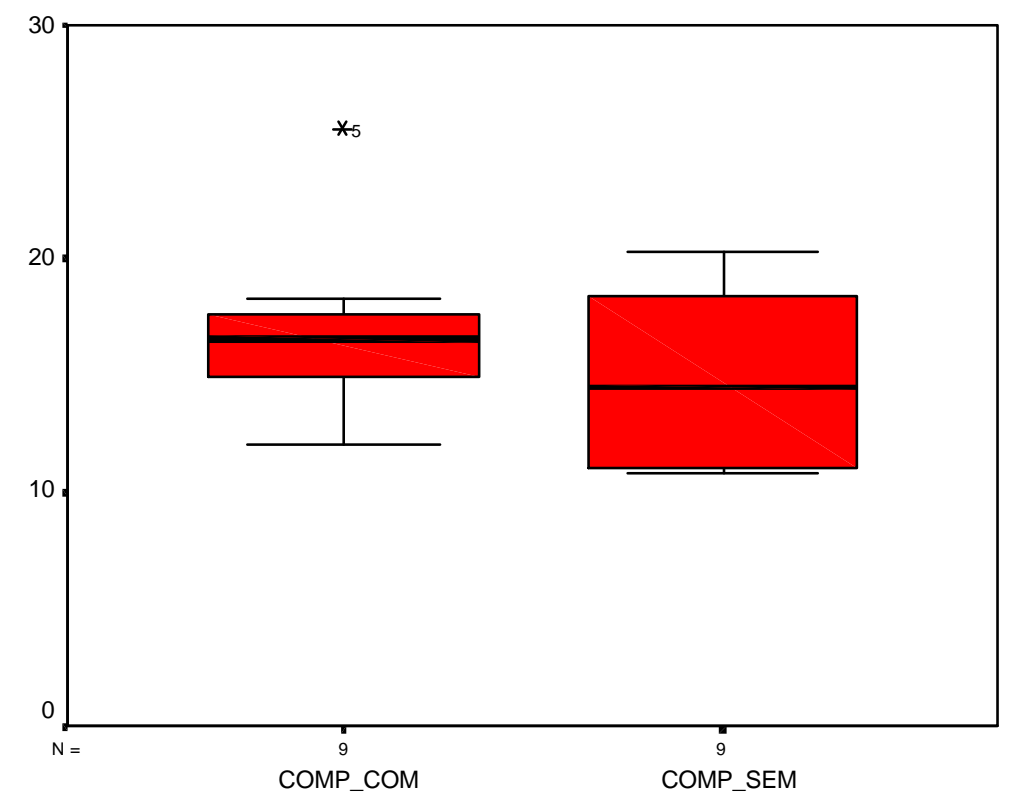

Gráfico 5.5 - Box-plot para o comprimento com e sem barra 
Neste gráfico observa-se que os valores para o comprimento máximo nos registros com barra estão com uma distribuição mais concentrada, exceto para um valor discrepante. Pela distância inter-quartil dos valores sem barra, conclui-se que estes têm uma distribuição menos concentrada.

5.5.3 análise descritiva da área

Tabela 5.6- Representação dos dados descritivos da área do ciclo mastigatório com e sem barra

\begin{tabular}{lcc}
\hline & AREA COM BARRA & AREA SEM BARRA \\
\hline $\mathrm{N}$ & 9 & 9 \\
Média & 83,22 & 70,52 \\
Mediana & 82,40 & 56,99 \\
D.P. & 35,45 & 52,16 \\
Mínima & 35,02 & 17,60 \\
Máxima & 130,67 & 180,81 \\
C.V. & $43 \%$ & $74 \%$ \\
\hline
\end{tabular}

Pelo alto coeficiente de variação obtido nos dois registros, especialmente para o registro sem barra (74\%) observou-se que os valores obtidos estão espaçados uns dos outros. 


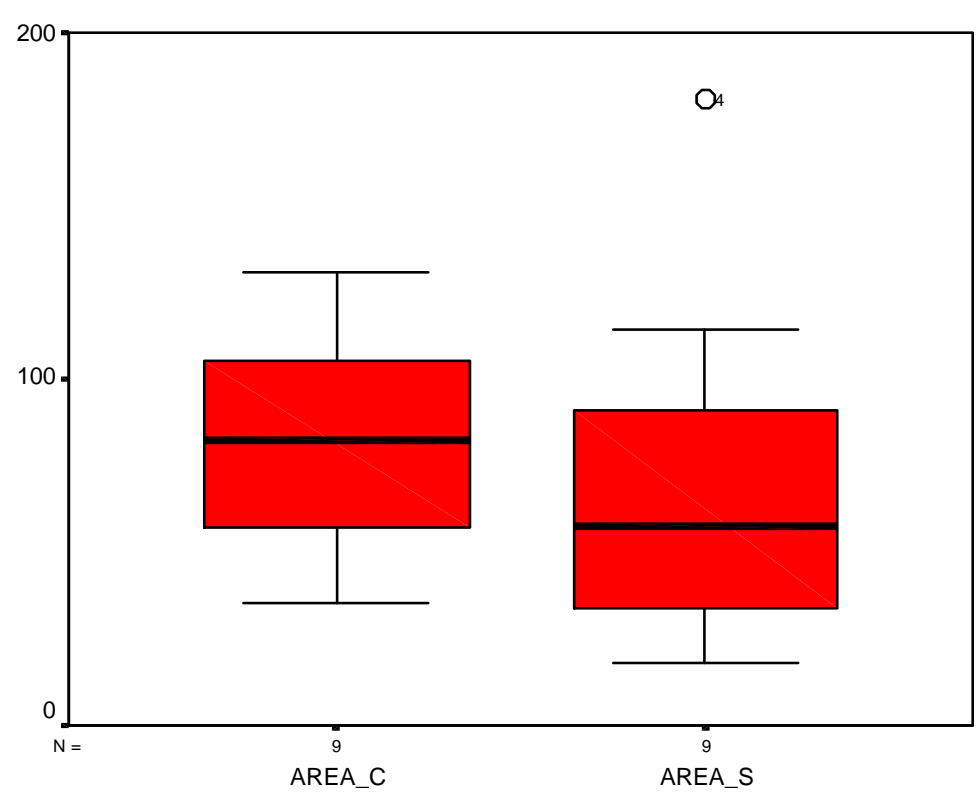

Gráfico 5.6 - Box-plot para a área com e sem barra

No gráfico acima, pode-se observar que os valores da área dos registros sem barra são menores que os valores com barra, com exceção de um valor discrepante no Box-plot sem barra.

5.5.4 inferência estatística

Com a aplicação do teste não-paramétrico de Wilcoxon, adotando o nível de significância de $5 \%$ verificou-se que não existe diferença estatisticamente significante entre os registros com e sem barra para largura, comprimento e área dos ciclos mastigatórios. 
Tabela 5.7 - Níveis descritivos (p) através do teste não paramétrico de Wilcoxon

\begin{tabular}{lc}
\hline & valor $\mathrm{p}$ \\
\hline LARGURA & 0,593954682 \\
COMPRIMENTO & 0,260392934 \\
ÁREA & 0,260392934 \\
\hline
\end{tabular}




\section{DISCUSSÃO}

O conhecimento dos padrões dos movimentos mandibulares tem sido de grande interesse em Odontologia. Bradley (1986) acredita que, de forma ideal, os movimentos mandibulares deveriam ser registrados durante a mastigação natural mais do que em laboratório. Até o momento, o estudo dos movimentos mandibulares tem sido feito com vários métodos de registro. Muitos autores fazem uso de técnicas não invasivas como Mongini, Tempia-Valenta e Benvegnu (1986), Wilding e Lewin (1994) que usaram o sirognatógrafo (indutor de campo magnético) para o registro dos movimentos mandibulares; Jemt e Karlssson (1980), Jemt (1981), Jemt e Stalblad (1986), Jemt (1986) e Karlsson e Carlsson (1990) que usaram o sistema Selspot (light-emiting-diode); Setz et al. (1989) que usaram um eletrognatógrafo. É atualmente possível efetuar determinações tridimensionais dos movimentos mandibulares, ainda que a análise e a interpretação dos dados tenham aumentado em complexidade. A dificuldade da análise dos resultados aumenta quando se registram todos os parâmetros, o que torna necessário o uso de computadores e programas específicos. Ainda que essas técnicas sejam realizadas em laboratório, não são, todavia, utilizadas no consultório dentário e sem dúvida, serão importantes elementos de diagnóstico no futuro próximo.

Trabalhos que envolvem o registro dos ciclos mastigatórios de indivíduos estão em desenvolvimento e se tornam necessários na medida em que fornecem dados importantes sobre o padrão mastigatório de um dado paciente.

Já existem indícios de qual padrão de ciclo mastigatório é o ideal para mastigar os alimentos. Apesar de ainda não haver uma concordância entre os 
autores de um modelo para guiar pesquisas ou a clínica, já existem trabalhos que norteiam essa questão (YAMASHITA, HATCH; RUGH, 1999; WILDING; LEWIN, 1994; BENZING et al., 1994).

O ciclo mastigatório já foi muito comparado com a oclusão ideal e a má oclusão; porém, pouco com medidas de eficiência mastigatória. Neste trabalho utilizourse um recurso para avaliar de maneira objetiva as características morfológicas do ciclo mastigatório para descrever o padrão de mastigação de pacientes reabilitados com overdentures, visando mais subsídios para desvendar as informações que possam estar escondidas por trás da mastigação desses pacientes.

Métodos objetivos de avaliação da eficiência mastigatória são necessários para averiguar as capacidades funcionais de cada indivíduo e para estudar o impacto de um tratamento reabilitador, pois dessa forma é possível saber da sua efetividade para um dado grupo de pacientes. Alguns autores já começam a afirmar que o padrão mastigatório é geralmente aceito como um dos métodos úteis para a avaliação objetiva da função mastigatória (YAMASHITA, HATCH; RUGH, 1999; WILDING; LEWIN, 1994; JEMT, LINDQUIST; HEDEGARD, 1985; BENZING et al., 1994).

Seguindo esta linha de pensamento, a utilização do eletrognatógrafo Arcus Digma (Kavo Dental GmbH \& Co. KG, Alemanha) no presente trabalho, registrou o ciclo mastigatório dos pacientes. Como em pesquisas de Mongini, Tempia-Valenta e Benvegnu (1986) e Jemt, Lindiquist e Hedegard (1985), os pacientes não foram induzidos quanto ao lado da mastigação para simular com mais fidelidade uma mastigação normal. A escolha de um alimento de consistência dura e de difícil trituração como a cenoura, fez com que o teste mastigatório possibilitasse ao paciente lançar mão de características do seu movimento que poderiam não se 
evidenciar caso um alimento comum e que demanda pouco esforço, como a goma de mascar, fosse utilizado. Dessa forma os pacientes fariam um esforço grande para mastigar o alimento e, portanto os ciclos sairiam completos, com clareza e fidelidade. Simulando também uma mastigação normal, Wilding e Lewin (1994) em seu trabalho usaram um alimento pegajoso para efetuar os registros do ciclo mastigatório com o objetivo de fazer com que o teste mastigatório fosse desafiador.

Não houve determinação de tempo para a mastigação do alimento o que não afetou os registros, pois os movimentos mais largos que poderiam comprometer as medições da largura, comprimento ou área do ciclo mastigatório aconteceram logo nas primeiras mordidas ou até a décima primeira mordida. As que aconteceram no início da mastigação são decorrentes da busca da mandíbula pela apreensão e quebra inicial do alimento e as que aconteceram mais próximas do décimo primeiro ciclo mastigatório são decorrentes, na sua maioria, da inversão do lado de mastigação.

Alguns trabalhos, em sua metodologia, utilizaram pacientes distintos entre o grupo controle e o grupo de estudo, fazendo com que os resultados pudessem ser diferentes uma vez que cada indivíduo tem as condições do sistema estomatognático alteradas. Jemt e Stalblad (1986) utilizaram dois grupos de pacientes: um grupo com próteses totais convencionais reembasadas e outro com próteses totais convencionais reembasadas convertidas em overdenture. Outros trabalhos fizeram os registros antes dos pacientes serem reabilitados com a prótese total nova, ou seja, os primeiros registros, que serviram como controle, foram feitos com os pacientes utilizando uma prótese total convencional antiga, que na maioria das vezes, se encontra desadaptada, com perda de retenção e estabilidade, com dimensão vertical de oclusão diminuída, e oclusão desbalanceada pelo desgaste 
dos dentes (BENZING et al., 1994). Essa situação também permite que os pacientes se sintam insatisfeitos com suas próteses antigas e que apresentem dificuldade para mastigar alimentos de consistência mais dura. A musculatura, altura e forma do rebordo, quantidade de saliva, coordenação motora, personalidade são alguns exemplos de variáveis que, como sabido, influenciam no sucesso e satisfação de uma prótese total. Comparar os registros de uma reabilitação com overdenture e de uma prótese total convencional antiga, pode evidenciar alterações mais acentuadas dos movimentos mastigatórios de um indivíduo, pois a fixação da barra promove um aumento clínico marcante da estabilidade e retenção da prótese. A pobre fixação das próteses totais convencionais antigas e a pressão dos lábios e da língua favoreceram movimentos desviados e incontrolados do ciclo mastigatório como afirmam Benzing et al. (1994) e Li et al. (2002).

Por outro lado, nesta pesquisa, com a obtenção dos registros pôde-se então avaliar particularidades que são marcantes tanto nos pacientes com a presença da barra quanto nos mesmos pacientes sem a barra. Os 9 pacientes participantes eram portadores da mesma condição protética: uma prótese total mandibular retida por dois implantes e uma barra; e uma prótese total superior convencional. Quando se quis avaliar os pacientes com próteses totais convencionais, para comparar os registros entre si, simplesmente retirou-se a fixação da barra, simulando desta maneira uma prótese apenas mucoso-suportada. Duas questões devem ser levadas em consideração neste momento: uma questão diz respeito ao grupo controle ser portador de uma prótese total convencional confeccionada dentro de rigorosos padrões e que propiciam ao paciente o máximo de retenção e estabilidade que suas condições intra-orais e seu controle neuromuscular permitem, proporcionando a estabilidade e retenção suficientes, na maioria das vezes, para o paciente mastigar o 
alimento proposto. Outra questão diz respeito ao fato de tanto os registros com barra quanto os registros sem barra terem sido efetuados no mesmo dia com distanciamento médio de 30 minutos. Desta forma, acredita-se que os pacientes não tiveram tempo nem condições para que o seu sistema neuromuscular perdesse a memória, o que faria com que o paciente se sentisse em outra condição quando a barra fosse retirada. Isso pode ser uma explicação para o fato da maioria dos pacientes terem conseguido mastigar o alimento nas duas situações. Uma exceção foi o paciente 8 que claramente mostrou dificuldade em quebrar e mastigar o alimento quando sua prótese estava sem a retenção da barra. Os outros pacientes conseguiram mastigar o pedaço de cenoura mesmo sem a barra, com diferenças menos marcantes quando comparados com a paciente 8.

O controle neuromuscular do paciente com prótese total é um ponto importante no sucesso da reabilitação com esse tipo de prótese (LECHNER; ROESSLER, 2001; ROESSLER, 2003). É um fator que independe dos passos técnicos para a confecção do aparelho, porém, que causa grande diferença quando está presente. Após o ajuste das próteses, se o paciente não tiver adquirido este controle neuromuscular, as bases continuarão machucando sua mucosa e perdendo estabilidade ao mastigar. O paciente precisa se conscientizar de que a prótese é um aparelho rígido, porém, que será colocado em um meio delicado, com musculatura em movimento e tecido flexíveis, que é a cavidade oral. Ele deverá, com auxílio do profissional, desenvolver técnicas que permitam que ele mastigue os alimentos, degluta-os e mantenha a prótese em seu local de repouso, que é o rebordo. Isso é o que se chama de controle neuromuscular. O paciente que não desenvolvê-lo provavelmente despertará insatisfação com sua prótese, mesmo em casos onde ela tenha sido confeccionada com todo o rigor técnico como ressaltam Lechner e 
Roessler (2001).

Desta maneira, ao analisar a conformação geral do ciclo mastigatório de cada paciente pôde-se observar que quase a totalidade dos pacientes, independente da fixação da prótese à barra, possui características individuais no padrão do seu ciclo mastigatório. A morfologia do ciclo mastigatório varia de paciente para paciente, ou seja, as variações interindividuais são grandes; porém, comparando-se os dois registros do mesmo paciente percebemos que a conformação geral se mantém. Dessa forma, pacientes que apresentaram uma morfologia estreita do ciclo, se comportaram desta maneira tanto nos registros com a barra quanto nos registros sem a barra. Por outro lado, pacientes que mastigam com ciclos mais largos repetem essa conformação nas duas situações, apenas, com pequenas alterações.

De acordo com Jemt e Olsson (1986) essa estabilidade no padrão dos ciclos mastigatórios pôde ser verificada em dentados, mostrando alta reprodutibilidade. $\mathrm{O}$ padrão de forma, tempo e amplitude mostraram características individuais que são únicas para um dado indivíduo e fazem com que esse padrão seja distinguível entre os outros pacientes. Por outro lado, em experimentos para avaliar alterações nos movimentos mandibulares na mastigação entre dentados e pacientes com prótese total reabilitados com overdentures mandibulares, para Jemt (1896) os resultados mostraram uma variação interindividual muito grande e uma variação intra-individual quando o alimento mastigado era diferente. Acredita-se que essas alterações parecem ser características de cada indivíduo que reflete uma performance que é parte integrante de todo um padrão mastigatório. Jemt, Lindiquist e Hedegard (1985) encontraram uma clara estabilidade para o padrão geral do ciclo entre os testes com a prótese total convencional e depois, com a overdenture, que pode ser explicada pela existência de um mecanismo de geração de movimento básico individual. 
Como uma seqüência de ciclo mastigatório implica posicionar o alimento, coletar e reforçar a informação sensorial, quebrar o alimento e alternar o lado de mastigação caso seja necessário, pequenas mudanças de direção ou forma de cada ciclo são aceitáveis dentro dos padrões de normalidade. Mongini, Tempia-Valenta e Benvegnu (1986) encontraram resultados similares em seu trabalho com pacientes dentados. Os autores acreditam que um padrão principal de ciclo pode ser identificado para cada paciente, mas, de acordo com a necessidade ciclos específicos são requeridos para contemplar a ou as funções necessárias, então, movimentos repetitivos com fechamento curvo predominante são provavelmente mais efetivos na quebra do alimento e se apresentam em grupos, alternando com outras formas de ciclo; sendo no geral simétricos, balanceados e bilaterais.

Assim, algumas alterações na conformação dos ciclos mastigatórios dos pacientes deste trabalho puderam ser observadas com a fixação à barra. Os ciclos de um modo geral se apresentaram com os traçados mais lisos e estáveis. Os direcionamentos dos movimentos mastigatórios se aproximaram mais dos padrões tidos como ideais. É como se a mandíbula tivesse mais precisão e calma ao executar os movimentos mastigatórios e por esse motivo, conseguisse desenhar ciclos mais harmônicos. Similarmente, Setz et al. (1989) na investigação da função mastigatória encontraram que os registros demonstraram que a fixação das próteses em implantes resultou em ciclos mais largos e estáveis. Isso resultou pelo fato dos pacientes acharem mais facilmente uma posição de mastigação efetiva, levando a um aumento da força de mordida e diminuindo o tempo de degradação do alimento. Os resultados de Benzing et al. (1994), Jemt, Lindiquist e Hedegard (1985) e Li et al. (2002) estão em concordância com esta opinião. Estes autores acreditam que a fixação da barra aumenta a estabilidade da base da prótese aumentando a função 
mastigatória dos pacientes.

Foi observado um aumento da área do ciclo mastigatório quando sete dos nove pacientes mastigaram com a prótese fixada à barra, enquanto a medida de largura aumentou para quatro pacientes e a de altura para cinco pacientes. Uma explicação para o equilíbrio no número de pacientes com aumento ou diminuição da altura e da largura nos registros com e sem a barra em face do predominante aumento da área do ciclo para os pacientes com barra, pode ser explicado pelo fato dos pacientes sem a barra apresentarem alguns movimentos fortemente desviados do padrão comum do ciclo mastigatório que é a forma em gota. Esses movimentos garantiram amplitudes maiores, pois têm uma projeção lateral grande. Pela maior dificuldade em mastigar o alimento duro e pela menor estabilidade da prótese na boca, esses pacientes jogam a mandíbula sem direcionamento correto na ânsia de apreender o alimento entre os dentes. Movimentos deste tipo com amplitude bem diferente dos outros ciclos são em pequeno número, e por isso, o aumento da área foi assegurado para os registros com a barra. Se esses movimentos perpetuassem em todo o tempo do registro, certamente os pacientes com a prótese total sem barra teriam a área aumentada também. Postic et al. (2002) acreditam que na necessidade do paciente estabilizar a prótese total no rebordo e dificuldade de centralizar o bolo alimentar, um esforço adicional muscular projeta a mandíbula para ciclos mais largos.

Estes resultados estão em concordância com outros trabalhos que afirmam que pacientes com prótese total convencional apresentam maior número de movimentos irregulares. Os resultados da pesquisa estão em concordância com Benzing et al. (1994) que encontraram que os movimentos laterais e a área medidos sem os implantes podem ser explicados pelo efeito de movimentos largos 
descontrolados, causados pelas próteses antigas não estabilizadas no rebordo alveolar. Após a implantação e estabilização das overdentures, movimentos mais precisos foram registrados.

Segundo a análise estatística aplicada, as variações dos valores obtidos nos registros sem e com a barra para a largura, altura e área, não são estatisticamente significantes. Benzing et al. (1994), com pacientes com overdenture e prótese total antiga, encontraram valores não significantes para a alteração da área, largura e comprimento total do diclo. Apenas um aumento de $10,75 \mathrm{~mm}^{2}$ na área foi medido após a colocação da overdenture, pois movimentos laterais foram freqüentes sem a barra. Setz et al. (1989) encontraram médias de $12 \mathrm{~mm}$ e $17 \mathrm{~mm}$ de comprimento máximo para os registros sem e com a barra respectivamente; enquanto nesta pesquisa as médias foram de 15mm e 16,8mm. Diferentemente, Pera et al. (1998) com pacientes com prótese total nova, e posterior conversão para overdenture encontrou aumento do comprimento de $45 \%$, a largura em $97 \%$ e a área em $171 \%$ para pacientes com a fixação dos implantes. Vale ressaltar que este autor teve 5 a 7 meses de intervalo entre os dois registros e isso pode ser uma explicação para os valores obtidos.

A relação entre eficiência mastigatória e ciclo mastigatório ainda rão foi tão bem explorada para pacientes com próteses totais retidas por implantes. Apesar de alguns relacionamentos terem sido encontrados através de parâmetros de função oral, a correta estrutura dessas relações permanece obscura e existe a necessidade de se colher mais informações para elucidar as questões que ainda permanecem sem resposta.

O ciclo mastigatório, através de seus parâmetros, tem sido usado para avaliar a eficiência mastigatória dos indivíduos. Mongini, Tempia-Valenta e Benvegnu 
(1986), Benzing et al. (1994), Karkasis (2002) e Li(2002) afirmam que movimentos regulares, repetidos e com margens mais largas favorecem a quebra efetiva do alimento, proporcionando uma melhor mastigação, juntamente com a estabilização da base da prótese pela fixação da barra.

Em seu trabalho Wilding e Lewin (1994) estudaram a possibilidade da eficiência mastigatória estar relacionada com certos padrões do movimento mandibular. Neste caso, as características do ciclo mastigatório que mais contribuiriam para a melhor performance deveriam ser as ideais para o sistema mastigatório. Concluíram que movimentos coordenados da mandíbula com ciclos mastigatórios bilaterais, largos, comum caminho lateral em fechamento e os ciclos com movimento liso e contínuo com mínima alteração de velocidade, são significantes determinantes da performance mastigatória, e, portanto, podem contribuir para desenvolver um protocolo básico para uma função mastigatória normal devido ao fato de existir um uso eficiente da energia muscular.

Porém, Yamashita, Hatch e Rugh (1999) discordam desta opinião. Em uma revisão da literatura sobre a relação entre um padrão ideal do ciclo mastigatório para a melhor eficiência mastigatória, concluíram que no momento não há um padrão de ciclo que possa ser usado em pesquisas para indicar a saúde do aparelho mastigatório ou a eficiência mastigatória do paciente, já que o padrão dos movimentos mandibulares têm uma variação muito grande devido a diferentes tipos de oclusão e função.

Os achados dos registros desta pesquisa demonstraram que os pacientes com overdenture mandibular apresentaram no geral, maior quantidade de ciclos regulares com bordas lisas e regulares, que segundo os autores acima citados, representaria uma melhor eficiência mastigatória. 


\section{CONCLUSÕES}

A partir dos resultados obtidos, chegoutse às seguintes conclusões:

7.1 A fixação à barra da prótese total promove alterações no ciclo mastigatório de pacientes edentados totais quando comparado à prótese total mucoso-suportada

7.2 Pacientes com overdenture apresentaram formas mais harmônicas, regulares e estáveis do ciclo mastigatório.

7.3 Pacientes com a prótese sem a fixação da barra apresentaram ciclos mastigatórios com formas mais irregulares

7.4 Não houve alteração estatisticamente significante nos valores de largura, comprimento e área total entre os registros com e sem a barra de retenção. 


\section{REFERÊNCIAS ${ }^{1}$}

Ahlgren J. Mechanism of mastication. Acta Odontol Scand 1966;24(suppl 44):1-106.

Anderson K, Throckmorton GS, Buschang PH, Hayasaki $\mathrm{H}$. The effect of bolul hardness on masticatory kinematics. J Oral Rehabil 2002;29(7):689-96.

Allen PF, McMillan AS, Walshaw D. A patient-based assesment of implant-stabilized and conventional complete dentures. J Prosth Dent 2001;85(2):141-7.

Att W, Stappert C. Implant therapy to improve quality of life. Quintessence Int 2003;34(8):573-81.

Awad MA, Lund JP, Dufresne E, Feine JS. Comparing the efficacy of mandibular implant-retained overdentures and convencional dentures among middle-aged edentulous patients: satisfaction and functional assessment. Int J Prosth 2003;16(2):117-22.

Bakke M, Holm B, Gotfredsen K. Masticatory function and patient satisfaction with implant-supported mandibular overdentures: a prospective 5-year study. Int J Prosth 2002;15(6):575-81.

Benzing $\mathrm{U}$, Weber $\mathrm{H}$, Simonis A, Engel E. Changes in chewing patterns after implantation in the edentulous mandible. Int J Oral Maxillofac Impl 1994;9(2):207-12.

Boerrigter EM, Stegenga B, Raghoebar GM, Boering G. Patient satisfaction and chewing ability with implant-retained mandibular overdentures: a comparison with new complete dentures with or without preprosthetic surgery. J Oral Maxillofac Surg 1995;53(10):1167-73.

Boerrigter EM, Geertman ME, Van Oort RP, Bouma J, Raghoebar GM, Van Wass AJ, Van't Hof MA, Boering G, Kalk W. Patient satisfaction with implant-retained mandibular overdentures. A comparison with new complete dentures not retained by implants- a multicentre randomized clinical trial. Brit J Oral Maxillofac Surg 1995;33(5):282-88.

${ }^{1}$ De acordo com Estilo Vancouver. Aberviatura de periódicos segundo base de dados MEDLINE. 
Botega DM, Mesquita MF, Henriques GE, Vaz LG. Retention force and fadigue strength of overdenture attachment systems. J Oral Rehabil 2004;31(9):884-9.

Bradley RM. Movimentos mastigatórios. In: Bradley RM. Fisiologia oral básica. Michigan: Ed. Médica Panamericana, 1986.

Burns DV, Unger JW, Elswick RK, Beck DA. Prospective clinical evaluation of mandibular implant overdenture: Part I-retention, stability, and tissue response. J Prosth Dent 1995; 73(4):354-63.

Camani A. Functión Masticatoria. In: Camani A, editors. Estudio macanico del aparato dentario. Buenos Aires: Ediar Sac Anón Editores , 1952.

Chong-Shan S, Guan O, Tian-Wen G. A comparative study of mastication between complete denture wearers and dentate subjects. J Prosthet Dent 1991;66(4):505-9.

Cune MS, Putter C, Hoogstraten J. Treatment outcome with implant-retained overdentures: part I - clinical findings and predictability of clinical treatment outcome. J Prosth Dent 1994a;72(2):144-51.

Cune MS, Putter C, Hoogstraten J. Treatment outcome with implant-retained overdentures: part II - patient satisfaction and predictability of subjective treatment outcome. J Prosth Dent 1994b;72(2):152-8.

Doundoulakis JH, Eckert SE, Lindquist CC, Jeffcoat MK. The implant-supported overdenture as an alternative to the complete mandibular denture. J Am Dent Assoc 2003; 134(11):1455-8.

Filipic S, Keros J. Dynamic influence of food consistency on the masticatory motion. J Oral Rehabil 2002;29(5):492-496.

Fontijn-Tekamp FA, Slagter AP, Van Der Bilt A, Van'T Hof MA, Witter DJ, Kalk W, Jansen JA. Biting and chewing in overdentures, full dentures and natural dentitions. J Dent Res 2000;79(7):1519-24.

Garret NR, Kapur KK, Hamada MO, Roumanas ED, Freymiller E, Han T, Diener RM, Levin S, Chen T. A randomized clinical trial comparing the efficacy of mandibular implant-supported overdentures and conventional dentures in diabetic patients. Part II. Comparisons of masticatory performance. J Prosth Dent 1998;79(6):632-40. 
Geertman ME, Boerrigter EM, Van'Tof MA, Van Wass MAJ, Van Oort RP, Boering G, Kalk W. Two-center clinical trial of implant-retained mandibular overdentures versus complete dentures - chewing ability. Commun Dent Oral Epidem 1996;24(1):79-84.

Geertman ME, Slagter AP, Van'Tof MA, Van Wass MA J, Kalk W. Masticatory performance and chewing experience with implant-retained mandibular overdentures. J Oral Rehabil 1999;26(1):7-13.

Geertman ME, Slagter AP, Van Wass MAJ, Kalk W. Comminution of food with mandibular implant-retained overdentures. J Dent Res 1994;73(12):1858-64.

Gibbs $\mathrm{CH}$, Masserman T, Reswick JB, Derda HJ. Functional movements of the mandible. J Prosth Dent 1971;26(6):604-20.

Haraldson T, Jemt T, Stalblad P, Lekholm U. Oral function in subjects with overdentures supported by osseointegrated implants. Scand J Dent Res 1988;96(3):235-242.

Jemt $\mathrm{T}$. Changes in masticatory movement parameters within the chewing period in young dentate persons and patients rehabilitated with bridges supported by implants in the mandible. J Oral Rehabil 1986;13(5):487-95.

Jemt T. Chewing patterns in dentade and complete denture wearers - recorded by light emitting diodes. Swed Dent J 1981;5(5):199-205.

Jemt T, Lindquist L, Hedegard B. Changes in chewing patterns of patients with complete dentures after placement of osseointegrated implants in the mandible. $\mathrm{J}$ Prosth Dent 1985;53(4):578-83.

Jemt T, Karlsson S. Mandibular movements during mastication before and after rehabilitations with new complete dentures recorded by light-emiting-diodes. Swed Dent 1980;(4)5:195-200.

Jemt T, Olsson K. Computer-based analysis of the single chewing cycle during mastication in repeated registrations. J Prosth Dent 1986;55(3):637-443.

Jemt T, Stalblad PA. The effect of chewing movements on changing mandibular complete dentures to osseointegrated overdentures. J Prosth Dent 1986;55(3);35661. 
Kapur KK, Garret NR, Hamada MO, Roumanas ED, Freymiller E, Han T, Diener RM, Levin S, Wong WK. Randomized clinical trial comparing the efficacy of mandibular implant-supported overdentures and conventional dentures in diabetic patients. Part III: comparisons of patient satisfation. J Prosth Dent 1999;82(4):416-27.

Karkasis HC. EMG activity of the masseter muscle in implant supported overdenture wearers during chewing of hard and soft food. J Oral Rehabil 2002;29(10):986-91.

Karlsson S, Carlsson GE. Characteristics of mandibular masticatory movement in young and elderly dentate subjects. J Dent Res 1990;69(2):473-476.

Kenney R, Richards MW. Photoelastic stress patterns produced by implant-retained overdentures. J Prosth Dent 1998;80(5):559-64.

Kimoto K, Garret NR. Effect of mandibular ridge height on masticatory performance with mandibular conventional and implant-assisted overdentures. Int J Oral Maxillofac Implants 2003;18(4):523-30.

Klemetti E, Chedade A, Takanashi Y, Feine JS. Two-implant mandibular overdenture: simple to fabricate and easy to wear. J Can Assoc 2003;69(1):29-33.

Kwok-Hung C, Cho-Yao C, Cagna DR, Cronin RJ. Retention characteristics of attachment system for implant overdentures. J Prosthodont 2004;13(4):221-6.

Lechner SK, Roessler D. Strategies for complete denture success: beyond technical excellence. Compend Cont Educ Dent 2001;22(7):553-9.

Li C, Qiufei X, Hailan F, Ye L, Jianhui L. The masticatory efficiency of mandibular implant-supported overdentures as compared with tooth-supported overdentures and complete dentures. J Oral Impl 2002;28(5):238-43.

Lindiquist LW, Carlsson GE. Changes in masticatory function in complete denture wearers after insertion of bridges on osseointegrated implants in the lower jaw. In: Lee AJC, Albrektsson T, Branemark PI. Clinical applications of biomaterials. $1^{\text {st }} \mathrm{ed}$. New York: John Wiley \& Sons, 1982. p. 151-5.

McCord JF, Blum I. Prevention of bone loss for edentulous patient. Eur J Prosthodont Rest Dent 2003;11(2):71-74. 
Melas F, Marcenes W, Wright PS. Oral health impact on daily performance in patients with implant-stabilized overdentures and patients with conventional complete dentures. J Oral Maxillofac Implants 2001;16(5):700-12.

Meijer HJA, Raghoebar GM, Van't Hof MA, Geertman ME, Van Oort RP. Implantretained mandibular overdentures compared with complete dentures; a 5-years' follow-up study of clinical aspects and patient satisfaction. Clin Oral Imlp Res 1999; 10(3):238-244.

Mongini F, Tempia-Valenta G, Benvegnu G. Computer-based assesment of habitual mastication. J Prosth Dent 1986;52(5):438-49.

Ow RKK, Carlsson GE, Karlsson S. Relationship of masticatory mandibular movements to masticatory performance of dentate adults: a method study. J Orla Rehabil 1998;25(11):821-9.

Pera P, Bassi F, Schierano G, Appendino P, Preti G. Implant anchored complete mandibular denture: evaluation of masticatory efficiency, oral function and degree of satisfaction. J Oral Rehabil 1998;25(6):462-7.

Positc SD, Krstic MS, Teodosijevic MV. A comparative study of the chewing cycles of dentate and denture-wearing subjects. Int J Prosthod 1992;5(3):244-256.

Raghoebar GM, Meijer HJA, Stegenga B, Van't Hof MA, Van Oort RP, Vissik A. Effectiveness of three treatment modalities for the edentulous mandible. A five-year randomized clinical trial. Clin Oral Impl Res 2000;11(3):195-201.

Raghoebar GM, Meijer HJA, Van't Hof MA, Stegenga B, Vissik A. A randomized prospective clinical trial on the effectiveness of three treatment modalities for patients with lower denture problems. A 10 year follow-up study on patient satisfaction. Int J Oral M axillofac Surg 2003;32(5):498-503.

Roessler DM. Complete denture success for patient and dentist. Int Dent J 2003;53 Suppl 5:340-345.

Sadowsky SJ, Caputo AA. Stress transfer of four mandibular implant overdenture cantilever designs. J Prosth Dent 2004;92(4):328-36.

Setz J, Kramer A, Benzing U, Heber H. Complete dentures fixed on dental implants: chewing patterns and implant stress. Int J Oral Maxillofac Impl 1989;4(2):107-11. 
Schimitt A, Zarb GA. The notion of implant-supported overdentures. J Prosth Dent 1998:79(1):60-5.

Svetilize CA, Bordereau EF. Comparative study of retentive anchor systems for overdenture. Quintessence Int 2004;35(6):443-8.

Tamaki T. Dentaduras Completas, São Paulo: Ed. Sarvier, 1983.

Timmerman T, Stoker GT, Wismeijer D, Oosterveld P, Vermeeren JIJF, Van Wass MAJ. An eight-year follow-up to a randomized clinical trial of participant satisfaction with three types of mandibular implant-retained overdentures. J Dent Res 2004;83(8):630-3.

Van Kampen FMC, Van der Bilt A, Cune MS, Fontijn-Tekamp FA, Bosman F. Masticatory function with implant-supported overdentures. J Dent Res 2004;83(9):708-11.

Visser A, Raghoebar GM, Meijer HJA, Batenburg RHK, Vissink A. Mandibular overdentures supported by two or four endosseous implants. A 5-year prospective study. Clin Oral Implants Res 2005;16(1):19-25.

Wilding RJC, Lewin A. The determination of optimal human jaw movements based on their association with chewing performance. Arch Oral Biol 1994;39(4):333-43.

Winkler S, Piermatti J, Rothman A, Siamos G. An overview of the O-ring implant overdenture attachment: clinical reports. J Oral Implantol 2002;28(2):82-6.

Yamashita S, Hatch JP, Rugh JD. Does chewing performance depend upon a specific masticatory pattern? J Oral Rehabil 1999;26(7):547-53. 
APÊNDICE A - Termo de consentimento livre e esclarecido

\section{CONSENTIMENTO PÓS-INFORMAÇÃO}

$\mathrm{Eu}$ portador(a) do RG estou participando deste trabalho de pesquisa voluntariamente. Declaro que a aluna de mestrado Andréia Carradori explicou de forma a elucidar as dúvidas, todos os detalhes da pesquisa e que eu teria o direito de desistir da participação da mesma a qualquer momento sem perder quaisquer benefícios.

O objetivo do estudo é avaliar a efetividade da retenção a barra no ciclo mastigatório de pacientes portadores de overdenture. $O$ envolvimento dos voluntários consistirá na coleta de dados do seu ciclo mastigatório através do aparelho Arcus Digma® (Kavo Dental GmbH \& Co. KG, Alemanha), sendo que nenhum procedimento é invasivo.

Esta pesquisa trará maior conhecimento sobre o tema abordado, e o benefício de uma consulta controle para a prótese do paciente sem ônus algum para o mesmo. A participação na pesquisa não trará nenhum risco de ordem física ou psicológica.

As informações fornecidas pelo paciente serão confidenciais e de conhecimento apenas dos pesquisadores responsáveis. Os sujeitos da pesquisa não serão identificados em nenhum momento, mesmo quando os resultados desta pesquisa forem divulgados em qualquer forma.

Ass. paciente:

Ass. aluna: 
ANEXO A - Parecer do Comitê de Ética

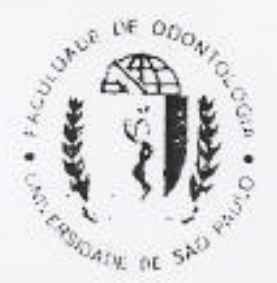

\author{
UNIVERSIDADE DE SÃO PAULO \\ FAC ULDADE DEODONTOLOCIA
}

\title{
PARECER DE APROVAÇĀO \\ Protocolo 199/04
}

Com base em parecer de relator, o Comité de Ética em Pesquisa, APROVOU o protocolo de pesquisa "Estudo comparativo do efeito da retenção a barra no ciclo mastigatório de pacientes usuários de overdentures", de responsabilidade da Pesquisadora Andréia Carradori, sob orientação da Professora Doutora Regina Tamaki.

Tendo em vista a legislaçăo vigente, devem ser encaminhados a este Comitê relatórios anuais referentes ao andamento da pesquisa e ao término cópia do trabalho em "cd". Qualquer emenda do projeto original deve ser apresentada a este CEP para apreciação, de forma clara e sucinta, identificando a parte do protocolo a ser modificada e suas justificativas.

Sāo Paulo, 23 de novembro de 2004

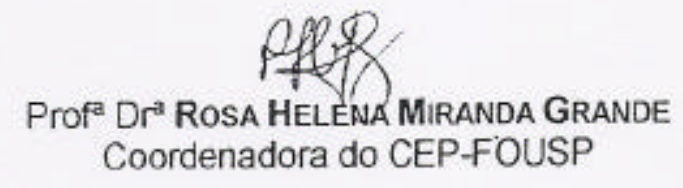


ANEXO B- Ficha de avaliaçăo de disfunçăo articular

Identificação:

RG:

Nome:

Sexo:

Data de nascimento:

Idade:

Endereço:

E-mail:

Responsável:

CEP:

Estado Civil:

Fone(s) para contato:

Profissão:

Raça:

Melhor forma de contato:

Paciente encaminhado por:

Grau de Instrução:

Data de atendimento:

Equipe de atendimento (nomes legiveis)

Queixa(s) e duração(ōes) (QD) (de modo resumido relacione o(s) motivo(s) p elo(s) qual(is) o paciente procurou o atendimento)

\begin{tabular}{|l|l|l|l|l|l|l|l|l|l|l|l|l|l|l|l|l|l|l|}
\hline Piorou & & & & & & & & & & & & & & & & & & \\
\hline Inalterado & & & & & & & & & & & & & & & & & & \\
\hline Pouco melhor & & & & & & & & & & & & & & & & & & \\
\hline Melhor & & & & & & & & & & & & & & & & & & \\
\hline Muito melhor & & & & & & & & & & & & & & & & & & \\
\hline Sem sintomas & & & & & & & & & & & & & & & & & & \\
\hline
\end{tabular}

DATAS

1. Você tem dor no lado direito da sua face, lado esquerdo ou ambos os lados? (Se o paciente indicar dor na linha média circule ambos)

nenhum $(0)$

direito (1)

esquerdo (2)

ambos (3)

2. Você poderia apontar as áreas aonde você sente dor?

\begin{tabular}{|l|l|l|l|}
\hline \multicolumn{2}{|c|}{ Direito } & \multicolumn{2}{c|}{ Esquerdo } \\
\hline Nenhuma & 0 & Nenhuma & 0 \\
Articulação & 1 & Articulação & 1 \\
Músculos & 2 & Músculos & 2 \\
Ambos & 3 & Ambos & 3 \\
\hline
\end{tabular}

(Examinador apalpa a àrea apontada pelo paciente, caso não esteja claro se é dor muscular ou articular, pressione levemente para identificar corretamente a regiăo anatömica) 
História pregressa da moléstia atual (HPMA) (caracterize os fatos que se relacionam à(s) queixa(s) atual(is) em ordem cronológica de ocorrẻncia, detalhando cada aspecto diretamente relacionado à queixa. Se houver mais de uma queixa, faça esta cronologia para uma delas. Utilize o roteiro para dados minimos de anamnese para tentar ser mais completo)

( ) Diurno

( ) Noturno

Outros: 
Paciente Desenha

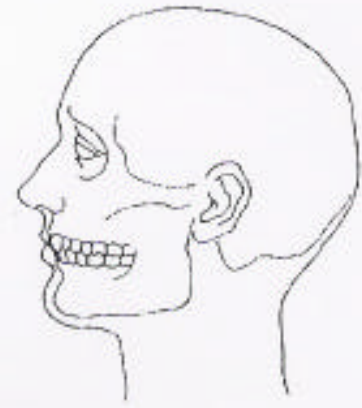

Lado Esquerdo

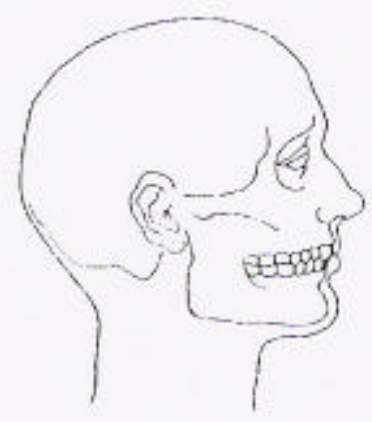

Lado Direito

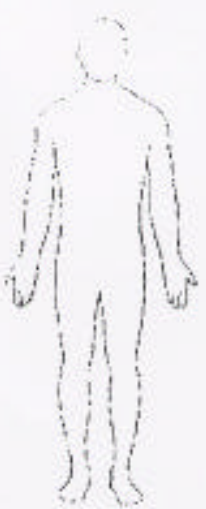

Frente

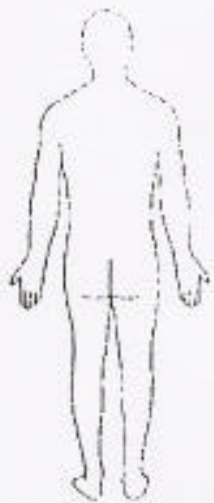

Trás

\begin{tabular}{|l|l|}
\hline \multicolumn{2}{|c|}{ História Médica } \\
\hline Tratamento atual: & Doenças infecciosas-contagiosas: \\
\hline Medicamentos: & Doenças respiratórias: \\
\hline Alergias: & Doenças cárdio-circulatórias: \\
\hline Sistema Sensorial: & Doenças neuropsiquiátricas: \\
\hline Tabagismo - Etilismo - Droga Adicto: & Doenças gastro-intestinais: \\
\hline Doenças músculo-esqueléticas: & Doenças gênito-urinárias: \\
\hline Doenças endócrinas: & Outras: \\
\hline
\end{tabular}

\begin{tabular}{|l|c|l|l|}
\hline \multicolumn{3}{|c|}{ Exame Cervical Funcional } \\
\hline & Dor (local) & Restrição & Sem Restrição \\
\hline Flexão & & & \\
\hline Extensão & & & \\
\hline Rotação D $\left(70^{\circ}\right)$ & & & \\
\hline Rotação E $\left(70^{\circ}\right)$ & & & \\
\hline Inclinação Lateral D $\left(60^{\circ}\right)$ & & & \\
\hline Inclinação Lateral D $\left(60^{\circ}\right)$ & & & \\
\hline
\end{tabular}

\begin{tabular}{|c|c|c|c|c|}
\hline \multicolumn{5}{|c|}{ Testes Funcionais } \\
\hline \multicolumn{5}{|l|}{ Teste Muscular ( $1 \mathrm{~min}$ ) } \\
\hline Anterior ( ) nấo & () direita & Local: & ( ) Esquerda & Local: \\
\hline Lado direito & ( ) direita & Local: & ( ) Esquerda & Local: \\
\hline Lado esquerdo & ( ) direita & Local: & ( ) Esquerda & Local: \\
\hline \multicolumn{4}{|l|}{ Teste Articular } & Loc \\
\hline Contra-teste lado esquerdo & Alivio & ( ) $\mathrm{Sim}$ & & \\
\hline Lado esquerdo () não & () direita & Local: & ( ) Esquerda & Local: \\
\hline Contra-teste lado direito & Alivio & ( ) Sim & & \\
\hline
\end{tabular}


3. Padrão de Abertura (Por favor, posicione sua boca o mais confortavelmente possivel, com os dentes se tocando levemente, agora eu gostaria que vocẽ abrisse sua boca o máximo que puder, mesmo que sinta um pouco de dor).

Reto

\begin{tabular}{lr} 
Desvio lateral direito (não corrigido) & 0 \\
Desvio lateral direito corrigido ("S") & 1 \\
Desvio lateral esquerdo (nāo corrigido) & 2 \\
Desvio lateral corrigido ("S") & 3 \\
Outro & 4 \\
Tipo & 5 \\
\hline & (especifique)
\end{tabular}

4. Extensão de movimento vertical dos incisivos maxilares utilizados (por exemplo: 11 e 21)

a. Abertura sem auxilio sem dor mm ("Eu gostaria que vocé abrisse a boca o mais amplamente possivel sem sentir dor")

b. Abertura máxima sem auxilio possivel, mesmo que vocè sinta um poucu de desconforto")

c. Abertura máxima com auxílio ___ $\mathrm{mm}$ ("Eu estou checando ; ara ver se você pode abrir a boca um pouco mais longe, se você sentir dor levante a mão que eu paro")

d. Trespasse incisal vertical $\mathrm{mm}$

Tabela abaixo: Para os itens "b" e "c" somente

\begin{tabular}{|c|c|c|c|c|c|c|c|}
\hline \multicolumn{4}{|c|}{ DOR MUSCULAR } & \multicolumn{5}{c|}{ DOR ARTICULAR } \\
\hline nenhuma & direito & esquerdo & ambos & nenhuma & direito & esquerdo & ambos \\
\hline 0 & 1 & 2 & 3 & 0 & 1 & 2 & 3 \\
\hline 0 & 1 & 2 & 3 & 0 & 1 & 2 & 3 \\
\hline
\end{tabular}

5. Ruidos articulares (palpação) ("Enquanto eu posiciono meus dedos na sua a riculação, eu g ostaria que vocè abrisse a boca vagarosamente, o máximo que puder, e fechasse vagarosamente até seus dentes estarem completamente juntos". Peça ao paciente para abrir e fechar três vezes.)

\section{a. Abertura}

Nenhum

Estalido

Crepitação grosseira

Crepitação fina

$\begin{array}{cc}\text { Direito } & \text { Esquerdo } \\ 0 & 0 \\ 1 & 1 \\ 2 & 2 \\ 3 & 3\end{array}$

Medida do estalido na abertura $\mathrm{mm}$ $\mathrm{mm}$

\section{b. Fechamento}

Nenhum

Estalido

Crepitação grosseira

Crepitação fina

Direito
0
1
2
3

Esquerdo

$0 \quad 0$

$1 \quad 1$

22

3

Medida do estalido na abertura $\mathrm{mm}$ $\mathrm{mm}$

\section{c. Estalido recíproco eliminado durante abertura protrusiva}

Sim

Direito

Não

0 
6. Excursões ("Mova sua mandibula o mais longe possivel para lateral, mesmo se sentir desconforto, e mova sua mandíbula para posiçăo normal. Mova sua mandibula novamente")
a. Excursão lateral direita $\mathrm{mm}$
b. Excursão lateral esquerda $\mathrm{mm}$
c. Protrusão $\mathrm{mm}$

Tabela abaixo: Para os itens "a", "b" e "c"

\begin{tabular}{|c|c|c|c|c|c|c|c|}
\hline \multicolumn{9}{|c|}{ DOR MUSCULAR } \\
\hline nenhuma & direito & esquerdo & ambos & nenhuma & direito & esquerdo & ambos \\
\hline 0 & 1 & 2 & 3 & 0 & 1 & 2 & 3 \\
\hline 0 & 1 & 2 & 3 & 0 & 1 & 2 & 3 \\
\hline 0 & 1 & 2 & 3 & 0 & 1 & 2 & 3 \\
\hline
\end{tabular}

d. Desvio de linha média $\mathrm{mm}$

\begin{tabular}{|c|c|c|}
\hline direito & esquerdo & NA \\
\hline 1 & 2 & 8 \\
\hline
\end{tabular}

\section{Ruidos articulares nas excursões}

Ruido direito

\begin{tabular}{|l|c|c|c|c|}
\hline & nenhum & estalido & Crepitação grosseira & Crepitação leve \\
\hline Excursão Direita & 0 & 1 & 2 & 3 \\
\hline Excursão Esquerda & 0 & 1 & 2 & 3 \\
\hline Protrusão & 0 & 1 & 2 & 3 \\
\hline
\end{tabular}

Ruido esquerdo

\begin{tabular}{|l|c|c|c|c|}
\hline & nenhum & estalido & Crepitaçāo grosseira & Crepitaçāo leve \\
\hline Excursão Direita & 0 & 1 & 2 & 3 \\
\hline Excursão Esquerda & 0 & 1 & 2 & 3 \\
\hline Protrusāo & 0 & 1 & 2 & 3 \\
\hline
\end{tabular}

PALPAÇÃO (Nós gostariamos que vocè indicasse se você náo sente dor ou apenas sente pressão (0), ou dor (1-3). Por favor, classifique o quanto de dor você sente para cada uma das palpaçōes de acordo com a escala)

$$
\begin{aligned}
& 0=\text { sem dor } / \text { somente pressāo } \\
& 1=\text { dor leve } \\
& 2=\text { dor moderada } \\
& 3=\text { dor severa }
\end{aligned}
$$

\section{Dor muscular extra-oral com palpaçāo}

\begin{tabular}{|l|cccc|cccc|}
\hline & \multicolumn{4}{|c|}{ DIREITO } & \multicolumn{5}{|c|}{ ESQUERDO } \\
\hline a. Temporal (posterior) & 0 & 1 & 2 & 3 & 0 & 1 & 2 & 3 \\
\hline b. Temporal (médio) & 0 & 1 & 2 & 3 & 0 & 1 & 2 & 3 \\
\hline c. Temporal (anterior) & 0 & 1 & 2 & 3 & 0 & 1 & 2 & 3 \\
\hline d. Masseter (superior) & 0 & 1 & 2 & 3 & 0 & 1 & 2 & 3 \\
\hline e. Masseter (médio) & 0 & 1 & 2 & 3 & 0 & 1 & 2 & 3 \\
\hline f. Masseter (inferior) & 0 & 1 & 2 & 3 & 0 & 1 & 2 & 3 \\
\hline g. Região mandibular posterior & 0 & 1 & 2 & 3 & 0 & 1 & 2 & 3 \\
\hline h. Região submandibular & 0 & 1 & 2 & 3 & 0 & 1 & 2 & 3 \\
\hline
\end{tabular}

\section{Dor articular com palpação}

\begin{tabular}{|l|llll|llll|}
\hline a. Pólo lateral & 0 & 1 & 2 & 3 & 0 & 1 & 2 & 3 \\
\hline b. Ligamento posterior & 0 & 1 & 2 & 3 & 0 & 1 & 2 & 3 \\
\hline
\end{tabular}


10. Dor muscular intra-oral com palpação (Agora cu vou palpar dentro da sua boca, mantenha sua mandibula relaxada)

\begin{tabular}{|l|c|ccc|cccc|}
\hline & \multicolumn{3}{|c|}{ DIREITO } & \multicolumn{3}{c|}{ ESQUERDO } \\
\hline a. Área do pterigóideo lateral & $-\frac{1}{0}-\frac{1}{2}$ & 2 & 3 & 0 & 1 & 2 & 3 \\
\hline b. Tendão do temporal & 0 & 1 & 2 & 3 & 0 & 1 & 2 & 3 \\
\hline
\end{tabular}

\begin{tabular}{|c|c|c|c|c|c|c|c|c|}
\hline & \multicolumn{4}{|c|}{ DIREITO } & \multicolumn{4}{|c|}{ ESQUERDO } \\
\hline Esternocleidomastóideo & 0 & 1 & 2 & 3 & & 1 & 2 & 3 \\
\hline Sub-occipital & 0 & 1 & 2 & 3 & $\overrightarrow{0}$ & 1 & 2 & 3 \\
\hline Trapézio & 0 & 1 & 2 & 3 & $\overline{0}$ & 1 & 2 & 3 \\
\hline
\end{tabular}

(Use o desenho abaixo para indicar dores referidas)
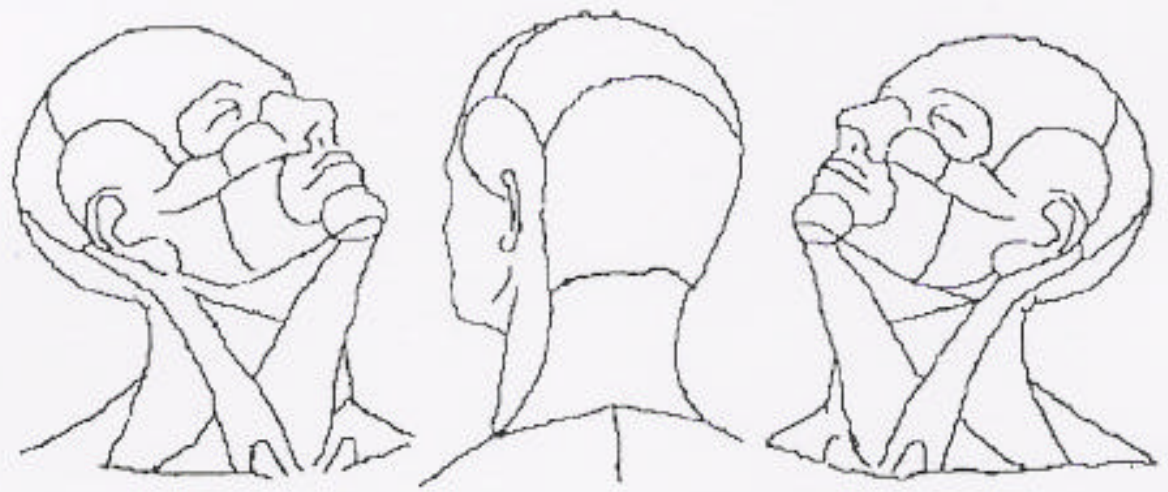

\section{PALPAÇĀO DA CADEIA LINFÁTICA CERVICAL}

Região sublingual:

Região submandibular:

Região júgulo-carotidea alta:

Região júgulo-carotidea média:

Regiāo júgulo-carotidea baixa:

Região supraclavicular:
( ) aparentemente normal

( ) aparentemente normal

( ) aparentemente normal

( ) aparentemente normal

( ) aparentemente normal

( ) aparentemente normal

\section{OROSCOPIA (INSPEÇĀO E PALPAÇĀO)}

Lábios:

( ) aparentemente normal

Mucosa jugal:

( ) aparentemente normal

Lingua:

( ) aparentemente normal

Soalho de boca:

( ) aparentemente normal

Palato duro:

( ) aparentemente normal

Palato mole:

( ) aparentemente normal

Gengiva:

( ) aparentemente normal

Area retromolar:

( ) aparentemente normal

Drenagem de glândulas salivares

( ) aparentemente normal

(parótida, submandibular e sublingual): 


\section{Doença Periodontal:}
Evidências :
( ) Sim
( ) Nāo
( ) Controlada
( ) Não controlada
Retração gengival:
( ) Não
( ) Sim
Dentes:

\section{Exame oclusal:}

\section{RELAÇÄO MOLAR}

D:

( ) Mordida aberta anterior Mordida cruzada: ( ) Anterior

E:

( ) Mordida aberta posterior Posterior: ( ) Esquerda ( ) Direita

Contatos em MIC: ( ) Estável ( ) Instável

Contatos Lateralidade Direita: Trabalho ( ) Presente ( ) Ausente

Contatos Lateralidade Esquerda: Trabalho ( ) Presente ( ) Ausente

Contatos em Protrusiva Anterior () Presente () Ausente

\begin{tabular}{|l|l|l|l|}
\hline \multirow{2}{*}{ Prótese total } & Superior & () Não & () Sim \\
\cline { 2 - 4 } & Inferior & () Não & () Sim \\
\hline \multirow{3}{*}{ Prótese parcial } & Superior & () Não & () Sim \\
\cline { 2 - 4 } & Inferior & () Não & () Sim \\
\hline Placa Interoclusal & ( ) Nenhuma & Tipo: \\
\hline
\end{tabular}

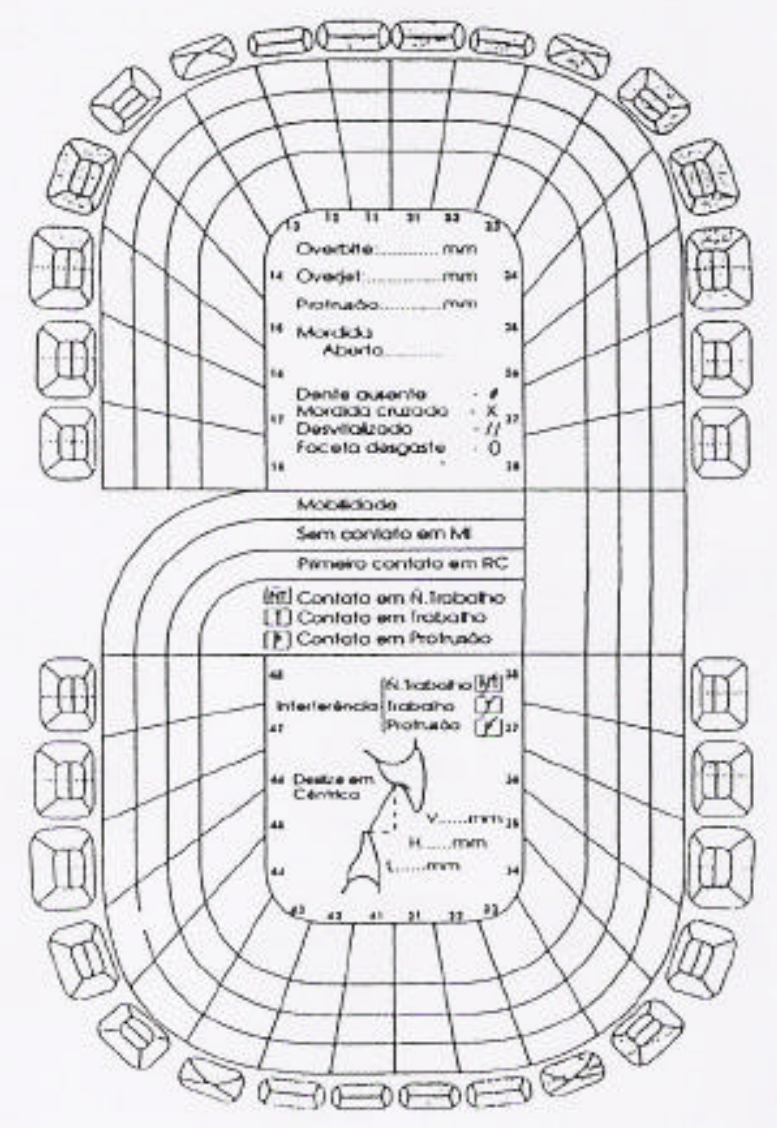


EXAME DOS NERVOS CRANIANOS

\begin{tabular}{|ll|}
\hline (II) Acuidade visual & ( ) aparentemente normal \\
\hline (III, IV, VI) Músculos extra-oculares & ( ) aparentemente normal \\
\hline Pupilas (tamanho, formato, simetria, reação à luz) & ( ) aparentemente normal \\
\hline (V) Motor & ( ) aparentemente normal \\
\hline (V) Sensorial $\left(V_{1}, V_{2}, V_{3}\right.$ ) & ( ) aparentemente normal \\
\hline (VII) Motor (músculos faciais) & ( ) aparentemente normal \\
\hline (VIII) Audição & ( ) aparentemente normal \\
\hline (IX, X) Reflexo do engasgo/elevação do palato & ( ) aparentemente normal \\
\hline (XI) Trapézio (elevação dos ombros, rotaçāo da cabeça) & ( ) aparentemente normal \\
\hline (XII) Hipoglosso (volume da lingua/movimento) & ( ) aparentemente normal \\
\hline
\end{tabular}

Hipóteses Diagnóstica (Topográfica, Sindrômica, Etiológica):

RDC:

I. ( ) Dor miofascial

( ) Dor miofascial com limitaçāo de abertura

II. ( ) Deslocamento do disco com redução

( ) Deslocamento do disco sem redução, com limitação da abertura

( ) Deslocamento do disco sem redução, sem limitação da abertura

III. ( ) Artralgia

( ) Osteoartrite da ATM

( ) Osteoartrose da ATM

tratamento psicológico:

inicio

1

término

Yoga: inicio

1

término 
PACIENTE ( ) A ( )B Comorbidades:

Condutas de Investigação e/ou Confirmação Diagnósticas:

Exames Complementares:

Confirmação Diagnóstica:

Condutas Terapêuticas: 


\section{TERMO DE CONSENTIMENTO LIVRE E ESCLARECIDO}

Estas informaçōes estão sendo fornecidas para sua participaçāo voluntária em trabalhos de pesquisas e/ou ensaios experimentais realizados pelos profissionais vinculados ao Instituto da Cabeça.

Os pacientes serão entrevistados quanto a HPMA (história pregressa da moléstia atual) seguindo o padrāo da ficha clinica do Instituto da C abeça para tratamento dos pacientes com disfunção temporomandibular e dores orofaciais.

A principio, não há desconforto ou riscos envolvidos nos procedimentos que serão realizados. Exames de imagem serăo solicitados, quando necessário.

Os benefícios obtidos pelo paciente serão o de ter o diagnóstico clínico confirmado e a partir dai aconselhamento técnico seguro para tratamento da DTM e encaminhamento, quando for o caso para outros profissionais.

Em qualquer etapa do processo o paciente terá garantia de acesso aos profissionais responsáveis pela pesquisa para esclarecimento de eventuais dúvidas. Se você tiver alguma consideraçăo ou dúvida sobre a ética da pesquisa, entre em contato com o Comitê de Ética em Pesquisa (CEP) - Rua Botucatu, 572 - $1^{\circ}$ andar - cj 14, 5571-1062, FAX: 5539-7162 - E-mail: cepunifesp@epm.br.

É garantida a liberdade da retirada de consentimento a qualquer momento e deixar de participar do estudo, sem quaiquer prejuizo à continuidade de seu tratamento na instituição. As informaçōes obtidas serão analisadas em conjunto com outros pacientes, năo sendo divulgado a identificação de nenhum deles.

O paciente terá o dircito de ser mantido atualizado sobre os resultados parciais das pesquisas, quando em estudos abertos, ou de resultados que sejam do conhecimento dos pesquisadores.

Não há despesas pessoais para o participante em qualquer fase do estudo, incluindo exames e consultas. Também não há compensação financeira relacionada à sua participação. Se existir qualquer despesa adicional, ela será absorvida pelo orçamento da pesquisa.

Em caso de dano pessoal, diretamente causado pelos procedimentos ou tratamentos propostos neste estudo (nexo causal comprovado), o participante tem direito a tratamento médico na Instituição, bem como às indenizações legalmente estabelecidas.

Há o compromisso do pesquisador de utilizar os dados e o material coletado somente para esta pesquisa.

Acredito ter sido suficientemente informado a respeito das informações que li ou que foram lidas para mim. Ficaram claros para mim quais são os propósitos do estudo, os procedimentos a serem realizados, seus desconfortos e riscos, as garantias de confidencialidade e de esclarecimentos permanentes. Ficou claro também que minha participação é isenta de despesas e que tenho garantia do acesso a tratamento hospitalar quando necessário. Concordo voluntariamente em participar deste estudo e poderei retirar o meu consentimento a qualquer momento, antes ou durante o mesmo, sem penalidades ou prejuizo ou perda de qualquer beneficio que eu possa ter adquirido, ou no meu atendimento neste Serviço.

Assinatura do paciente/representante legal

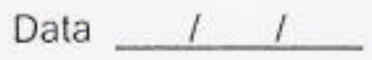

Assinatura da testemunha

Data 11

Declaro que obtive de forma apropriada e voluntária o Consentimento Livre e Esclarecido deste paciente ou representante legal para a participação neste estudo. 
ANEXO C - Ciclo mastigatório do paciente 1 com barra (esquerda) e sem barra (direita)
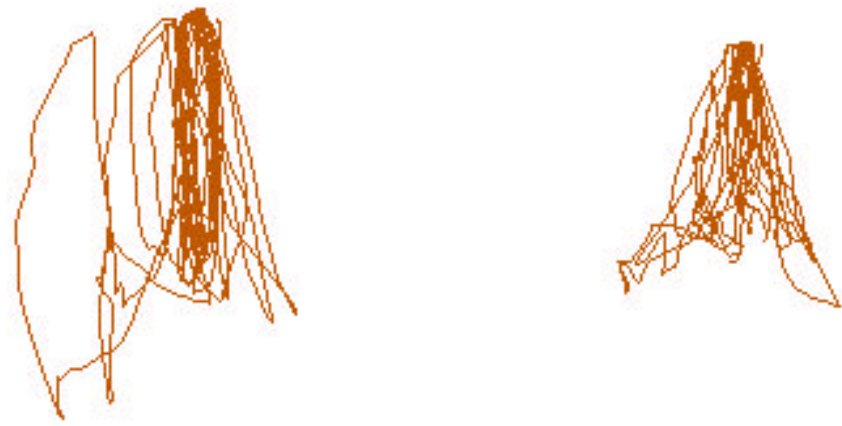
ANEXO D - Ciclo mastigatório do paciente 2 com barra (esquerda) e sem barra (direita)
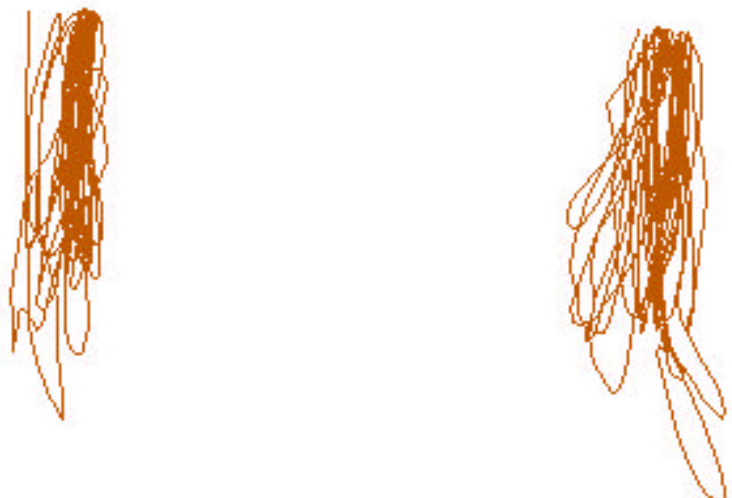
ANEXO E - Ciclo mastigatório do paciente 3 com barra (esquerda) e sem barra (direita)
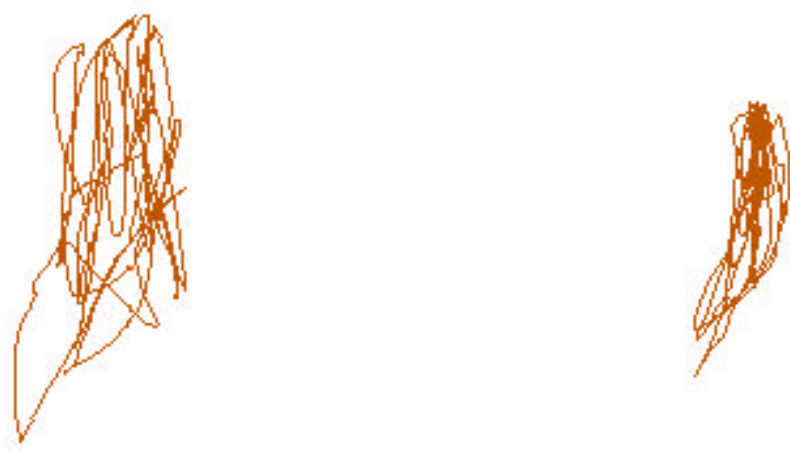
ANEXO F - Ciclo mastigatório do paciente 4 com barra (esquerda) e sem barra (direita)
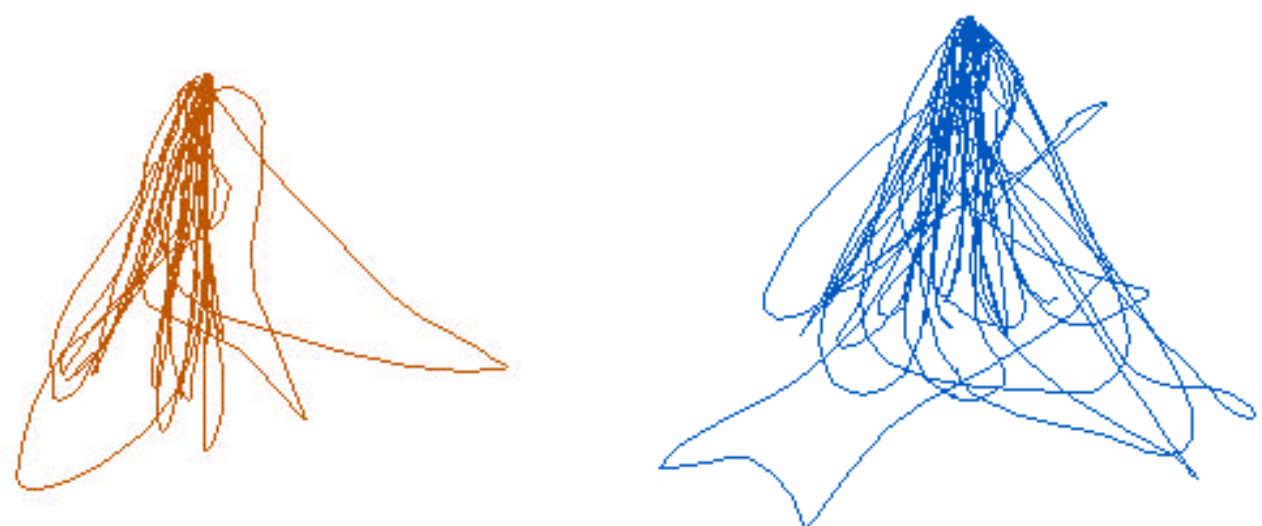
ANEXO G - Ciclo mastigatório do paciente 5 com barra (esquerda) e sem barra (direita)
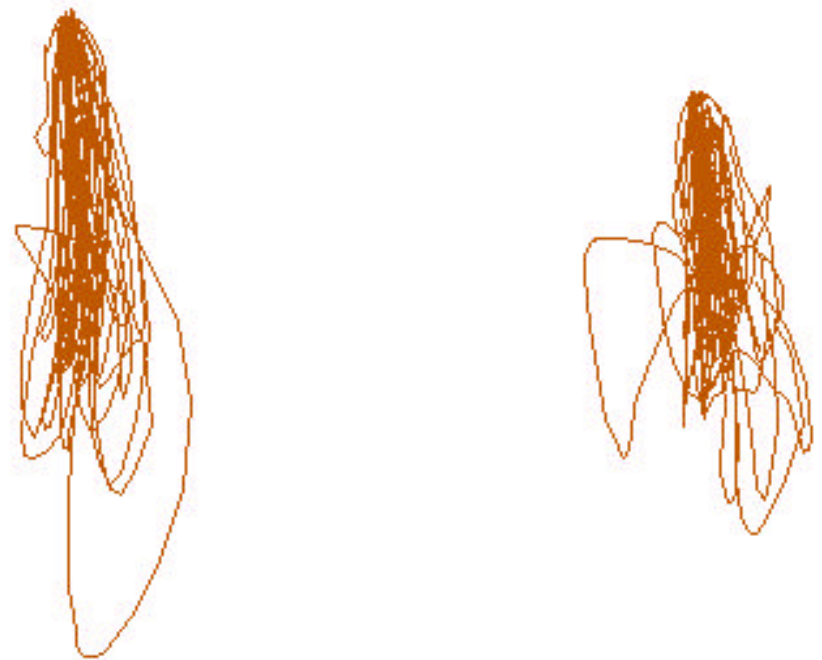
ANEXO H- Ciclo mastigatório do paciente 6 com barra (esquerda) e sem barra (direita)
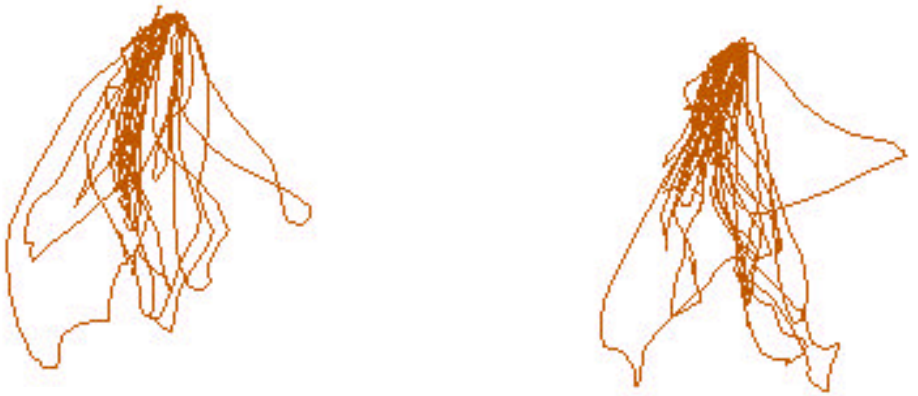
ANEXO I- Ciclo mastigatório do paciente 7 com barra (esquerda) e sem barra (direita)
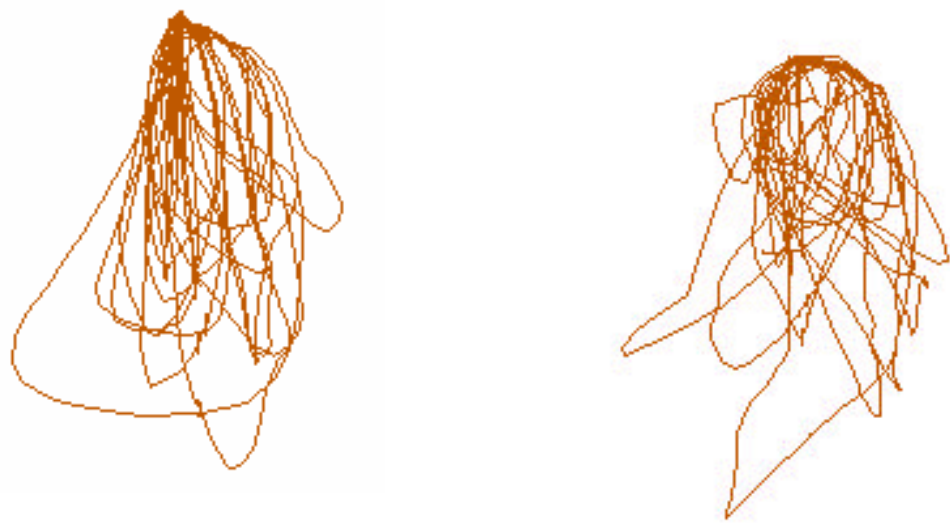
ANEXO J- Ciclo mastigatório do paciente 8 com barra (esquerda) e sem barra (direita)
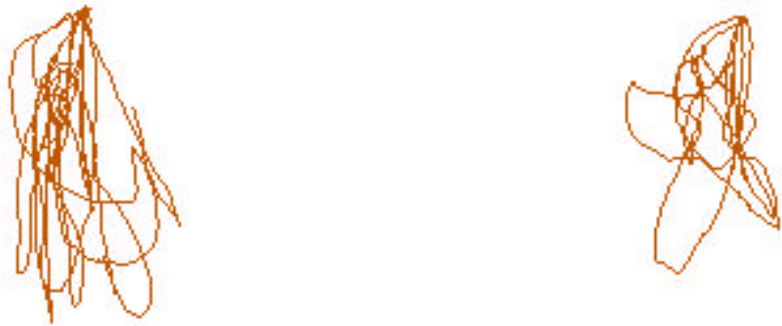
ANEXO K- Ciclo mastigatório do paciente 9 com barra (esquerda) e sem barra (direita)
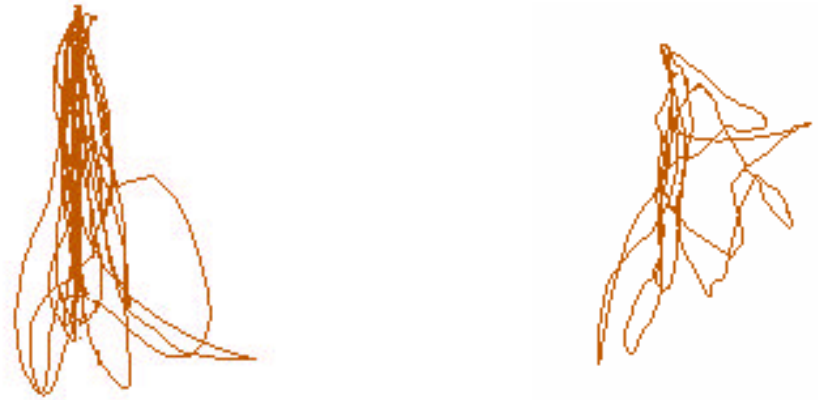
ANEXO L- Tabela com sexo e idade dos pacientes

\begin{tabular}{llll}
\hline PACIENTE & NÚMERO & SEXO & IDADE \\
\hline D.O & 1 & Feminino & 51 anos \\
G.T & 2 & Masculino & 53 anos \\
J.T & 3 & Masculino & 55 anos \\
J.Ta & 4 & Masculino & 46 anos \\
L.T & 5 & Masculino & 56 anos \\
M.S & 6 & Feminino & 58 anos \\
M.V & 7 & Feminino & 56 anos \\
S.B & 8 & Feminino & 35 anos \\
M.T & 9 & Masculino & 58 anos \\
\hline
\end{tabular}

